\title{
DIALELO PARCIAL CIRCULANTE INTERPOPULACIONAL EM MILHO (Zea mays L.): EFEITO DO NÚMERO (s) DE CRUZAMENTOS
}

\author{
SANDRO RICARDO FUZATTO
}

Tese apresentada á Escola Superior de Agricultura

“Luiz de Queiroz", Universidade de São Paulo, para

obtenção do título de Doutor em Agronomia, Área de

Concentração: Genética e Melhoramento de Plantas.

\author{
PIRACICABA \\ Estado de São Paulo - Brasil \\ Fevereiro - 2003
}




\title{
DIALELO PARCIAL CIRCULANTE INTERPOPULACIONAL EM MILHO (Zea mays L.): EFEITO DO NÚMERO (s) DE CRUZAMENTOS
}

\section{SANDRO RICARDO FUZATTO}

Engenheiro Agrônomo

Orientador: Prof. Dr. JOSÉ BRANCO DE MIRANDA FILHO

Tese apresentada á Escola Superior de Agricultura

"Luiz de Queiroz", Universidade de São Paulo, para obtenção do título de Doutor em Agronomia, Área de Concentração: Genética e Melhoramento de Plantas.

\author{
PIRACICABA \\ Estado de São Paulo - Brasil
}

Fevereiro -2003 


\section{Dados Internacionais de Catalogação na Publicação (CIP)} DIVISÃO DE BIBLIOTECA E DOCUMENTAÇÃO - ESALQ/USP

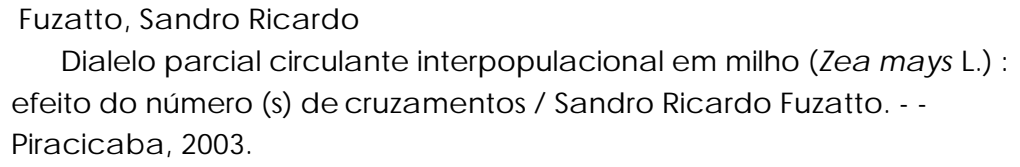

Tese (doutora do) - Escola Superior de Agricultura Luiz de Queiroz, 2003. Bibliografia.

1. Cruza mento 2. Linhagens vegetal 3. Va riação genética vegetalI. Título

CDD 633.15 
Aos meus pais Antonio e Dalva e aos meus irmãos Celso e César

\section{OFEREÇO}

A minha esposa Lílian Raquel e aos meus filhos Mateus e Giovani DEDICO 


\section{AGRADECIMENTOS}

$\checkmark$ A DEUS pela vida e saúde;

$\checkmark$ Ao Prof. José Branco de Miranda Filho pela orientação e amizade;

$\checkmark$ Ao Dr. Ricardo Magnavaca, ao Oswaldo Gomes Marques Junior e ao Pedro Hélio Estevam Ribeiro pelo constante incentivo;

$\checkmark$ À Patrícia Gorgulho, pelas sugestões e correções prestadas;

$\checkmark$ Aos amigos do curso, Américo dos Santos Reis, Raimundo Nonato e Aurélio Mendes Aguiar, pela ajuda nas análises;

$\checkmark$ Aos professores da ESALQ/USP e UFLA pelos ensinamentos recebidos;

$\checkmark$ À FAPESP pelo apoio financeiro;

$\checkmark$ Aos funcionários do Departamento de Genética pela colaboração na condução dos ensaios;

$\checkmark$ À empresa Bayer Seeds Ltda e aos colaboradores do centro de pesquisa de Uberlândia pela ajuda na condução e colheita dos ensaios;

$\checkmark$ Aos amigos e colegas do curso de Pós-Graduação em Genética e melhoramento de plantas da ESALQ/USP.

"Os melhores momentos de nossas vidas estão diretamente relacionados a pessoas. A conclusão do curso é um desses momentos e não seria possível se não existisse apoio e um bom relacionamento com todos. Agradecer no entanto é o mínimo; o máximo é cultivar essas amizades no decorrer da vida". 


\section{SUMÁRIO}

Página

RESUMO ....................................................................................

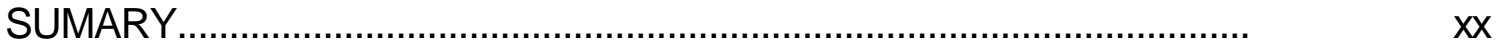

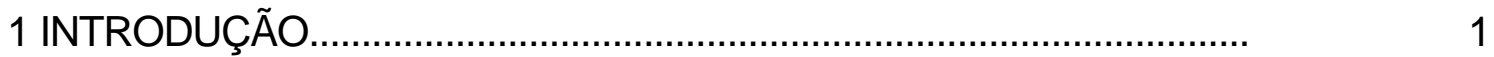

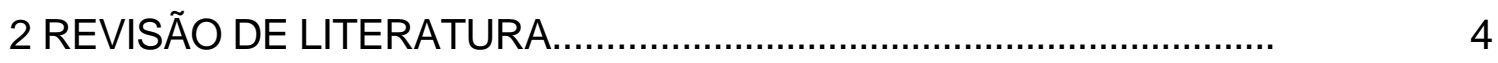

2.1 Processo de avaliação de linhagens......................................................

2.1.1 Cruzamento top-cross.................................................................

2.1.2 Dialelos completos.........................................................................

2.1.3 Dialelos parciais intra e interpopulacional.......................................... 9

2.4 Estimativas da capacidade geral e especifica de combinação................ 13

2.5 Emprego dos quadrados mínimos ordinários (OLS) vs BLUP ("Best Linear Unbiased Prediction")............................................................. 15

3 MATERIAL E MÉTODOS ............................................................... 21

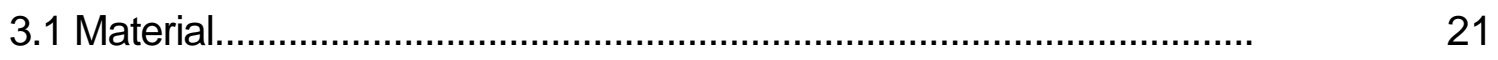

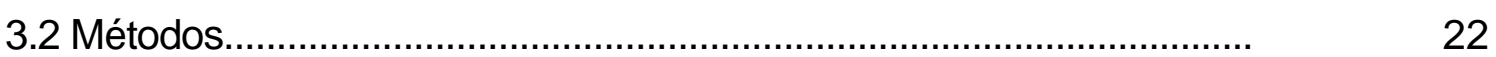

3.2.1 Obtenção dos cruzamentos........................................................... 22

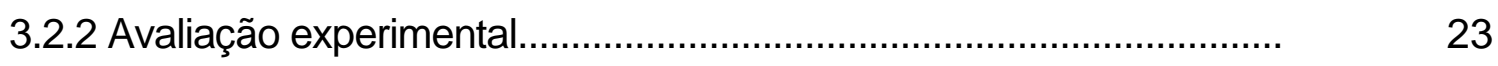

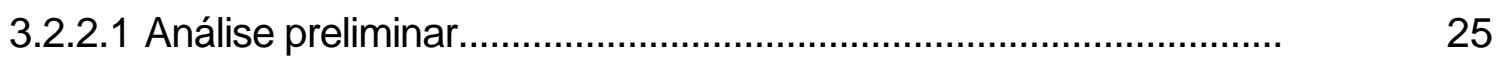

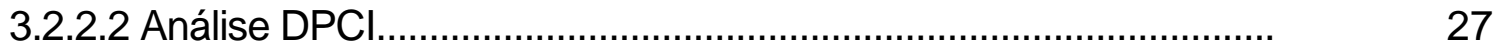

3.2.2.3 Estimativas de componentes de variância pelo método da análise $\quad 29$ de variância ou dos momentos.

3.3 Estudo da influência do tamanho do número $s$ na eficiência do dialelo

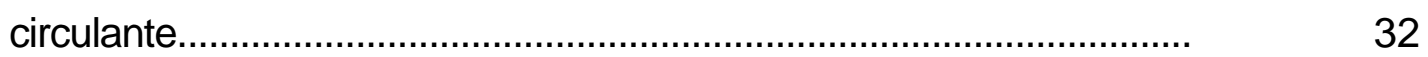

4 RESULTADOS E DISCUSSÃO............................................................ 
4.1 Análise de variância preliminar.........................................................

4.2 Análise de variância do DPCl........................................................... 36

4.2.1 Análise de variância do $\operatorname{DPCl}(\mathrm{A})$..................................................... 37

4.2.2 Análise de variância do DPCl (B)................................................. 39

4.3 Efeitos da capacidade geral e especifica de combinação...................... 40

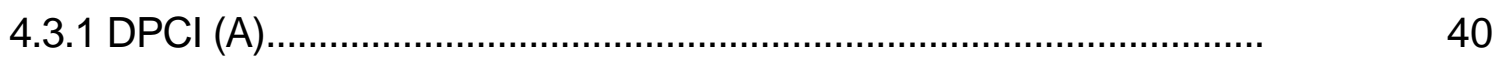

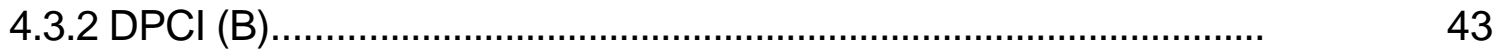

4.4 Influência do número s de cruzamentos nas estimativas de CGC......... $\quad 45$

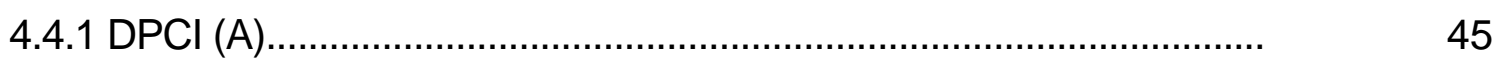

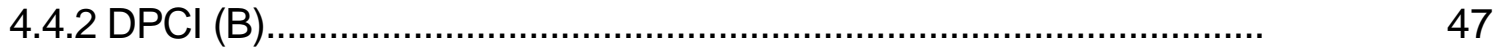

4.5 Influência do número s de cruzamentos nas estimativas de CEC.......... 48

4.6 Estimativas de parâmetros genéticos................................................ 51

4.6.1 Com base nas análises de linhas e diagonais.................................... 51

4.7 Considerações finais......................................................................

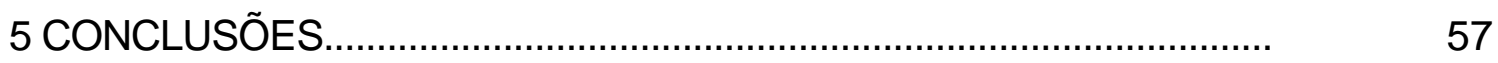

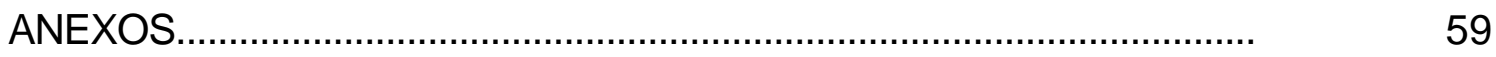

REFERENCIAS BIBLIOGRÁFICAS......................................................... 125 


\section{LISTA DE TABELAS}

Página

1 Materiais utilizados para síntese dos compostos GN-03 e GN-04 pelo Departamento de Genética da ESALQ/USP, Piracicaba-SP

2 Esquema de cruzamento dialelico parcial circulante ao nível interpopulacional, $n=50$ e $s=6$.

3 Quadro da análise de variância individual ao nível de totais

4 Análise de variância segundo o esquema dialélico parcial circulante interpopulacional; conjunto $50 \times 50$ e $s=6$.

5 Representação do modelo completo e reduzido e suas respectivas soma de quadrados.

6 Quadro da análise de variância de tabela de dupla entrada representando $s$ diagonais do grupo I.

7 Média e coeficiente de variação (CV\%) para os caracteres peso de espigas (PE) e altura de planta (AP). Piracicaba, 2001/02; Uberlândia, 2001/02 e Jataí, 2002 
8 Média dos híbridos $S_{1} \times S_{1}$ e das testemunhas para os caracteres peso de espigas (PE) em t/ha e altura de planta (AP) em cm em três locais. Piracicaba, SP 2001/02; Uberlândia, MG 2001/02 e Jataí, GO 2002......

9 Quadro da análise de variância ao nível de médias do DPCI (A) para diferentes tamanhos de $\mathbf{s}$ para as variáveis peso de espiga (PE) e altura de planta (AP). Piracicaba, 2001/02

10 Quadro da análise de variância ao nível de médias do DPCI (B) para diferentes tamanhos de $\mathbf{s}$ para as variáveis peso de espiga (PE) e altura de planta (AP). Piracicaba, 2001/02 ..........................................

11 Quadro da análise de variância ao nível de médias do DPCI (A) para diferentes tamanhos de $\mathbf{s}$ para as variáveis peso de espiga (PE) e altura de planta (AP). Uberlândia, 2001/02

12 Quadro da análise de variância ao nível de médias do DPCI (B) para diferentes tamanhos de $\mathbf{s}$ para as variáveis peso de espiga $(\mathrm{PE})$ e altura de planta (AP). Uberlândia, 2001/02

13 Quadro da análise de variância ao nível de médias do DPCI (A) para diferentes tamanhos de $\mathbf{s}$ para a variável peso de espiga (PE) em t/ha. Jataí, 2002.

14 Estimativas dos parâmetros do modelo utilizado para o caráter peso de espigas (t/ha) dos 30 melhores híbridos, avaliados no DPCI (A) com $s$ igual a 6. Piracicaba, 2001/02 
15 Estimativas dos parâmetros do modelo utilizado para o caráter peso de espigas (t/ha) dos 30 melhores híbridos, avaliados no DPCI (B) com $s$ igual a 6 . Piracicaba, 2001/02

16 Estimativas dos parâmetros do modelo utilizado para o caráter peso de espigas (t/ha) dos 30 melhores híbridos, avaliados no DPCI (A) com $s$ igual a 6. Uberlândia, 2001/02

17 Estimativas dos parâmetros do modelo utilizado para o caráter peso de espigas (t/ha) dos 30 melhores híbridos, avaliados no DPCI (B) com $s$ igual a 6. Uberlândia, 2001/02

18 Estimativas dos parâmetros do modelo utilizado para o caráter peso de espigas (t/ha) dos 30 melhores híbridos, avaliados no DPCI (A) com $s$ igual a 6 . Jataí, 2001/02

19 Estimativas da capacidade geral de combinação da população GN-03 para o caráter peso de espigas (t/ha) em três locais para o $\mathrm{DPCl}(\mathrm{A})$ e suas respectivas posições em ordem decrescente.

20 Estimativas da capacidade geral de combinação da população GN-04 para o caráter peso de espigas (t/ha) em três locais para 0 $\mathrm{DPCl}(\mathrm{A})$ e suas respectivas posições em ordem decrescente.

21 Estimativas da capacidade geral de combinação da população GN-03 para o caráter peso de espigas em três locais para o DPCI (B) e suas respectivas posições em ordem decrescente 
22 Estimativas da capacidade geral de combinação da população GN-04 para o caráter peso de espigas (t/ha) em três locais para 0 $\mathrm{DPCl}(\mathrm{B})$ e suas respectivas posições em ordem decrescente..............

23 Estimativas da capacidade geral de combinação da população GN-03 para o caráter altura de planta $(\mathrm{cm})$ em dois locais para 0 $\mathrm{DPCl}(\mathrm{A})$ e suas respectivas posições em ordem decrescente..............

24 Estimativas da capacidade geral de combinação da população GN-04 para o caráter altura de planta $(\mathrm{cm})$ em dois locais para o $\mathrm{DPCl}(\mathrm{A})$ e suas respectivas posições em ordem decrescente

25 Estimativas da capacidade geral de combinação da população GN-03 para o caráter altura de planta $(\mathrm{cm})$ em dois locais para o DPCI (B) e suas respectivas posições em ordem decrescente.............

26 Estimativas da capacidade geral de combinação da população GN-04 para o caráter altura de planta $(\mathrm{cm})$ em dois locais para 0 DPCI (B) e suas respectivas posições em ordem decrescente..............

27 Coeficientes de correlação entre os valores observados e preditos pelo modelo reduzido $\left(\hat{\mu}+\hat{g}_{i}+\hat{g}_{j}\right)$ em três locais para diferentes valores de $\boldsymbol{s}$ e para o caráter peso de espiga (t/ha)............................

28 Coeficientes de correlação entre os valores observados e preditos pelo modelo reduzido $\left(\hat{\mu}+\hat{g}_{i}+\hat{g}_{j}\right)$ em dois locais para diferentes valores de $\boldsymbol{s}$ e para o caráter altura de planta $(\mathrm{cm})$............................... 
29 Limite superior (LS) e inferior (LI), e amplitude de variação (A) das estimativas de CGC da população GN-03 para valores de $\boldsymbol{s}$ iguais a $6,5,4$ e 3 obtidas em três locais para a variável peso de espigas (tha)

30 Limite superior (LS) e inferior (LI), e amplitude de variação (A) das estimativas de CGC da população $\mathrm{GN}-04$ para valores de $\boldsymbol{s}$ iguais a $6,5,4$ e 3 obtidas em três locais para a variável peso de espigas (tha)

31 Limite superior (LS) e inferior (LI), e amplitude de variação (A) das estimativas de CEC para valores de $\boldsymbol{s}$ iguais a 6, 5, 4 e 3 obtidas em três locais para a variável peso de espigas (t/ha)

32 Limite superior (LS) e inferior (LI), e amplitude de variação (A) das estimativas de CGC da população GN-03 para valores de $\boldsymbol{s}$ iguais a $6,5,4$ e 3 obtidas em dois locais para a variável altura de planta (cm)

33 Limite superior (LS) e inferior (LI), e amplitude de variação (A) das estimativas de CGC da população $\mathrm{GN}-04$ para valores de $\boldsymbol{s}$ iguais a B6, 5, 4 e 3 obtidas em dois locais para a variável altura de planta (cm)

34 Limite superior (LS) e inferior (LI), e amplitude de variação (A) das estimativas de CEC para valores de $s$ iguais a 6, 5, 4 e 3 obtidas em dois locais para a variável altura de planta $(\mathrm{cm})$ 
35 Quadrados médios da análise de variância agrupada (DPCI A e DPCI B) dos dois arranjos de diagonais, para o caráter peso de espigas (t/ha) em dois locais para estimação de parâmetros genéticos..............

36 Quadrados médios da análise de variância dos dois arranjos de diagonais, para o caráter peso de espigas (t/ha) avaliados em Jataí-

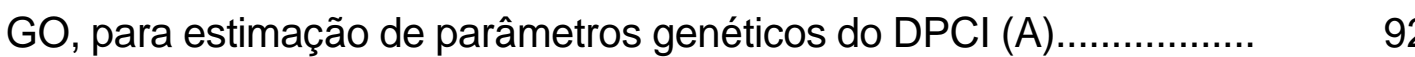

37 Estimativas das variâncias interpopulacionais, em (g/planta $)^{2}$, para a variável peso de espigas (t/ha) e para as populações GN-03 e GN-04

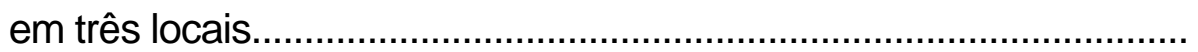




\section{LISTA DE FIGURAS}

Página

1 Dispersão das estimativas obtidas para CGC do DPCl (A) da população GN-03, obtidas entre os valores de $s$ iguais à 6/5; 6/4 e 6/3 e suas correlações para o caráter peso de espigas (t/ha). PiracicabaSP, 2001/02.

2 Dispersão das estimativas obtidas para CGC do DPCl (A) da população GN-03, obtidas entre os valores de $s$ iguais à $6 / 5 ; 6 / 4$ e 6/3 e suas correlações para o caráter peso de espigas (t/ha). UberlândiaMG, 2001/02.

3 Dispersão das estimativas obtidas para CGC do DPCI (A) da população $\mathrm{GN}-03$, obtidas entre os valores de $s$ iguais à $6 / 5 ; 6 / 4$ e 6/3 e suas correlações para o caráter peso de espigas (t/ha). Jataí-GO, 2002.

4 Dispersão das estimativas obtidas para CGC do DPCl (A) da população GN-04, obtidas entre os valores de $s$ iguais à $6 / 5 ; 6 / 4$ e 6/3 para o caráter peso de espigas (t/ha). Piracicaba-SP, 2001/02

5 Dispersão das estimativas obtidas para CGC do $\mathrm{DPCl}(\mathrm{A})$ da população GN-04, obtidas entre os valores de $s$ iguais à $6 / 5 ; 6 / 4$ e 6/3 e suas correlações para o caráter peso de espigas (t/ha). UberlândiaMG,2001/02. 
6 Dispersão das estimativas obtidas para CGC do DPCl (A) da população GN-04, obtidas entre os valores de $\mathbf{s}$ iguais à $6 / 5 ; 6 / 4$ e 6/3 e suas correlações para o caráter peso de espigas (t/ha). Jataí-GO, 2001/02.

7 Distribuição dos erros associados as estimativas de $\mathrm{g}$ e $\mathrm{g}_{\mathrm{j}}$ para os diferentes tamanhos de $\boldsymbol{s}$ para o caráter peso de espigas (t/ha) do DPCI (A) em três locais. Piracicaba-SP2001/02; Uberlândia-MG 2001/02 e .Jataí-GO, 2000.

8 Dispersão das estimativas obtidas para CGC do $\mathrm{DPCl}$ (A) da população GN-03, obtidas entre os valores de $s$ iguais à 6/5; 6/4 e 6/3 e suas correlações para o caráter altura de planta $(\mathrm{cm})$. PiracicabaSP, 2001/02

9 Dispersão das estimativas obtidas para CGC do DPCl (A) da população GN-03, obtidas entre os valores de $s$ iguais à $6 / 5 ; 6 / 4$ e 6/3 para e suas correlações 0 caráter altura de planta $(\mathrm{cm})$. UberlândiaMG, 2001/02

10 Dispersão das estimativas obtidas para DPCl (A) da população GN04 , obtidas entre os valores de $s$ iguais à $6 / 5 ; 6 / 4$ e 6/3 e suas correlações para o caráter altura de planta $(\mathrm{cm})$. Piracicaba-SP, $2001 / 02$

11 Dispersão das estimativas obtidas para CGC do DPCl (A) da população GN-04, obtidas entre os valores de $\mathbf{s}$ iguais à 6/5; 6/4 e $6 / 3$ e suas correlações para o caráter altura de planta $(\mathrm{cm})$. Uberlândia-MG,2001/02. 
12 Distribuição dos erros associados as estimativas de $g_{\mathrm{i}} \mathrm{e}$ gj para os diferentes tamanhos de $\boldsymbol{s}$ para 0 caráter altura de planta $(\mathrm{cm}) \mathrm{do}$ DPCI (A) em dois locais. Piracicaba-SP2001/02; Uberlândia-MG, 2001/02.

13 Dispersão das estimativas obtidas para CGC do DPCl (B) da população $\mathrm{GN}-03$, obtidas entre os valores de $s$ iguais à $6 / 5 ; 6 / 4 \mathrm{e}$ 6/3 para o caráter peso de espigas ( $\mathrm{t} / \mathrm{ha}$ ). Piracicaba-SP, 2001/02......

14 Dispersão das estimativas obtidas para CGC do DPCI (B) da população GN-03, obtidas entre os valores de $s$ iguais à 6/5;6/4 e 6/3 e suas correlações para o caráter peso de espigas (t/ha). Uberlândia-MG, 2001/02

15 Dispersão das estimativas obtidas para CGC do DPCl (B) da população $\mathrm{GN}-04$, obtidas entre os valores de $s$ iguais à $6 / 5 ; 6 / 4 \mathrm{e}$ $6 / 3$ e suas correlações para o caráter peso de espigas (t/ha). Piracicaba-SP, 2001/02

16 Dispersão das estimativas obtidas para CGC do DPCl (B) da população GN-04, obtidas entre os valores de $s$ iguais à 6/5; 6/4 e 6/3 e suas correlações para o caráter peso de espigas (t/ha). Uberlândia-MG, 2001/02.

17 Dispersão das estimativas obtidas para CGC do DPCl (B) da população $\mathrm{GN}-03$, obtidas entre os valores de $s$ iguais à $6 / 5 ; 6 / 4 \mathrm{e}$ $6 / 3$ e suas correlações para o caráter altura de planta $(\mathrm{cm})$. Piracicaba-SP, 2001/02 
18 Dispersão das estimativas obtidas para CGC do DPCl (B) da população GN-03, obtidas entre os valores de $s$ iguais à 6/5; 6/4 e 6/3 para o caráter altura de planta $(\mathrm{cm})$. Uberlândia-MG, 2001/02.......

19 Dispersão das estimativas obtidas para CGC do DPCl (B) da população GN-04, obtidas entre os valores de $s$ iguais à $6 / 5 ; 6 / 4 \mathrm{e}$ 6/3 e suas correlações para o caráter altura de planta (cm). Piracicaba-SP, 2001/02

20 Dispersão das estimativas obtidas para CGC do DPCI (B) da população GN-04, obtidas entre os valores de $s$ iguais à 6/5; 6/4 e $6 / 3$ e suas correlações para o caráter altura de planta (cm). Uberlândia-MG, 2001/02.

21 Distribuição dos erros associados as estimativas de $g_{\mathrm{e}} \mathrm{e}$ gj para os diferentes tamanhos de $\boldsymbol{s}$ para o caráter peso de espigas (t/ha) do DPCl (B) em dois locais. Piracicaba-SP2001/02; Uberlândia-MG, $2001 / 02$

22 Distribuição dos erros associados as estimativas de $g_{\mathrm{f}} \mathrm{e} \mathrm{g}_{\mathrm{j}}$ para os diferentes tamanhos de $\boldsymbol{s}$ para o caráter altura de planta $(\mathrm{cm})$ do DPCI (B) em dois locais. Piracicaba-SP2001/02; Uberlândia-MG, 2001/02.

23 Dispersão das estimativas obtidas para CEC do DPCl (A), obtidas entre os valores de $s$ iguais à $6 / 5 ; 6 / 4$ e 6/3 e suas correlações para o caráter peso de espigas (t/ha). Piracicaba-SP, 2001/02 
24 Dispersão das estimativas obtidas para CEC do DPCl (A), obtidas entre os valores de $s$ iguais à $6 / 5 ; 6 / 4$ e 6/3 e suas correlações para o caráter peso de espigas (t/ha). Uberlândia-MG, 2001/02 ......................

25 Dispersão das estimativas obtidas para CEC do DPCI (A), obtidas entre os valores de $\mathbf{s}$ iguais à $6 / 5 ; 6 / 4$ e 6/3 e suas correlações para o caráter peso de espigas (t/ha). Jataí-GO, 2002

26 Dispersão das estimativas obtidas para CEC do DPCl (A), obtidas entre os valores de $\mathbf{s}$ iguais à $6 / 5 ; 6 / 4$ e 6/3 e suas correlações para o caráter altura de planta $(\mathrm{cm})$. Piracicaba-SP, 2001/02

27 Dispersão das estimativas obtidas para CEC do DPCI (A), obtidas entre os valores de $\mathbf{s}$ iguais à 6/5; 6/4 e 6/3 e suas correlações para o caráter altura de planta (cm). Uberlândia-MG, 2001/02

28 Dispersão das estimativas obtidas para CEC do DPCl (B), obtidas entre os valores de $s$ iguais à $6 / 5 ; 6 / 4$ e 6/3 e suas correlações para 0 caráter peso de espigas (t/ha). Piracicaba-SP 2001/02........................

29 Dispersão das estimativas obtidas para CEC do DPCI (B), obtidas entre os valores de $s$ iguais à $6 / 5 ; 6 / 4$ e $6 / 3$ e suas correlações para 0 caráter peso de espigas (t/ha). Uberlândia-MG 2001/02

30 Dispersão das estimativas obtidas para CEC do DPCI (B), obtidas entre os valores de $\mathbf{s}$ iguais à $6 / 5 ; 6 / 4$ e 6/3 e suas correlações para 0 caráter altura de planta (cm). Piracicaba-SP, 2001/02 
31 Dispersão das estimativas obtidas para CEC do DPCl (B), obtidas entre os valores de $\mathbf{s}$ iguais à $6 / 5 ; 6 / 4$ e 6/3 e suas correlações para o caráter altura de planta (cm). Uberlândia-MG, 2001/02........................ 


\title{
DIALELO PARCIAL CIRCULANTE INTERPOPULACIONAL EM MILHO (Zea mays L.): EFEITO DO NÚMERO (s) DE CRUZAMENTOS
}

\author{
Autor: SANDRO RICARDO FUZATTO \\ Orientador: Prof. Dr. JOSÉ BRANCO DE MIRANDA FILHO
}

\section{RESUMO}

No esquema de cruzamentos do dialelo parcial circulante interpopulacional (DPCl) cada linhagem da população é cruzada com s linhagens da população contrastante. $O$ objetivo deste trabalho foi estudar 0 efeito do número s nas estimativas de capacidade geral de combinação (CGC) e capacidade especifica de combinação (CEC) de linhagens $S_{\uparrow}$ para duas populações contrastantes (GN-03 e GN-04) de milho (Zea mays L.). Dois dialelos (DPCl A e DPCl B) com 50 linhagens cada, foram cruzadas (GN-03 x GN-04) usando $s=6$, de acordo com o esquema circulante de cruzamento. Dos 300 híbridos possíveis de cada dialelo, foram obtidos 297 no DPCl (A) e 282 no DPCI B. Os híbridos foram avaliados em três locais (Piracicaba-SP e Uberlândia-MG, com três repetições; e em Jataí-GO com duas repetições); o DPCI B foi avaliado somente nos dois primeiros locais. Os híbridos foram divididos em seis experimentos para cada DPCl. As análises foram realizadas para cada experimento e agrupadas posteriormente; os caracteres analisados foram peso de espigas (t/ha) e altura de planta $(\mathrm{cm})$. As análises do DPCI foram realizadas para diferentes tamanhos de $s$, a saber, $s=3,4,5$, e 6 . A produtividade média dos híbridos $S_{1} \times S_{1}$ nos dois grupos variou de $94 \%$ a $99 \%$ 
em relação à média das testemunhas em Uberlândia e Piracicaba. Na época safrinha avaliada em Jataí, a média dos híbridos foi $17 \%$ superior a média da testemunha. A fonte de variação CEC não mostrou significância em todos locais e caracteres avaliados. Em alguns casos a perda de graus de liberdade para a fonte de variação CEC com a redução de $s$, diminuiu o poder do teste de $F$. A redução de s levou a uma maior variação das estimativas de CGC e também a uma diminuição na precisão das estimativas de CEC. Os coeficientes de correlação $(r)$ entre os valores obtidos pelo modelo reduzido $\left(\hat{Y}_{i j}=\hat{\mu}+\hat{g}_{i}+\hat{g}_{j}\right)$ com os observados $\left(Y_{i j}=\mu+g_{i}+g_{j}+s_{i j}+\bar{e}_{i j}\right)$ foram calculados para ambos os dialelos em todos os locais. Os maiores coeficientes de correlação foram observados com os menores valores de $\mathrm{s}$, induzindo à falsa interpretação de que as estimativas de CEC têm pouca influência na média do híbrido. Resultados consistentes foram obtidos quando utilizou-se o mínimo de cinco cruzamentos por parental $(s=5)$, pois pode-se obter estimativas significativas e adequadas de CGC e CEC. As estimativas de componentes de variância ao nível interpopulacional foram estimados para o caráter peso de espigas, usando $\mathrm{s}=6$. As estimativas de variância aditiva expressas em ( $\mathrm{g} /$ planta $)^{2}$ foram 120,56 , 61,92 e 38,44 para os locais Piracicaba, Uberlândia e Jataí, respectivamente. A variância de dominância foi superior a variância aditiva ao nível interpopulacional em todos os locais. As relações encontradas foram 6,05, 4,30 e 7,15 para os locais Piracicaba, Uberlândia e Jataí, respectivamente evidenciando a importância dos efeitos não aditivos entre as populações. 


\title{
CIRCULANT PARTIAL DIALLEL IN AN INTERPOPULATION OF MAIZE: EFECT OF THE NUMBER (s) OF CROSSES
}

\author{
Author: SANDRO RICARDO FUZATTO \\ Adviser: Prof. Dr. JOSÉ BRANCO DE MIRANDA FILHO
}

\section{SUMMARY}

In the partial mating scheme, each line of one population is crosses with a number (s) of lines of the opposite population. The objective of this work was to study the effect of the number $s$ in the estimates of general combining ability (GCA) and specific combining ability (SCA) of $S_{1}$ lines from two contrasting populations (GN-03 and GN-04) of maize (Zea mays L.) crossed according to the partial diallel. Two groups $\left(G_{A}\right.$ and $\left.G_{B}\right)$ of fifth $S_{1}$ lines were randomly crossed (GN-03 $\times$ GN-04) using $s=6$. From the 300 possible crosses in each group, some were last resulting 297 in $G_{A}$ and 282 in $G_{B}$. Crosses were evaluated in three locations (Piracicaba-SP and Uberlandia-MG with three replications; and Jatai-GO with two replications); group $G_{B}$ was evaluated only in the first two locations. The whole set of crosses was divided into six experiments for each group. The analyses of variance were performed for each experiment and then grouped over experiments. The traits ear yield (t/ha) and plant height $(\mathrm{cm})$ were analysed. The analyses were performed for varying number of crosses per line; i.e., for $S=3,4,5,6$. Ear yield of $S_{1} \times S_{1}$ crosses in both groups varied from $94 \%$ to $99 \%$ in relation to the mean of both checks in Uberlandia and Piracicaba. In Jatai, only group $G_{A}$ in midseason planting yielded $17 \%$ more 
than the average of checks. Specific combining ability didn't showed significance for every traits and locations. While general combining ability was always significant. Decreasing $s$ led to a higher variation in the estimates of GCA and also to a decrease in the precision of SCA estimates. The coefficient of correlation between observed means $\left(Y_{i j}=\mu+g_{i}+g_{j}+s_{i j}+\bar{e}_{i j}\right)$ and predicted means through the reduced model $\left(\hat{Y}_{i j}=\hat{\mu}+\hat{g}_{i}+\hat{g}_{j}\right)$ was calculated for boths groups in all locations. The higher coefficients of correlations were observed for smaller $s$ values, leading to a miss interpretation. That SCA is of low importance in the phenotypic expression. Consistent results were observed by using $S=5$ allowing the detection of significance and good of the estimates of GCA and SCA. The estimates of the interpopulation variance components were obtained for ear yield using $s=6$. The estimates of the additive genetic variance expressed in (g/plant $)^{2}$ were 120.56, 61.92 and 38.44 in Piracicaba, Uberlandia and Jatai, respectively. The dominance variance were higher than the additive variance in all locations; the ratios $\left(\sigma_{\mathrm{D}}^{2} / \sigma_{\mathrm{A}}^{2}\right)$ were $6.1,4.3$ and 7.2 , respectively, indicating the importance of the non additive effects in the interpopulation. 


\section{INTRODUÇÃO}

O sistema de endogamia-hibridação estabelecido por SHULL (1908, 1909) para a exploração da heterose ainda persiste atualmente como sistema básico para a produção de sementes híbridas.

Um obstáculo enfrentado pelos melhorista de milho para 0 desenvolvimento de linhagens e híbridos desde seu estabelecimento diz respeito à sua avaliação. Isso ocorre pois aumentando-se a quantidade de linhagens endogâmicas, torna-se impraticável a confecção e avaliação de todas as combinações híbridas (Hallauer, 1990).

O sistema "top-cross" sugerido por Davis (1927), mostrou-se eficiente no trabalho experimental realizado por Jenkins e Brunson(1932), sendo rotineira sua utilização nos programas de milho híbrido.

Na década de 1940 com a definição de capacidade geral de combinação (CGC) e capacidade especifica de combinação (CEC) feita por Sprague e Tatum (1942), surgiram novos modelos para análise de cruzamentos dialélicos, que trouxeram contribuições adicionais para o aprimoramento do sistema de avaliação do valor genético de linhagens em combinações híbridas. Entre os modelos que se destacaram o que se mostra mais apropriado na avaliação de uma amostra de linhagens, são os dialelos circulantes proposto inicialmente por Kempthorne e Curnow (1961) para o nível intrapopulacional e adaptado ao nível interpopulacional por Miranda Filho e Vencovsky (1999).

No processo de obtenção de híbridos procura-se explorar ao máximo os efeitos de CGC (avaliados em top-cross ou dialelos) e também de CEC, sendo estes últimos função de efeitos gênicos não aditivos. Resultados da literatura 
têm mostrado que em geral os efeitos CGC são mais expressivos do que CEC como fontes de variação, independente do nível de significância. Entretanto, vários trabalhos como os de Hoegemmeyer e Hallauer (1976); Stangland et al. (1983) e Martins e Miranda Filho (1997), tem mostrado que os efeitos de CEC podem ser bastante expressivos em combinações híbridas específicas.

A exploração dos efeitos da CEC em híbridos deve constituir-se em objetivo indispensável para a máxima manifestação dos efeitos genéticos que controlam a produtividade. No método de cruzamento dialelico parcial circulante ao nível interpopulacional (DPCl) proposto por Miranda Filho e Vencovsky (1999), utilizam-se $n$ genótipos (linhagens) de cada população (P1 e P2), sendo cada uma cruzada com $s$ linhagens da população contrastante; portanto, ns híbridos são avaliados experimentalmente. Dispõe-se de $n-1$ graus de liberdade (GL) para avaliar a capacidade de combinação (CGC) de linhagens em cada população; e $n(s-2)+1$ GL para CEC. Assim, para $n$ igual a 50 e $s$ iguais a 6, 5, 4 e 3, os números de graus de liberdade são, 98 (49 para cada população) para CGC para qualquer valor de $s$, e de 51, 101, 151 e 201 para CEC. O aumento de $s$ aumenta sobremaneira a amostragem dos efeitos de CEC, além de melhorar a precisão das estimativas de CGC.

Para a aplicação da metodologia do DPCl, procura-se usar um valor de s que garanta uma boa precisão nas estimativas dos efeitos de CGC e CEC, as quais irão refletir o valor genético das linhagens para utilização em híbridos. Neste sentido os objetivos do trabalho foram:

- Utilizar o esquema de DPCI para estimar e testar hipóteses sobre os efeitos de capacidade geral (CGC) e específica (CEC) de combinação de linhagens $S_{1}$ das populações $\mathrm{GN}-03$ e GN-04.

- Avaliar o efeito do tamanho s, ou seja, o número de vezes que uma linhagem é cruzada com linhagens da população contrastante, na oscilação e precisão das estimativas de CGC e CEC. 
- Estimar os componentes de variância genética (variância aditiva e dominante) ao nível interpopulacional (GN-03 x GN-04). 


\section{REVISÃO DE LITERATURA}

\subsection{Processo de avaliação de linhagens}

Desde do estabelecimento do sistema de endogamia-hibridação proposta por Shull $(1908,1909)$ pesquisas na área de melhoramento genético de milho contribui com metodologias importantes para o desenvolvimento de híbridos cada vez mais produtivos. Com essas novas técnicas, os melhoristas dispõem de diversos tipos de dialelos e métodos de análise para avaliar suas combinações híbridas. Este fato confere aos melhoristas uma grande flexibilidade na escolha do procedimento de acordo com o objetivo do programa.

Apesar de Shull ter proposto o sistema para síntese de híbridos, foi Jones (1918) quem propiciou a produção sistemática de híbridos duplos, já que a produção de híbridos simples era inviável na época devido à baixa produtividade das linhagens. O primeiro obstáculo encontrado foi avaliar as combinações híbridas à medida que o número de linhagens aumentava. Davis (1927) sugeriu o uso de top-cross, onde o valor genético é avaliado em cruzamento das linhagens com um testador comum. Assim, em vez de avaliar todas as $n(n-1) / 2$ combinações híbridas possíveis, são avaliados $n$ top-crosses. O esquema top-cross mostrou-se eficiente em trabalho experimental realizado por Jenkins \& Brunson (1932) e é atualmente bastante utilizado nos programas de milho híbrido. Em seqüência, Sprague \& Tatum (1942) definiram os termos capacidade geral de combinação e capacidade específica de combinação, com base em resultados experimentais de avaliação de híbridos de linhagens em todas as 
combinações possíveis. A partir daí surgiram novos modelos para análise de cruzamentos dialélicos (Griffing, 1956; Kempthorne \& Curnow, 1961; Gardner \& Eberhart, 1966; Eberhart \& Gardner, 1966; Miranda Filho \& Geraldi, 1984; Miranda Filho \& Vencovsky, 1999) que trouxeram contribuições adicionais para o aprimoramento do sistema de avaliação do valor genético dos genótipos em combinações híbridas.

Em programas de melhoramento visando a obtenção de híbridos, existe a necessidade de avaliação de uma grande quantidade de linhagens. No processo de obtenção de linhagens, a seleção precoce para capacidade de combinação quando realizado em gerações precoces, isto é, antes de atingir a geração $S_{6}$ e $S_{7}$ de endogamia, aumenta a eficiência do processo. Isto reduz substancialmente 0 número de linhagens antes de atingir homozigose completa (Souza Junior, 2001). O autor comenta que a partir de linhagens $S_{3}$ da geração $n$, a correlação com $S_{\infty}$ é 0,93 e os acréscimos para as demais gerações são muitos pequenos.

Devido à dimensão dos programas de melhoramento atuais a avaliação precoce das linhagens em desenvolvimento de maneira eficiente tem sido um dos desafios para os melhoristas. Neste contexto, dois sistemas de cruzamentos se destacam no que diz respeito à abrangência de sua utilização: i) cruzamento top cross ii) cruzamento dialélico.

\subsubsection{Cruzamento top cross}

O esquema de cruzamento top-cross proposto por Davis (1927) é bastante utilizado na avaliação de linhagens. O maior questionamento que tem sido feito a respeito do método desde sua invenção, refere-se a escolha do testador. Nos programas de melhoramento de empresas o uso de linhagens elites ou híbridos simples como testadores tem sido um procedimento comum. $\mathrm{O}$ fato da linhagem elite ou do híbrido simples possuir uma série de características desejáveis já selecionadas devido à alta concentração de alelos favoráveis, o uso destes pode levar a identificação 
de pares de linhagens com elevado grau de complementação, mas não necessariamente a avaliação do potencial genético intrínseco das linhagens testadas. $O$ uso de um testador com valor genético mais baixo (alta freqüência de alelos recessivos) é mais indicado (Miranda Filho \& Gorgulho, 2001; Hull, 1945).

Segundo Souza Junior (2001) o uso de linhagens elites como testadora é indicado quando o objetivo do programa é a obtenção de híbridos simples; quando o objetivo for à obtenção de híbridos triplos devese usar como testador um híbrido simples. Com a média desses híbridos, dois tipos de seleção podem ser efetuados: i) uma seleção com híbridos simples com estas linhagens elites ou híbridos testadores e, neste caso, uma alta intensidade de seleção é aplicada; ii) uma seleção para capacidade de combinação onde é aplicada uma intensidade de seleção mediana. Ressalta que o esquema ii de seleção é utilizado devido ao fato de as correlações entre as capacidades de combinação das linhagens com diversos tipos de testadores serem muito baixas para se ter algum valor preditivo e, portanto, uma alta intensidade de seleção só pode ser aplicada para um testador especifico, pois a probabilidade de selecionar linhagens com alta capacidade de combinação para testadores distintos é muito baixa.

Existem na literatura trabalhos que compararam os esquemas de cruzamentos dialélicos e "top-cross". Bellucci (1995) concluiu que o sistema de cruzamentos em "top-cross" pode ser usado no lugar de dialélicos desde que o objetivo não seja identificar cruzamentos específicos. Gorgulhho (1997) avaliou dois grupos de variedade de milho usando como metodologia - esquema de cruzamentos dialelico parcial e "top-cross". Verificou limitações do esquema "top-cross" em relação ao dialelo parcial, indicando este em avaliações de populações no inicio dos programas de melhoramento, onde a variabilidade presente é alta. Em programas mais avançados ressalta que outros métodos podem ser mais proveitosos.

Apesar da grande utilidade do esquema de cruzamentos "top-cross", as tentativas visando identificar um testador perfeito, ainda não foi possível. 
Esse argumento já havia sido utilizado por Hallauer (1975), pois sempre existe a possibilidade de eliminação de linhagens úteis por não apresentarem boa capacidade combinatória com o testador utilizado.

\subsubsection{Dialelos completos}

Entende-se por cruzamento dialélico completo todos os cruzamentos possíveis entre um conjunto de $\mathrm{n}$ linhagens. Após a introdução dos conceitos de capacidade geral e específica de combinação proposta por Sprague e Tatum (1942) os esquemas de cruzamentos dialélicos receberam maior atenção dos pesquisadores.

Os primeiros trabalhos propostos foram bem elaborados e aceitos, que são atualmente utilizados na avaliação de linhagens e populações de milho, principalmente nos casos de dialelos balanceados com modelos totalmente fixos ou aleatórios. Já nos dialelos desbalanceados e ou com modelos mistos (aleatórios e fixos), a Metodologia de Modelos Mistos (MMM), proposta por Henderson (1949) é mais apropriada segundo observações feitas por André (1999) e Duarte (2000).

Com os métodos de Griffing (1956), obtem-se os efeitos da CGC e CEC de combinação e na análise de variância um desdobramento desses efeitos, aplicável tanto para um modelo considerado fixo quanto aleatório. Neste esquema pode-se avaliar $n^{2}$ combinações híbridas. Este total pode no entanto ser dividido em três grupos: os $n$ genitores, híbridos $F_{1}$ com $\frac{1}{2} n(n-1)$ combinações e os híbridos $F_{1}$ recíprocos com $\frac{1}{2} n(n-1)$. Com esses grupos, quatro métodos de análise podem ser aplicados: i) Método 1São incluídos os pais, os híbridos $F_{1}$ e os híbridos recíprocos ( $n^{2}$ combinações); ii) Método 2 São incluídos somente os pais e os híbridos F1, com $\frac{1}{2} n(n-1)$ combinações; iii) Método 3- São incluídos somente os híbridos $\mathrm{F} 1$ e os recíprocos, totalizando $n(n-1)$ combinações; iiii) Método 4 - 
inclui somente os híbridos $F 1$, com $\frac{1}{2} n(n-1)$ combinações. Na avaliação de caracteres em que os efeitos maternos não são importantes a avaliação dos recíprocos pode ser dispensada (Cruz e Regazzi, 1994).

O método de Gardner \& Eberhart (1966) tem como principal vantagem um estudo detalhado da heterose, com sua decomposição em vários componentes, porém aplicável somente para modelos considerados fixos. Segundo considerações feitas por Miranda Filho e Gorgulho (2001), este método é mais apropriado para o estudo do valor genético dos genitores e seu potencial heterótico em cruzamentos. Ressalta-se ainda que não têm sido utilizados na avaliação de linhagens para utilização em híbridos, mesmo quando se trabalha com conjuntos fixos. Especificamente na avaliação de linhagens os métodos baseados nos conceitos de CGC e CEC são mais apropriados.

Jinks e Hayman (1953) também propuseram uma metodologia de análise que se destaca pela quantidade de informações genéticas em espécies estudadas (Vencovsky, 1970), porém com uma série de restrições para sua validade. Uma dessas restrições é que a metodologia aplicase somente em linhagens puras e por este motivo tem sido mais utilizado em espécies autógamas.

As informações obtidas envolvendo cruzamentos dialélicos são amplamente utilizadas nos programas de melhoramento de milho. Estimativas de parâmetros genéticos podem, por exemplo, auxiliar na seleção de genitores, na predição de médias de compostos e cruzamentos não realizados. Vencovsky (1970) apresentou um amplo estudo sobre o modelo de Gardner e Eberhart (1966), mostrando sua utilização, análise e interpretação de resultados. O autor derivou equações e desenvolveu expressões simplificadas para estimar a média de compostos de variedades. André (1999) verificou que, tendo disponível a informação sobre o grau de similaridade entre materiais genéticos, em associação ao BLUP (Best linear 
unbiased prediction), este permite a predição dos valores genéticos de cruzamentos.

\subsubsection{Dialelos parciais intra e interpopulacional}

O emprego de dialelos completos citados anteriormente tem-se limitado a um número restrito de genitores. Com o aumento destes ocorre um aumento no número de cruzamentos a serem realizados, associados æ̀̀ dificuldades de avaliação desses cruzamentos ao nível de campo com a precisão experimental desejada, tornando inviável a avaliação de todos os cruzamentos possíveis.

Este fato fez surgir o conceito de dialelo parcial, em que com um número reduzido de cruzamentos, pode-se avaliar um maior número de materiais.

A metodologia denominada de dialelo parcial circulante foi desenvolvida por Kempthorne e Curnow (1961). Apesar das vantagens deste tipo de dialelos muitas vezes é questionada a sua eficiência em relação aos dialelos completos. Veiga (1998) avaliou por meio de simulação de dados a eficiência dos dialelos circulantes na obtenção de estimativas de capacidade geral (CGC) e específica de combinação (CEC). Para esse fim, o autor simulou linhagens com 100 genes, considerados independentes, com efeitos iguais, sem epistasia, que foram utilizados para gerar dialelos completos, pelo método II do modelo de Griffing (1956). Considerou situações de herdabilidade de $10 \%$, 20\%, 50\% e $75 \%$, em modelos com efeitos aditivos e com dominância completa. A partir disso foram simulados todos os dialelos circulantes possíveis para cada caso. Nesse estudo, considerou-se também dados de experimentos disponíveis na literatura para simulação de dialelos circulantes. Com isso concluiu-se que: i) Os dialelos circulantes demonstraram eficiência comparável à dos completos, tanto na classificação dos pais quanto a CEC e a CGC, como nas magnitudes das estimativas desses parâmetros; ii) No dialelo circulante, o número de cruzamentos de 
cada pai (s), afeta as estimativas de CGC e CEC, entretanto com um valor mínimo de (s), é possível obter boa concordância nas estimativas em relação aos dialelos completos; iii) Especialmente em condições de baixa herdabilidade, pode ser vantajoso aumentar o número de cruzamentos de cada pai, contudo a melhoria na eficiência ocorre com um aumento de (s) até o máximo da metade do número de pais envolvidos.

Existem na literatura outros trabalhos que propuseram estudar 0 numero s de cruzamentos. Os trabalhos de Murty et alii (1967) e Anand e Murty (1969) foram realizados com o objetivo de estudar as precisões das estimativas da CGC para valores de $s=9,7,5$ e 3. Trabalhando com dez cultivares de linho (Linum usitatissimum L.) concluíram que o numero s não deve ser menor que a metade do numero de genitores (n). Ressaltaram ainda que se o $\mathbf{n}$ for grande, o valor de $\mathbf{s}$ poderá ser menor que $\mathrm{n} / 2$. Na seqüência Bray (1971) trabalhando com doze clones de alfafa (Medicago sativa L.) não encontrou um número ótimo de $s$ para dialelo circulante. Porém, considerou que mais que oito ou dez cruzamentos por parental é desnecessário. Deve-se considerar que neste trabalho os clones foram avaliados em apenas um local.

Dhillon e Singh (1978) salientaram que os trabalhos anteriores utilizaram valores de $n$ muito pequeno, e os resultados são inflacionados por terem sido avaliados em poucos ambientes. Trabalhando com 20 genitores diversos de milho, esses autores obtiveram 190 híbridos $F_{1}$ avaliados em dois locais e em dois anos, totalizando quatro ambientes. Compararam dialelos parciais segundo o método de Kempthorne \& Curnow (1961) com $\mathbf{s}=15,11,7,5$ e 3 , com dialelos completos $(s=19)$ analisados pelo método de Griffing (1956). Para os autores um $s=7$ fornece precisão razoável para as estimativas de CGC. As estimativas de CGC mostraram flutuações no dialelo circulante, sendo mais pronunciada em $\mathrm{s}=5$ e $\mathrm{s}=3$, particularmente para caracteres de baixa herdabilidade. $O$ autor comenta que $s=7$ pode não ser um número ideal para dialelos parciais. Comenta que no estudo de um maior número de parentais poucos cruzamentos (s) pode ser suficiente. Observa- 
se que estes trabalhos utilizaram um número reduzido de genitores e ainda não utilizaram genitores que representassem uma população de referência, sendo desta forma considerados de natureza fixa. Nesta situação, extrapolar esses resultados para outras situações principalmente quando $\mathrm{n}$ for elevado, deve seria recomendável.

Miranda Filho e Geraldi (1984 e 1988), apresentaram as bases teóricas de um modelo para análise de dialelos parciais entre grupos distintos de variedades, representando adaptações do modelo completo de Gardner e Eberhart (1966) e do método II do modelo de Griffing (1956), respectivamente. Esses modelos, exceto o de Griffing (1956) referem-se a conjuntos fixos de variedades, sendo portanto, úteis para estimação dos componentes de médias e de efeitos genéticos e para testes de hipóteses sobre nulidade dos efeitos, não sendo adequados para estimar componentes de variância genética.

O programa de melhoramento genético em milho, valoriza a exploração de híbridos e linhagens pertencentes a diferentes grupos heteróticos. Acredita-se que com este tipo de exploração a heterose a ser expressa no híbrido é maximizada, tornando o programa mais eficiente (Lee,1995). Este fato motivou pesquisadores do Departamento de Genética da ESALQ/USP a desenvolverem uma metodologia de análise de tabelas dialélicas, compatível com essa realidade, já que a metodologia proposta por Kempthorne \& Curnow (1961) referem-se a apenas um grupo aleatório de linhagens. Método esse publicado por Miranda filho \& Vencovsky (1999) denominado de "dialelo parcial circulante interpopulacional" (DPCI).

O primeiro trabalho sobre a aplicabilidade do referido método foi realizado por Gonçalves (1987), estudando 30 linhas $S_{5}$ de duas populações, ESALQ-PB2 e ESALQ-PB3; apresentou análises de variância e estimativas dos efeitos de capacidade geral de combinação ( $g_{i}$ e $\left.g_{j}\right)$, bem como a eficiência de estimação de médias de híbridos a partir de estimativas de $g_{i}$ e $g_{j}$ obtidas pelo modelo reduzido. Dantas (1988) estudou linhagens das populações ESALQ-PB1 e SUWAN e verificou a possibilidade de utilizar 
os parâmetros $\mathrm{K}_{\mathrm{i}}$ e $\mathrm{K}_{\mathrm{j}}$ em vez de $\mathrm{g}_{\mathrm{i}}$ e $\mathrm{g}$ para predizer médias de híbridos simples, duplos e triplos. Sampaio (1989) analisou a capacidade de combinação de famílias de meios irmãos das populações ESALQ-PB4 e ESALQ-PB5, segundo o esquema de DPCI. Dantas (1992) trabalhou com linhagens $S_{2}$ das populações ESALQ-PB2 e ESALQ-PB3, avaliando-as em cruzamento em duas fases subseqüentes, nos esquemas $\mathrm{DPCl} e$ cruzamento dialelico parcial intergrupos (Miranda Filho \& Geraldi, 1984) de linhagens selecionadas na fase anterior. Andrade (1996) estudou linhagens parcialmente endogamicas das populações ESALQ-PB1 e SUWAN, multiplicadas através de dois sistemas (autofecundação e cruzamentos fraternais). O último trabalho nesta linha foi realizado por Araújo (2000), o autor comparou a eficiência entre o esquema de cruzamento $\mathrm{DPCl}$ com o método de cruzamento "top-cross". Para esse fim utilizou progênies $S_{2}$ das populações de milho (Zea mays L.) BR 106 e IAPAR26. Este verificou que o método de DPCl foi mais eficiente que o "top-cross" na seleção de linhagens pois além de uma melhor precisão nas estimativas de capacidade geral de combinação, fornece também informações sobre a CEC, o que não ocorre com o uso do "top-cross". Vale ressaltar que todos os trabalhos aprovaram a eficiência do método, tanto para obtenção de estimativas de capacidade de combinação como também para a predição de híbridos simples, duplos e triplos.

A metodologia DPCl proposta por Miranda filho \& Vencovsky (1999) foi adaptada ao modelo de Gardner e Eberhart (1966) por Reis (2000). Em seu trabalho o autor utilizando 34 linhagens de milho e um $\mathbf{s}=5$, concluiu que a metodologia proposta foi eficiente na discriminação das linhagens per se, além de possibilitar a identificação de combinações especificas superiores.

No que diz respeito sobre ao número aceitável de cruzamentos por linhagem (s), os trabalhos de Miranda Filho ${ }^{1}$, conclui que $s=4$ fornece uma

\footnotetext{
${ }^{1}$ MIRANDA FILHO, J.B. Aspectos teóricos e aplicados do cruzamento dialélico parcial circulante. 1995. (Relatório FAPESP não publicado)
} 
boa precisão nas estimativas da CGC. Burdon (1992) citado por Rezende (1994) também relata que tem sido adequado para avaliação da CGC, um número de 4 a 5 cruzamentos com outros genitores. Porém não relata a metodologia e como chegou a esses valores.

No entanto, o mesmo não tem sido relatado a respeito da influência de $s$ nos efeitos de CEC. Sabe-se que com a diminuição $s$ o grau de liberdade da análise de variância é menor, diminuindo o poder de teste de $\mathrm{F}$, no caso, em detectar significância para a fonte de variação CEC (kempthorne \& Curnow, 1961).

\subsection{Estimativas da Capacidade Geral e Específica de Combinação}

Como já mencionado anteriormente, os termos CGC e CEC foram utilizados inicialmente por Sprague e Tatum (1942). O efeito da CGC expressa o desempenho médio do genitor (i) em combinação com $p$ genitores e a CEC avalia a parte da combinação não explicada pela CGC de cada genitor envolvido. Em termos genéticos, diz-se que a estimativa da CGC está associada a genes de efeitos predominantemente aditivos, além de efeitos de dominância e algumas interações epistáticas do tipo aditiva $x$ aditiva. Já a estimativa CEC, depende basicamente de efeitos de dominância e de outras interações epistáticas que em geral são de pequena magnitude e portanto negligenciadas (Vencovsky e Barriga, 1992).

No processo de obtenção de híbridos procura-se explorar ao máximo os efeitos de CGC (avaliados em "top-cross" e dialelos) e também de CEC. Nesse processo, o desempenho "per-se" da linhagem usado como fêmea é extremamente importante para viabilizar e baratear a comercialização do híbrido. Esse desempenho no entanto, é observado nas linhagens que possuem boa CGC, fato este devido aos efeitos aditivos da mesma. Com isso, espera-se que nos programas visando a obtenção de híbridos de linhagens pelo menos um dos parentais possua boa CGC e que em cruzamento expressem ao máximo o efeito de CEC. 
Resultados na literatura têm mostrado que em geral os efeitos da CGC são mais expressivos do que os da CEC como fontes de variação, independentes do nível de significância. Entretanto, tem sido mostrado que os efeitos CEC podem ser bastante expressivos em combinações híbridas específicas, principalmente entre linhagens pertencentes a grupos heteróticos distintos.

Hoegemeyer \& Hallauer (1976) estudaram o comportamento de linhagens endogamicas obtidas por seleção de híbridos "cripticos", pelo qual as plantas genitoras dos híbridos $\left(S_{0} \times S_{0}\right)$ são autofecundadas obtendo-se as respectivas linhas $S_{1}$. Em seguida são autofecundadas as linhas $S_{1}$ que deram origem aos híbridos $\left(S_{1} \times S_{1}\right)$, e assim por diante. No final do processo, as linhagens $S_{n}$ formam pares específicos representando os híbridos $\left(S_{n} \times S_{n}\right)$. As linhagens assim selecionadas foram cruzadas segundo o esquema fatorial (5x5); na tabela dialelica os híbridos específicos $\left(S_{4} \times S_{4}\right)$ estão representados na diagonal, e fora da diagonal está representada uma amostra aleatória de híbridos $\left(S_{4} \times S_{4}\right)$. Os autores verificaram uma maior freqüência de efeitos de CEC positivos e significativos nos híbridos da diagonal, ou seja, nos pares de linhagens selecionadas. Os resultados também demonstraram que os efeitos de CEC podem contribuir expressivamente para a produtividade dos híbridos, variando de $-1,5$ a 0,9 tha. Stangland et al. (1983) também encontraram efeitos altamente significativos para CEC, variando de $-0,8$ a 1,1 t/ha em híbridos envolvendo linhagens $S_{2}$ de quatro diferentes populações.

Martins \& Miranda Filho (1997) também utilizaram o esquema fatorial para estudar os efeitos de CGC e CEC em linhagens representativas de duas populações, Piranão-VD2 e Piranão-VF1. Constataram que nos dez híbridos mais produtivos entre os 120 avaliados, a CEC foi positiva em nove deles, atingindo valores de até 0,84 tha, equivalente a $10,4 \%$ da média do respectivo híbrido.

A exploração dos efeitos de capacidade específica de combinação em híbridos deve constituir-se em objetivo indispensável para a máxima 
manifestação dos efeitos genéticos que controlam a produtividade. A detecção e exploração de efeitos epistáticos favoráveis também contribuem para a máxima expressão dos efeitos genéticos.

\subsection{Emprego dos Quadrados Mínimos Ordinários (OLS) vs BLUP ("Best Linear Unbiased Prediction")}

Como mencionado anteriormente, as estimativas de efeitos genéticos como a CGC e CEC de combinação são extremamente importantes para 0 melhoramento genético do milho. Sendo assim, é de fundamental importância usar técnicas estatísticas, que melhor predizem ou estimem esses efeitos genéticos.

Segundo Robinson (1991), o termo estimar ou predizer um efeito, depende basicamente da sua natureza; em casos de efeitos de natureza fixa diz-se que estas são estimáveis; em caso de aleatórios, predizíveis.

A metodologia dos quadrados mínimos ordinários, tem como objetivo estimar os efeitos genéticos para os demais fatores não genéticos, através do emprego de modelos linear fixos (Martins, 1995) citado por André (1999).

Para Duarte (2000) o emprego de modelos lineares fixos $(Y=X \beta+\varepsilon$, $\operatorname{com} \varepsilon \sim \mathrm{N}\left(\phi, R=\mathrm{l} \sigma^{2}\right)$, não permite lidar com efeitos aleatórios, além do erro experimental. Comenta ainda que a matriz $\mathbf{V}$, de variâncias-covariâncias dos dados, coincide com matriz de variâncias - covariâncias dos erros ( $V=R=$ $\left(\sigma^{2}\right)$ ' o que corresponde a uma situação de completa independência entre as observações.

Se as observações são independentes, inferências a respeito de dados não observados não poderiam ser feitas; em outras palavras, trata-se de um modelo fixo por definição. No entanto, predizer um valor genético de um híbrido simples por exemplo, antes de sua realização e com precisão, é uma ferramenta que possibilita ganhos de tempo e recursos no programa.

No melhoramento genético trabalhar com modelos aleatórios é uma prática comum e que segundo Resende (1997) e André (1999) os efeitos de 
genótipos por definição devem ser considerados de natureza aleatória. Henderson (1974, 1975a e 1984) ressalta que pressupor um valor genético aleatório com sendo fixo, induz distorções nas avaliações e estas influenciam nas estimativas dos valores genéticos.

No esquema DPCl, em que apenas uma amostra de todos os cruzamentos é utilizada, predizer os demais com a máxima precisão, tornase fundamental. Nesse esquema, com um $\mathbf{s}=6$ e $\mathbf{n}=100$, sendo $\mathbf{s}$ o número de cruzamentos que cada genitor participa e n é o número de genitores, por exemplo, um total de 600 híbridos é avaliados, sendo possível predizer 9.400 híbridos.

O emprego dos modelos mistos (MMM) avaliados através da metodologia dos quadrados mínimos generalizados (GLS) foi desenvolvido inicialmente por melhoristas de animais. No entanto, o referido método tem sido bastante aplicado no melhoramento florestal, e tem sido sugerido por diversos autores como, por exemplo em André (1999); Duarte (2000); Panter e Allen (1995). Nesse método, proposto por Henderson (1949), ambos efeitos são considerados (fixos e aleatórios), em que se pode obter a melhor predição linear não tendenciosa (Best linear unbiased prediction - BLUP), dos valores genéticos de cada indivíduo, além da melhor estimativa linear não tendenciosa (Best linear unbiased estimation - BLUE), dos efeitos fixos.

Utilizando-se o BLUP, observações não são mais independentes como nos OLS mantendo fidelidade à correta definição de valores genéticos tratando-os como variáveis aleatórias. Neste caso informações a respeito do parentesco dos indivíduos, quando disponíveis, podem ser levados em consideração na análise, trazendo benefícios a estimativas e predições.

No trabalho realizado por Bernardo (1994), o autor comenta que apesar dos esforços na predição de híbridos o mesmo não tem obtido êxito. O autor realizou alguns trabalhos neste sentido verificando que a predição de cruzamentos não realizados utilizando BLUP, tem mostrado eficiência considerável. No entanto, o sucesso da metodologia depende dentre outros 
fatores do grau de parentesco dos genitores utilizados como preditores (Bernardo, 1994, 1995, 1996a e 1996b).

Nesse ponto é importante ressaltar que à informação a respeito da genealogia entre as linhagens não fazia muito sentido no processo endogamia-hibridação dos programas de melhoramento. Este tipo de anotação é trabalhoso e a justificativa para sua utilização fica restrita para obtenção de híbridos simples modificado. No entanto, na abordagem do MMM, visando a predizer cruzamentos não avaliados, informação a respeito do parentesco entre as linhagens é de fundamental importância. Este fato valoriza 0 trabalho de gerenciamento do parentesco entre as linhagens através do método genealógico.

Apesar de existir outras formas de obtenção do parentesco, como por exemplo, o uso de marcadores molecular, essas só faz-se necessárias quando não se dispõem de informações confiáveis da genealogia entre as linhagens.

O trabalho de Bernardo (1994) foi realizado neste sentido. O autor comparou os resultados de predição empregando MMM. A matriz de parentesco entre linhagens de milho de diferentes grupos heteróticos foi calculada através de marcadores moleculares do tipo RFLP e através da genealogia entre as linhagens. A partir de dados de 54 híbridos obtidos entre o cruzamento de seis linhagens lowa Stiff Stalk Synthetic (SSS) e nove não Stiff Stalk Synthetic (NSSS), foram amostrados aleatoriamente híbridos a serem utilizados como preditores de tamanhos 10, 15, 20, 25 e 30. Em seguida comparou através de correlações os valores preditos e observados através do modelo completo e do modelo reduzido (sem o efeito da CEC). O autor concluiu que não houve diferenças significativas entre os dois procedimentos de cálculo da matriz de parentesco, indicando o método genealógico pelo menor custo. As estimativas de correlação para a variável produção de grãos variaram de 0,654 a 0,800. Comenta ainda que a eficiência aumenta à medida que se utiliza um maior número de cruzamentos como preditores. No entanto, a diferença entre as correlações 
do modelo completo e do reduzido foram pequenas, ilustrando a pouca importância da CEC entre as linhagens avaliadas. Ressalta que a importância do modelo completo deve aumentar entre cruzamentos de linhagens pertencentes a diferentes grupos heteróticos.

Bernardo (1995) encontrou estimativas de correlação variando entre 0,58 a 0,74 entre os valores preditos e observados. Verificou que mesmo em situações em que o número de preditores utilizados era menor que $20 \%$ do número de híbridos a ser predito, as correlações foram positivas e elevadas.

Nesta mesma linha de estudo Bernardo (1996a e 1996b) utilizando um conjunto de 4.099 híbridos (número bem maior de híbridos que nos trabalhos anteriores) de 16 combinações em nove grupos heteróticos de milho, oriundo de até 15 locais, obteve correlações entre o valor predito e o desempenho fenotípico para peso de grãos variando de 0,49 a 0,76. Comenta que no trabalho realizado por Jenkins (1934), comparando a performance de híbridos duplos preditos e observados, o mesmo obteve correlações de 0,76. Concluiu que o BLUP pode ser considerado efetivo na predição de híbridos simples, à medida que foi considerada efetiva a predição de híbridos duplos.

Um outro ponto a ser considerado, diz respeito ao balanceamento dos dados. Quando não se dispõe de informações a respeito do parentesco dos genitores e mesmo assim deseja-se empregar a MMM em detrimento as do OLS, as duas apresentam a mesma ordem de classificação nos casos de dados balanceados. No entanto, verificase que MMM apresentam menores estimativas de erro padrão de predição (White \& Hodge, 1989). A classificação pode ser alterada com o aumento no desbalanceamento dos dados. Neste caso a MMM através das GLS melhora sua eficiência.

$\mathrm{Na}$ abordagem dos MMM, torna-se necessário o conhecimento prévio dos componentes de variância-covariâncias envolvidos. Desta forma uma determinação precisa desses, melhora tanto o processo de estimação, como de predição dos efeitos (André, 1999). 
Existem diversas metodologias disponíveis que visam estimar componentes de variâncias-covariâncias. $O$ mais usado é chamado método dos momentos ou da análise de variância. Este método consiste em se obter a esperança matemática dos quadrados médios da análise de variância. São também de análise de variância para dados não balanceados o método da máxima verossimilhança - ML ("Maximum Likelihood") e os métodos I, II e III de Henderson (Barbin, 1993). Os componentes de variância podem ser estimados diretamente como as variâncias dos efeitos aleatórios do modelo linear misto. Neste contexto citam-se os métodos dos estimadores não viciados de norma mínima - MINQUE ("Minimum Norm Quadratic Unbiased Estimators"); método da estimação não viesada de mínima variância quadrática - MIVQUE ("Minimum Variance Quadratic Unbiased Estimators"); método da máxima verossimilhança restrita - REML (" Restricted Maximum Likelihood").Todos os métodos citados estão sobre o enfoque da inferência Estatística Clássica. De acordo com Dempfle (1989) citado por Resende (1997) é sabido que os fundamentos básicos da predição de valores genéticos são essencialmente de natureza Bayesiana. $O$ método interativo da verossimilhança integrada "VEIL" ("variance Estimation from Integrated Likelihoods) é um exemplo neste sentido para estimar componentes de variância". Detalhes a respeito das deduções de cada uma delas pode ser encontrada no trabalho de Verneque (1994). Outros comentários sobre utilização e restrições de cada método são encontrados nos trabalhos de Resende (1997) e Duarte (2000).

Meyer (1989 e 1991) citado por Verneque (1994) comenta que o método REML tem sido preferido para estimação de componentes de variância em melhoramento animal ao fazer a partição das covariâncias fenotípicas em covariâncias genéticas e outros componentes. Verneque (1994) acrescenta ainda, que esta escolha deve-se não apenas as propriedades estatísticas desejáveis que o método apresenta, mas também a grande evolução dos recursos computacionais disponíveis, ao desenvolvimento de algoritmos especializados, explorando características 
específicas da estrutura dos dados ou do modelo de análise, e a utilização de uma variedade de técnicas numéricas.

O método REML foi desenvolvido por Patterson \& Thompson (1971), é um estimador de componentes de variância que apresenta como vantagem propriedades desejáveis como por exemplo gerar estimativas não negativas de componentes de variância e ser não viesado (Estimador cuja esperança matemática é igual ao valor do parâmetro populacional relativo). Com este, os componentes de variância interagem nas MMM do BLUP até a convergência para um valor adequado (Resende, 1997).

Para aplicar o REML são necessárias as MMM associadas ao modelo linear e dos algoritmos associados aos estimadores, como por exemplo EM (Expectation-Maximization) descrita por Dempster et al. (1977). No melhoramento vegetal o REML tem sido preferido tendo sido utilizado, por Bernardo (1994, 1995, 1996a e 1996b), André (1999) dentre outros.

Um programa computacional utilizando a linguagem SAS, para realização da análise dialelica dos modelos I e II de Griffing (1956) sob uma abordagem BLUP, com estimativas de componentes de variância pelo método REML, usando o algoritmo EM, pode ser encontrada no trabalho de André (1999). 


\section{MATERIAL E MÉTODOS}

\subsection{Material}

Para o desenvolvimento do trabalho foram utilizados dois compostos de milho GN-03 e GN-04, sintetizados no departamento de genética da ESALQ (Escola Superior de Agricultura "Luiz de Queiroz"). Esses compostos possuem ampla base genética, haja vista que nas suas sínteses entraram outros compostos e variedades de ampla base genética (Tabela 1).

Tabela 1. Materiais utilizados para síntese dos compostos GN-03 e GN-04 pelo Departamento de Genética da ESALQ/USP, Piracicaba-SP.

\begin{tabular}{lllll}
\hline \multicolumn{2}{c}{ COMPOSTO GN-03 } & & \multicolumn{2}{c}{ COMPOSTO GN-04 } \\
\cline { 1 - 1 } CMS 14C & Pool 25 & CMS 50 & \multicolumn{2}{c}{ Composto vega precoce } \\
CMS 28 & $\begin{array}{l}\text { Tuxpeño seleção para } \\
\text { amarelo }\end{array}$ & & BR 106 & $\begin{array}{l}\text { Composto planta baixo } \\
\text { dentado }\end{array}$ \\
CMS 39 & Composto nacional & & Cunha & Cunha \\
BR 105 & Suwan-1 DMR & & Sintético elite & CMS 59 \\
Nitrodent & CMS 58 & & Saracura & CMS 54 (BRS 154) \\
\hline
\end{tabular}

Esses compostos foram formados a partir do estudo realizado por Santos et al. (1994) em que 28 populações que representam germoplasmas adaptados a diferentes áreas do Brasil foram avaliadas per se e em cruzamentos. As cinco populações que deram origem a cada composto (Tabela 1) foram selecionadas 
para capacidade de combinação e padrão heterótico, sendo esperada uma boa expressão de heterose no cruzamento entre linhagens extraídas de cada grupo (Nass \& Miranda Filho, 1999).

\subsection{Métodos}

\subsubsection{Obtenção dos cruzamentos}

De cada composto foram obtidas $n=100$ linhagens $S_{1}$ Para facilitar as operações de polinizações no campo, as progênies $S_{1}$ foram divididas em 2 conjuntos com 50 progênies de cada composto. No primeiro conjunto foram denominadas de linhagens 1 a 50 as da população GN-03 e de 1' a 50' as da população GN-04. O segundo conjunto foi formado pelas linhagens 51 a $100 \mathrm{da}$ população GN-03 e de 51' a 100' para a população GN-04. Em cada conjunto, as linhagens $S_{1}$ foram cruzadas seguindo o esquema dialelico parcial circulante interpopulacional (DPCl), conforme o esquema apresentado na Tabela 2. 0 primeiro conjunto foi denominado de $\mathrm{DPCl}(\mathrm{A})$ e o segundo de $\mathrm{DPCl}(\mathrm{B})$. Foi adotado um $s=6$, ou seja, cada linha $S_{1}$ foi cruzada com 6 linhas da população contrastante.

Os cruzamentos referentes ao $\mathrm{DPCl}$ (A) foram realizados na safra 2000/2001, no centro de pesquisa Bayer Seeds Ltda, em Uberlândia-MG e o DPCI (B) no campo experimental do departamento de genética da ESALQ/USP. Para o processo de cruzamentos foram semeadas de acordo com a Tabela 2, linhas de 3 metros com 5 plantas por metro, sendo realizado no mínimo 8 cruzamentos, com ou sem recíprocos, totalizando uma amostra de no mínimo 8 espigas por híbrido $S_{1}$. Devido a problemas de ordem experimental dos 300 híbridos $\left(S_{1} \times S_{1}\right)$ possíveis para cada conjunto, foram obtidos 297 para DPCl (A) e 282 para o DPCI (B). 
Tabela 2. Esquema de cruzamento dialelico parcial circulante ao nível interpopulacional, $n=50$ e $s=6$.

\begin{tabular}{|c|c|c|c|c|c|c|c|c|c|}
\hline V/II & $1^{\prime}$ & 2' & $3^{\prime}$ & $4^{\prime}$ & $5^{\prime}$ & $6^{\prime}$ & $7^{\prime}$ & $8^{\prime}$ & $50^{\prime}$ \\
\hline 1 & $1 \times 1^{\prime}$ & $1 \times 2^{\prime}$ & $1 \times 3^{\prime}$ & $1 \times 4^{\prime}$ & $1 \times 5^{\prime}$ & $1 \times 6^{\prime}$ & & & \\
\hline 2 & & $2 \times 2^{\prime}$ & 2X3' & $2 \times 4^{\prime}$ & $2 \times 5^{\prime}$ & $2 \times 66^{\prime}$ & $2 \times 7^{\prime}$ & & \\
\hline 3 & & & $3 \times 3^{\prime}$ & $3 \times 4^{\prime}$ & $3 \times 5^{\prime}$ & $3 \times 6^{\prime}$ & $3 \times 7^{\prime}$ & $3 \times 8^{\prime}$ & \\
\hline 4 & & & & & & & & & \\
\hline 5 & & & & & & & & & \\
\hline 6 & & & & & & & & & \\
\hline 7 & & & & & & & & & \\
\hline 8 & & & & & & & & & \\
\hline . & & & & & & & & & \\
\hline . & & & & & & & & & \\
\hline 50 & $50 \times 1^{\prime}$ & $50 \times 2$ & $50 \times 3$ & $50 \times 4$ & $50 \times 5^{\prime}$ & & & & $50 \times 50^{\circ}$ \\
\hline
\end{tabular}

I- Grupo heterótico GN-03; II - Grupo heterótico GN-04

\subsubsection{Avaliação experimental}

Os híbridos foram avaliados em três locais, sendo dois na primeira safra ou safra normal de verão no ano agrícola 2001/02 e um na segunda safra, também chamada de safrinha em 2002. Os locais de plantio da primeira safra foram na área experimental da ESALQ/USP situada em Piracicaba estado de São Paulo a 547 metros de altitude, $22^{\circ} 43^{\prime}$ S latitude e $47^{\circ} 38^{\prime}$ W longitude e na área experimental da empresa de sementes Bayer Seeds Ltda, situada na cidade de Uberlândia estado de Minas Gerais a 800 metros de altitude, $19^{\circ} 1^{\prime} \mathrm{S}$ latitude e $48^{\circ} 22^{\prime} \mathrm{W}$ longitude. Na segunda safra os experimentos foram instalados na cidade de Jataí no estado de Goiás situada a 696 m de latitude, $17^{\circ} 52^{\prime}$ S latitude e $51^{\circ} 42^{\prime} \mathrm{W}$ longitude .

Os 579 híbridos $\left(S_{1} \times S_{1}\right)$, sendo 297 do DPCl (A) e 282 do DPCl (B) foram avaliados em Piracicaba e Uberlândia em blocos completos casualizados 
com três repetições e com duas testemunhas intercaladas a cada 10 híbridos $\left(S_{1} \times S_{1}\right)$. A unidade experimental foi constituída de uma linha de 4 metros de comprimento com espaçamento entre linhas de 0,90 metros nos experimentos avaliados na cidade de Piracicaba-SP e de 5 metros e espaçamento de 0,80 metros nos experimentos de Uberlândia-MG. Pela falta de sementes, na segunda safra (Jataí) foram avaliados 272 híbridos no DPCI (B), totalizando 569 híbridos, em blocos casualizados com duas repetições e com uma testemunha intercalada a cada 10 híbridos $\left(S_{1} \times S_{1}\right)$. As parcelas foram constituídas de uma linha de quatro metros e espaçamento de 0,90 metros.

Foram semeadas 40 sementes, sendo deixado 5 plantas/metro após 0 desbaste. Este estande corresponde a uma densidade de plantio de aproximadamente 55.000 plantas/ha para o espaçamento de 0,90 metros e 62.500 plantas/ha para o espaçamento de 0,80 metros, estando dentro de um padrão recomendado para plantios comerciais.

Nos locais Piracicaba e Uberlândia foram utilizadas como testemunhas dois híbridos simples (A2555 e A2560) da empresa Bayer Seeds Ltda. Em Jataí, Goiás foi utilizada como testemunha o híbrido simples AGN-3050 da empresa Agromen Sementes Agrícolas Ltda.

Foram avaliados os seguintes caracteres :

Peso de Espiga (PE): Foram tomados os pesos de espigas despalhadas para cada parcela, sendo posteriormente transformados para a unidade t/ha de grãos. Esse caráter foi avaliado nos três locais;

Altura da planta (AP): Medida em metros da superfície do solo até a inserção da ultima folha (folha bandeira); foi tomada de cinco plantas competitivas, escolhidas ao acaso, dentro da parcela, sendo utilizado como variável a média dessas cinco plantas. Estes caracteres foram tomados em dois locais que foram, Piracicaba e Uberlândia. 


\subsubsection{Análise preliminar}

Foram realizadas as análises de variância individuais para cada experimento.

O modelo matemático utilizado pertinente àanálise de variância foi:

$$
Y_{i k}=\mu+b_{k}+t_{i}+e_{j k}
$$

em que;

$Y_{\mathrm{ij}}$ :é a observação do tratamento i no bloco j, com i= 1,2, .., l e j=1, 2 e 3 ;

$\mu \quad$ :é a média geral, fixa, $\therefore \mathrm{E}(\mu)=0$ e $\mathrm{E}\left(\mu^{2}\right)=\mu^{2}$;

$\mathrm{b}_{\mathrm{k}} \quad$ :com $\mathrm{r}=1,2$, e 3 é o efeito de bloco $\mathrm{k}$, aleatório, $\therefore \mathrm{b} \sim \mathrm{NID}\left(0 ; \sigma_{\mathrm{r}}^{2}\right)$;

$t_{i} \quad$ :com $i=1,2, \ldots, \quad \mathrm{l}$ é $\mathrm{o}$ efeito dos tratamentos englobando: 1.híbridos $S_{1} \times S_{1}$, tida como aleatória e aqui representada por $t_{i}$, sendo $i=1,2, \ldots, \mathrm{l}$; $\mathrm{t} \sim \operatorname{NID}\left(0 ; \sigma_{\mathrm{t}}^{2}\right)$. 2. testemunhas, tidas como fixas, representadas por $t$,', $\operatorname{com} i^{\prime}=1,2,3 ; E\left(t_{i}^{\prime}\right)=0$ e $E\left(t_{i}^{2}\right)=t_{i}^{\prime 2}$;

$\mathrm{e}_{\mathrm{jk}} \quad$ :é o erro experimental, aleatório, $\therefore \mathrm{e}_{\mathrm{ik}} \sim \operatorname{NID}\left(0 ; \sigma^{2}\right)$.

O esquema da análise individual para cada experimento em cada local está representado na Tabela 3. Para o DPCI (A) os 297 híbridos foram avaliados em seis experimentos, sendo cinco com 50 e um com 47 tratamentos nos três locais. No DPCl (B) avaliados em Piracicaba e Uberlândia, os 282 híbridos foram avaliados em seis experimentos sendo cinco com 50 e um com 32 tratamentos. Em Jataí, dos 272 híbridos avaliados do DPCI (B), dez foram considerados perdidos pelo baixo estande nas duas repetições. Portanto, foram analisados 262 híbridos em seis experimentos, sendo quatro com 50, um com 43 e um com 19 tratamentos.

Os graus de liberdade de tratamentos foram desdobrados em híbridos, testemunhas e no contraste híbridos vs testemunhas. As análises individuais 
foram agrupadas e o quadrado médio do resíduo ao nível de totais foi transformado ao nível de médias para análise do DPCI.

Tabela 3. Quadro da análise de variância individual ao nível de totais.

\begin{tabular}{|c|c|c|c|}
\hline Fonte de Variação & $\overline{G L}$ & QM & $\mathrm{F}$ \\
\hline Repetição & 2 & Q1 & Q1/Q6 \\
\hline Tratamentos & 51 & Q2 & Q2/Q6 \\
\hline Híbridos $(\mathrm{H})$ & 49 & Q3 & Q3/Q6 \\
\hline Testemunhas ( $\mathrm{T}$ ) & 1 & Q4 & Q4/Q6 \\
\hline H vs T & 1 & Q5 & Q5/Q6 \\
\hline Resíduo" & 126 & Q6 & \\
\hline
\end{tabular}

\#Graus de liberdade do resíduo com 102 referente aos tratamentos, mais 24 referente às testemunhas intercalares.

A variável PE foi corrigida para o estande ideal de 20 plantas por parcela para os locais Piracicaba e Jataí e para 25 plantas para Uberlândia, através da metodologia de correção por covariâncias modificada citado por Vencovsky \& Barriga (1992). Esta correção foi realizada devido a variações no estande ocorrerem devido à manifestação de genes deletérios que poderiam causar a morte ou a não germinação das sementes. Sendo assim as diferenças de estande foi tida como aleatória e ficou creditada principalmente aos fatores ambientais. Foi realizada análise de variância para o caráter estande e não foi identificada diferença significativa, mostrando ser esta uma variação aleatória.

As correções foram efetuadas ao nível de total de parcelas, pela seguinte expressão:

$$
P C=P-b(x-20)
$$

em que; 
PC : peso de espiga corrigido;

P : peso de espiga observado;

b : Coeficiente de regressão linear do peso de espiga em relação às variações de estande;

$x$ : estande observado.

\subsubsection{Análise DPCI}

Análise dialélica foi realizada utilizando-se do software SAS, com a média das repetições, seguindo o modelo proposto por Miranda Filho \& Vencovsky (1999).

O modelo matemático é:

$$
Y_{i j}=m+g_{i}+g_{j}+s_{i j}+\bar{e}_{i j}
$$

em que;

$Y_{i j}$ :é o valor observado do híbrido entre a linhagem i do composto GN-03 e a linhagem j do composto $\mathrm{GN}-04, \mathrm{com} \mathrm{i}=1,2, \ldots$, I e $\mathrm{j}=1,2, \ldots, \mathrm{J}$;

$\mu \quad$ :é a média geral, fixa, $\therefore \mathrm{E}(\mu)=0$ e $\mathrm{E}\left(\mu^{2}\right)=\mu^{2}$;

$g_{i}$ :é o efeito da capacidade geral de combinação, aleatório, das linhagens do composto GN-03, $\therefore g_{\mathrm{i}} \sim \operatorname{NID}\left(0 ; \sigma_{\mathrm{gi}}^{2}\right)$;

$g_{j}$ :é o efeito da capacidade geral de combinação, aleatório, das linhagens do composto GN-04, $\therefore g_{\mathrm{j}} \sim \operatorname{NID}\left(0 ; \sigma_{\mathrm{gj}}^{2}\right)$;

$\mathrm{s}_{\mathrm{ij}}$ :é o efeito da capacidade especifica de combinação, aleatório para o cruzamento entre linhagens i e j, $\therefore \mathrm{s}_{\mathrm{ij}} \sim \operatorname{NID}\left(0 ; \sigma_{\mathrm{s}}^{2}\right)$;

$\overline{\mathrm{e}}_{\mathrm{ij}}$ :é o erro experimental, aleatório, $\therefore \mathrm{e}_{\mathrm{ij}} \sim \operatorname{NID}\left(0 ; \sigma^{2}\right)$.

As estimativas dos parâmetros do modelo foram obtidas segundo o processo dos quadrados mínimos ordinários (OLS). O modelo matricial utilizado

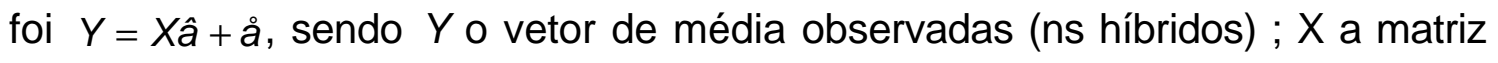


dos coeficientes com valores de 0 e 1 relacionados aos parâmetros m, $g_{i}, g_{j}$ e $s_{i j}$; $\beta d$ vetor dos parâmetros a serem estimados e $\varepsilon$ é o vetor representativo do erro associado æ̀ médias.

Inicialmente, devido à tabela dialélica estar incompleta, faltando alguns híbridos, as estimativas dos paramentos foram obtidas por operação de matrizes. A partir destas estimativas foram preditos os valores para os híbridos perdidos utilizando o modelo reduzido $\left(\hat{Y}_{i j}=\hat{\mu}+\hat{g}_{i}+\hat{g}_{j}\right)$. No DPCI $(A)$ foram preditos três híbridos e no DPCI (B) 18, os quais foram: 24x25'; 47x50' e 48x50' no DPCI (A) e 56x58'; 64x67'; 70x71'; 71x71'; 76x78'; 85x87'; 88x90'; 89x91'; 90x94'; 93×94'; 96x99'; 96x100'; 97x98'; 97x99'; 97x52'; 99x52'; 99x53' e 100x52' no DPCI (B). Achou-se conveniente descartar o DPCI (B) avaliado em Jataí pelo maior desbalanceamento do mesmo.

Após a predição de média para os caracteres dos híbridos perdidos, as análises foram refeitas e estimados os parâmetros do modelo. A análise de variância foi realizada para os experimentos agrupados em cada local, seguindo o modelo apresentado na Tabela 4.

Tabela 4. Análise de variância segundo o esquema dialélico parcial circulante interpopulacional; conjunto $50 \times 50$ e $s=6$.

\begin{tabular}{lll}
\hline \multicolumn{1}{c}{$F V$} & \multicolumn{1}{c}{$G L$} & \multicolumn{1}{l}{ Soma de quadrados } \\
\hline Híbridos & $\mathrm{ns}-1$ & $\mathrm{R}_{1}=\sum_{\mathrm{ij}} \mathrm{Y}_{\mathrm{ij}}^{2}-\frac{1}{\mathrm{~ns}} \mathrm{Y}^{2}$ \\
CGC & $2 \mathrm{n}-2$ & $\mathrm{R}_{11}-\mathrm{R}_{14}$ \\
$\mathrm{CGC}^{1}$ & $\mathrm{~N}-1$ & $\mathrm{R}_{11}-\mathrm{R}_{13}$ \\
$\mathrm{CGC}^{2}$ & $\mathrm{~N}-1$ & $\mathrm{R}_{11}-\mathrm{R}_{12}$ \\
CEC & $\mathrm{n}(\mathrm{s}-2)+1$ & $\mathrm{R}_{1}-\mathrm{R}_{11}$ \\
Resíduo\# & $(\mathrm{r}-1) \mathrm{ns}-1$ & \\
\hline
\end{tabular}

\# Ao nível de médias obtidas através da análise agrupada. 
As somas de quadrados da análise de variância, foram calculadas para o modelo completo e para os modelos reduzidos seguindo o esquema de Miranda Filho e Vencovsky (1999) apresentado na Tabela 5. As somas de quadrado foram obtidas pelo método OLS pelo modelo $S=\hat{\beta}^{\prime} x y$, em que $S$ é a soma de quadrados e os demais parâmetros já foram anteriormente descritos.

Tabela 5. Representação do modelo completo e reduzido e suas respectivas soma de quadrados.

\begin{tabular}{cll}
\hline Modelo 1 & $\mathrm{Y}_{\mathrm{ij}}=\mathrm{m}+\mathrm{g}_{\mathrm{i}}+\mathrm{g}_{\mathrm{j}}+\mathrm{s}_{\mathrm{ij}}+\mathrm{e}_{\mathrm{ij}}$ & $\mathrm{R}_{1}=\sum_{\mathrm{ij}} \mathrm{Y}_{\mathrm{ij}}^{2}-\frac{1}{\mathrm{~ns}} \mathrm{Y}^{2}$ \\
\hline Modelo 11 & $\mathrm{Y}_{\mathrm{ij}}=\mathrm{m}+\mathrm{g}_{\mathrm{i}}+\mathrm{g}_{\mathrm{j}}+\ddot{\mathrm{a}}_{1 i j}$ & $\mathrm{R}_{11}=\mathrm{R}\left(\mathrm{m}, \mathrm{g}_{\mathrm{i}}, \mathrm{g}_{\mathrm{j}}\right)$ \\
Modelo 12 & $\mathrm{Y}_{\mathrm{ij}}=\mathrm{m}+\mathrm{g}_{\mathrm{i}}+\ddot{\mathrm{a}}_{2 \mathrm{ij}}$ & $\mathrm{R}_{12}=\mathrm{R}\left(\mathrm{m}, \mathrm{g}_{\mathrm{j}}\right)$ \\
Modelo 13 & $\mathrm{Y}_{\mathrm{ij}}=\mathrm{m}+\mathrm{g}_{\mathrm{j}}+\ddot{\mathrm{a}}_{3 \mathrm{ij}}$ & $\mathrm{R}_{13}=\mathrm{R}\left(\mathrm{m}, \mathrm{g}_{\mathrm{j}}\right)$ \\
Modelo 14 & $\mathrm{Y}_{\mathrm{ij}}=\mathrm{m}+\ddot{\mathrm{a}}_{4 \mathrm{ij}}$ & $\mathrm{R}_{14}=\mathrm{R}(\mathrm{m})$ \\
\hline$R=\hat{\beta}\left(X^{\prime} Y\right)$ para cada modelo &
\end{tabular}

As estimativas dos parâmetros foram obtidas diretamente utilizando a solução de mínimos quadrados $\hat{a}=(X X){ }^{1} X ' Y$. Pelo fato da matriz $X$ ser singular o sistema de equações normais não tem solução única, sendo necessário impor as seguintes restrições:

$$
\sum_{i} \hat{g}_{i}=\sum_{j} \hat{g}_{j}=0
$$




\subsubsection{Estimativas de componentes de variância pelo método da análise de variância ou dos momentos}

O esquema DPCl apresentado por Miranda Filho \& Vencovsky (1999) permite estimar os componentes de variância $\left(\hat{\sigma}_{\mathrm{gl}}^{2} ; \hat{\sigma}_{\mathrm{gll}}^{2}\right.$ e $\left.\hat{\sigma}_{\mathrm{s}}^{2}\right)$ a partir de uma análise de variância de tabelas de dupla entrada apresentada na Tabela 6.

Tabela 6. Quadro da análise de variância de tabela de dupla entrada representando $s$ diagonais do grupo $\mathrm{I}$.

\begin{tabular}{lcll}
\hline \multicolumn{1}{c}{ Fonte } & g.l & $\mathrm{QM}$ & $\mathrm{E}(\mathrm{QM})$ \\
\hline Diagonais (D) & $\mathrm{s}-1$ & $\mathrm{Q}_{\mathrm{d}}$ & $\sigma^{2}+\sigma_{\delta}^{2}$ \\
Linhas (L) & $\mathrm{n}-1$ & $\mathrm{Q}_{\mathrm{t}}$ & $\sigma^{2}+\sigma_{v \delta l}^{2}+\sigma_{v 1}^{2}=\sigma^{2}+\left(\bar{\sigma}_{\mathrm{H}}^{2}-\mathrm{COV}_{\mathrm{gl}}\right)+\mathrm{sCOV} \mathrm{gl}$ \\
$\mathrm{LxD}$ & $(\mathrm{n}-1)(\mathrm{s}-1)$ & $\mathrm{Q}_{\mathrm{td}}$ & $\sigma^{2}+\sigma_{v \delta l}^{2}=\sigma^{2}+\left(\bar{\sigma}_{\mathrm{H}}^{2}-\mathrm{COV}_{\mathrm{gl}}\right)$ \\
Resíduo & $(\mathrm{r}-1)(\mathrm{ns}-1)$ & $\mathrm{Q}_{\mathrm{e}}$ & $\sigma^{2}$ \\
Híbridos/D & $\mathrm{s}(\mathrm{n}-1)$ & $\mathrm{Q}_{\mathrm{H} / \mathrm{D}}$ & $\sigma^{2}+\bar{\sigma}_{\mathrm{H}}^{2}$ \\
\hline
\end{tabular}

$\bar{\sigma}_{H}^{2:}$ média de $s$ variâncias de diagonais; cov: média de $s(s-1) / 2$ covariâncias entre diagonais

O modelo fatorial utilizado é:

$$
\begin{aligned}
& \mathrm{Y}_{\mathrm{ij}}=\mu+\tau_{\mathrm{i}}+\delta_{\mathrm{k}}+(\tau \delta)_{\mathrm{ik}}+\overline{\mathrm{e}}_{\mathrm{ik}} \text { para o composto GN-03 e } \\
& Y_{\mathrm{ij}}=\mu+\tau_{\mathrm{j}}+\delta_{\mathrm{k}}+(\tau \delta)_{\mathrm{jk}}+\overline{\mathrm{e}}_{\mathrm{jk}} \quad \text { para o composto GN-04. }
\end{aligned}
$$

Em que:

$$
\begin{aligned}
& Y_{\mathrm{ij}} \quad \text { : é media observado do híbrido entre a linhagem } \mathrm{i} \text { do } \\
& \text { composto GN-03 e da linhagem j do composto GN-04; } \\
& \mu \quad \text { :é a média geral, fixa, } \therefore \mathrm{E}(\mu)=0 \text { e } E\left(\mu^{2}\right)=\mu^{2} ;
\end{aligned}
$$


$\tau_{\mathrm{i}}$ e $\tau_{\mathrm{j}} \quad:$ são os efeitos constantes das linhas, aleatório, $\therefore \mathrm{E}\left(\tau_{\mathrm{i}}^{2}\right)=\sigma_{\tau \mid}^{2}=\sigma_{\mathrm{gl}}^{2} \mathrm{e} \mathrm{E}\left(\tau_{\mathrm{j}}^{2}\right)=\sigma_{\tau \mid l}^{2}=\sigma_{\mathrm{gll}}^{2}$;

$\delta_{k} \quad$ :é o efeito devido æ̀s diferenças entre as diagonais, aleatório, $\therefore \mathrm{E}\left(\delta_{\mathrm{k}}^{2}\right)=\sigma_{\delta}^{2}=\sigma_{\mathrm{s}}^{2}$;

$(\tau \delta)_{i k e}(\tau \delta)_{j k}$ : são os efeitos da interação de linhagens com diagonais dentro dos respectivos grupos, aleatório, $\therefore \mathrm{E}\left(\tau \delta_{i \mathrm{k}}^{2}\right)=\sigma_{\tau \delta}^{2}$ e $E\left(\tau \delta_{j k}^{2}\right)=\sigma_{\tau \delta}^{2} ;$

$\overline{\mathrm{e}}_{\mathrm{ik}} \mathrm{e} \overline{\mathrm{e}}_{\mathrm{jk}} \quad$ : é o erro experimental associado a média dos híbridos, aleatório, $\therefore \mathrm{E}\left(\overline{\mathrm{e}}_{\mathrm{ik}}^{2}\right)=\sigma^{2}$ e $\mathrm{E}\left(\overline{\mathrm{e}}_{\mathrm{jk}}^{2}\right)=\sigma^{2}$.

As estimativas de componentes de variância foram obtidas por:

$$
\begin{aligned}
& \overline{\operatorname{COV}}_{\mathrm{I}}=\overline{\operatorname{COV}}_{\mathrm{gl}}=\hat{\sigma}_{\mathrm{gl}}^{2}=\frac{1}{\mathrm{~s}}\left(Q_{\mathrm{t}}-\mathrm{Q}_{\mathrm{td}}\right), \text { para análise do grupo I; } \\
& \overline{\operatorname{COV}}_{\mathrm{Il}}=\overline{\mathrm{COV}}_{\mathrm{gll}}=\hat{\sigma}_{\mathrm{gll}}^{2}=\frac{1}{\mathrm{~s}}\left(\mathrm{Q}_{\mathrm{t}}-\mathrm{Q}_{\mathrm{td}}\right), \text { na análise do grupo II; } \\
& \bar{\sigma}_{\mathrm{H}}^{2}=\frac{\mathrm{s}-1}{\mathrm{~s}} \mathrm{Q}_{\mathrm{td}}+\frac{1}{\mathrm{~s}} \mathrm{Q}_{\mathrm{t}}-\mathrm{Q}_{\mathrm{e}} \mathrm{e} \\
& \sigma^{2}=Q_{\mathrm{e}}
\end{aligned}
$$

Sendo, $\sigma_{\mathrm{H}}^{2}=\sigma_{\mathrm{gl}}^{2}+\sigma_{\mathrm{gll}}^{2}+\sigma_{\mathrm{s}}^{2}$ então, $\sigma_{\mathrm{s}}^{2}=\sigma_{\mathrm{H}}^{2}-\sigma_{\mathrm{gl}}^{2}+\sigma_{\mathrm{gll}}^{2}$. As estimativas de variâncias aditiva e dominante foram obtidas das expressões:

$$
\begin{aligned}
& \sigma_{\mathrm{g} 1}^{2}=\frac{1+\mathrm{F}}{4} \sigma_{\mathrm{A} 12}^{2} ; \\
& \sigma_{\mathrm{g} \mid 1}^{2}=\frac{1+\mathrm{F}}{4} \sigma_{\mathrm{A} 21}^{2} \mathrm{e} \\
& \sigma_{\mathrm{s}}^{2}=\left(\frac{1+\mathrm{F}}{2}\right)^{2} \sigma_{\mathrm{D} 12}^{2}
\end{aligned}
$$


em que $F$ é o coeficiente de endogamia dos genitores.; $\sigma_{g l}^{2}$ e $\sigma_{g \mid l}^{2}$ são as variâncias da capacidade geral de combinação dos grupos I e II; $\sigma_{\mathrm{A} 12}^{2}$ e $\sigma_{\mathrm{A} 21}^{2}$ são os homólogos da variância aditiva ao nível interpopulacional e $\sigma_{\mathrm{D} 12}^{2}$ é a variância dominante interpopulacional. Os componentes de variância genética foram estimados por:

$$
\begin{aligned}
& \hat{\sigma}_{(\mathrm{A} 12)}^{2}=\frac{2}{1+\mathrm{F}}\left(\sigma_{\mathrm{gl}}^{2}+\sigma_{\mathrm{gll}}^{2}\right) \mathrm{e} \\
& \hat{\sigma}_{\mathrm{D} 12}^{2}=\left(\frac{2}{1+\mathrm{F}}\right)^{2} \sigma_{\mathrm{s}}^{2}
\end{aligned}
$$

O F adotado correspondeu ao nível de endogamia dos genitores que deram origem aos híbridos avaliados Souza Junior (1988). Assim, para os cálculos apresentados adoto-se o $\mathrm{F}$ dos genitores $\mathrm{S}_{0}$, ou seja, $\mathrm{F}=0$.

\subsection{Estudo da influência do tamanho do número $s$ na eficiência do dialelo circulante}

A partir do dialelo circulante original $(s=6)$, foram amostrados dialelos com $\mathrm{s}$ iguais a três, quatro e cinco. Os dialelos circulantes com s de tamanho 3 , 4 e 5 foram então avaliados e estimados parâmetros.

A influência do número s foi avaliada pelos seguintes critérios.

Análises gráficas e correlações entre as estimativas de CGC: Foram feitos gráficos entre as estimativas obtidas com os pares de siguais a 6 e 5; 6 e 4 e 6 e 3. Em cada caso foram obtidos os coeficientes de correlação com o objetivo de verificar o grau de associação entre as estimativas obtidas com diferentes valores de s.

Erro da estimativa: Foi obtido o desvio padrão das estimativas de CGC para cada tamanho de s. Os valores da diagonal da matriz $\left(x^{\prime} x\right)^{-1}$ são por definição 
as variâncias das estimativas. A raiz quadrada desses valores multiplicada pela raiz quadrada do QMerro, fornece o erro associado a cada estimativa. Esses erros foram calculados para cada tamanho de $s$ de cada variável, sendo plotadas num gráfico para fins didáticos.

Correlações entre os modelos preditos e o observados: Os coeficientes de correlações foram realizadas entre os valores preditos (modelo reduzido; $\hat{Y}_{i j}=\hat{\mu}+\hat{g}_{i}+\hat{g}_{j}$ ) e observados (modelo completo; $Y_{i j}=m+g_{i}+g_{j}+s_{i j}+\bar{e}_{i j}$ ), para cada tamanho de s.

Análises gráficas e correlações entre as estimativas de CEC: Os gráficos foram feitos com o objetivo de observar a dispersão entre as estimativas comuns de CEC obtidas em cada tamanho de s.

Foram calculados os coeficientes de correlação $(r)$ entre as estimativas de $C E C$ obtidas com $s=6$ com as obtidas com $s=5,4$ e 3 . 


\section{RESULTADOS E DISCUSSÃO}

\subsection{Análise de variância preliminar}

As médias e os coeficientes de variação para peso de espigas despalhadas (PE) e altura de planta (AP) e em cada local estão apresentados nas Tabelas 7; no local 3 apenas para PE.

Os ambientes escolhidos para a avaliação dos híbridos $\mathrm{S} 1 \times \mathrm{S} 1$ foram bastante contrastantes, tanto no que diz a época de plantio (safra normal e safrinha), ao sistema de plantio (plantio direto e convencional) e textura de solo (arenoso e argiloso). Portanto os resultados devem ser interpretados em cada local separadamente.

Em Piracicaba a ocorrência regular das chuvas, bem como a fertilidade do solo proporcionou uma maior média dos experimentos. O coeficiente de variação (CV\%) apresentou valores entre $12,40 \%$ e 16,05\% para PE e de $3,80 \%$ a $6,00 \%$ para o caráter altura de planta.

Os CV's dos experimentos de Uberlândia, apresentaram valores entre $16,81 \%$ a $24,16 \%$ para PE e de $6,89 \%$ a $10,68 \%$ para altura de planta. A maior heterogeneidade do solo e a baixa fertilidade onde foram instalados os ensaios foram as principais causas dos altos CV's e da baixa média.

Já os experimentos avaliados na época safrinha, também chamada de segunda época, avaliados em Jataí, apenas a variável PE foi avaliada. Nessa época, onde em geral as média são mais baixas; o CV variou de $14,4 \%$ a $17,31 \%$. 
Um levantamento da estimativa de coeficiente de variação com a cultura do milho foi realizada por Scapim et al (1995). Em um total de 399 informações para a característica peso de espigas, o CV médio foi de 16,22\%, com valor máximo de $44,30 \%$ e mínimo de $5,05 \%$. Para o caráter altura de planta e um total de 232 informações o CV médio foi de 6,65 com valor máximo de $13,86 \%$ e mínimo de 2,50\%.

Esses autores propuseram então, uma classificação da precisão experimental. Segundo essa classificação, para o caráter PE O CV é considerado baixo $(\leqslant 8)$; médio (8-20); alto $(20-25)$ e muito alto $(>25)$. Para o caráter altura de planta esses valores são: baixo $(\leqslant 4,5)$; médio $(4,5-9)$; alto (911) e muito alto ( $>11)$.

De acordo com as observações apresentadas, a precisão dos experimentos do presente trabalho pode ser considerada média para os locais Piracicaba e Jataí e variando de médio a alto para o local Uberlândia, tanto para o caráter PE e AP.

Nas Tabelas 8 encontram-se as médias dos híbridos $\mathrm{S} 1$ e das testemunhas de cada DPCl em cada local. As testemunhas A2555 e A2560, são híbridos simples, de origem tropical, de grãos tipo flint e de cores púrpura e alaranjada respectivamente. Em Jataí foi utilizado o híbrido simples AGN-3050, super precoce de grãos duros alaranjados pertencente àempresa Agromen.

Pela tabela nota-se que as populações GN-03 e GN-04 são bastante promissoras. A produtividade média dos híbridos $\mathrm{S}_{1} \times \mathrm{S}_{1}$ avaliados em Piracicaba representou em $94 \%$ a média das testemunhas em ambos dialelos analisados (DPCI A e DPCI B). Para PE, $24 \%$ dos híbridos foram superiores a média das testemunhas no DPCl (A) e de $35 \%$ no DPCl (B).

Em Uberlândia, representando um ambiente desfavorável, nota-se uma situação semelhante. A média dos híbridos $S_{1}$ representou $94 \%$ da média das testemunhas no DPCl (A) e de 99\% no DPCI (B) para o caráter PE. Neste local, 
29\% dos híbridos foram superiores a média das testemunhas no DPCI (A) e $49 \%$ no DPCl (B).

$\mathrm{Na}$ condição de safrinha, os valores são bastante favoráveis æ̀̀ populações GN-03 e GN-04. A média dos híbridos avaliados foi $17 \%$ superior a média da testemunha. Observou-se que $86 \%$ dos híbridos foram superiores a média da testemunha. Essa superioridade dos híbridos com relação à testemunhas se deve as populações e também ao baixo desempenho da testemunha. O híbrido usado como testemunha pode não ter bom desempenho na condição de safrinha (3,57t/ha). Nesta época, a pressão com doenças é forte, sendo este um fator limitante para recomendação de híbridos. Uma outra explicação é que provavelmente nenhuma empresa sementeira no Brasil tenha projetos específicos para o desenvolvimento de híbridos para essa época. Pelos resultados as populações GN-03 e GN-04 são qualificadas como populações base para um programa de milho safrinha.

O caráter altura de planta (AP) foi avaliado em Piracicaba e Uberlândia. As populações GN-03 e GN-04 são tipicamente de origem tropical que normalmente possuem médias altas para AP. As testemunhas também são de origem tropical e não são híbridos considerados de porte baixo, porém com AP aceitável. No entanto, nenhum dos dialelos e locais avaliados, as médias de AP dos híbridos excedeu $6 \%$ a média das testemunhas. Isto indica uma condição favorável a seleção de parentais produtivos e com AP satisfatória.

\subsection{Análise de variância do DPCI}

Inicialmente é oportuno enfatizar que a idéia central do DPCI é utiliza-lo como uma ferramenta adicional ao melhorista para descriminar as linhagens candidatas a híbridos comerciais do seu programa. Atualmente, o uso de "topcross" proposto por Davis (1927), é usual nos programas atuais. No entanto, como já salientado, o uso de linhagens elites do programa como testadoras é 
de natureza fixa, não sendo eficiente para selecionar linhagens eficientes em outras combinações.

Para viabilizar o esquema de DPCI na seleção de linhagens candidatas, existem um entrave prático. O número de linhagens a serem testadas ( $n$ ) normalmente é alto, conseqüentemente o número de cruzamentos por linhagem (s) em que ser mínimo. No presente trabalho adotou-se $s$ igual a seis como limitante, pois valores acima deste limitaria sobremaneira o esquema.

\subsubsection{Análise de variância do $\mathrm{DPCl}(\mathrm{A})$}

A partir de $\boldsymbol{s}$ igual a 6 é possível obter varias amostragens com valores de $s$ iguais a 5,4 e 3 . Pelo fato dos dados serem de natureza aleatória, estes representam a população de referencia. Portanto uma única amostra foi feita, pois as demais levariam a resultados semelhantes.

Nas tabelas 9, 11 e 13 encontram-se as análises de variância dos locais Piracicaba, Uberlândia e Jataí para diferentes tamanhos de $\boldsymbol{s}(6,5,4$ e 3).

Observa-se que em Piracicaba houve significância $(p<0,01)$ para todas as fontes de variação e para os diferentes tamanhos de $\boldsymbol{s}$ para as variáveis $\mathrm{PE}$ e AP. Já em Uberlândia, onde a precisão experimental foi menor, constatou-se diferença significativa $(p<0,01)$ para a maioria das fontes de variação, exceto para a CEC tanto para a variável PE como AP. Em Jataí os resultados foram semelhantes aos obtidos em Piracicaba para o caráter PE. Chama a atenção à influência de $\boldsymbol{s}$ nos números de graus de liberdade (GL) para a fonte de variação CEC. Para s iguais a 6, 5, 4 e 3 os GL são 198, 148, 98 e 49. Nota-se que essa redução nos GL, não foi suficiente para impedir que fosse detectada diferença significativa em Piracicaba e Jataí, mesmo quando $\boldsymbol{s}$ foi igual a 3. Entretanto não foi suficiente também para detectar diferença significativa em Uberlândia, mesmo com $s$ igual a 6 , em que o número de GL é maior e a precisão experimental foi menor. De fato a baixa precisão ocorrida nos 
experimentos de Uberlândia diminuiu o poder do teste de $F$, impedindo de detectar diferenças significativas. Comentários a este respeito foram feitos por Veiga (1998), que para caracteres de baixa herdabilidade mesmo com efeitos de dominância significativos torna-se necessários aumentar o número de repetições para detectar diferenças significativas para a CEC.

Especificamente no DPCl, quando a CGC é mais importante que a CEC, indica que a predição dos demais híbridos não observados usando o modelo reduzido pode ser realizada (Dantas, 1992; Andrade, 1995; Araújo, 2000). Analisando os quadrados médios da CGC e CEC para $\boldsymbol{s}$ igual a 6 verifica-se que a CGC superou em 79\%, 93\% e 104\% a CEC para a variável PE para os locais Piracicaba, Uberlândia e Jataí, respectivamente. Para a variável AP esses valores foram $541 \%$ e $119 \%$ para os locais Piracicaba e Uberlândia.

É mister observar que, nas esperanças do quadrado médio para a fonte de variação CGC, além da variância para CGC $\left(\sigma_{g}^{2}\right)$, inclui também a variância para CEC $\left(\sigma_{s}^{2}\right)$ (Griffing, 1956; Kempthorne e Curnow 1961). Assim sendo, os maiores valores dos quadrados médios para CGC são esperados. Não são portanto, indicativos a priori de que os efeitos aditivos são mais expressivos que os não aditivos. Tal procedimento parece ser mais lógico, quando se trabalha com efeitos fixos (Griffing, 1956), e não quando os efeitos são aleatórios, como neste estudo.

O predomínio da CGC em relação a CEC tem sido constatado na cultura do milho. Hallauer e Miranda Filho (1988), analisando diversos dados de pesquisa relataram que as evidências indicam predomínio da CGC sobre a CEC. Outros trabalhos que chegaram à mesma conclusão foram os de Dantas (1988); Dantas (1992), Andrade (1995) e Araújo (2000). Esses resultados foram obtidos com base nos quadrados médios da CGC e da CEC. Este tipo de procedimento, conforme já comentado, pode levar a conclusões incorretas. 


\subsubsection{Análise de variância do $\mathrm{DPCl}(\mathrm{B})$}

Nas Tabelas 10 e 12 encontram-se as análises de variância dos locais Piracicaba, Uberlândia para diferentes tamanhos de $\boldsymbol{s}$ (6, 5, 4 e 3). Em Jataí, decidiu-se pela exclusão deste dialelo devido ao maior grau de desbalanceamento do mesmo. Este desbalanceamento ocorreu devido à falta de sementes para avaliação de alguns híbridos e pela perda de parcelas pelo baixo estande.

Em ambos os locais houve diferenças significativas $(p<0,01)$ para as fontes de variação híbridos, CGC, CGC-1 e CGC-2 para as variáveis PE e AP. As diferenças ocorreram em relação àfonte de variação CEC. Em Piracicaba foi detectada significância $(p<0,01)$ para CEC para o caráter PE quando $s$ foi igual a 6 e para AP quando $s$ foi igual a 6,5 e 4 . Verifica-se no entanto uma perda gradativa no poder do teste de $\mathrm{F}$ para CEC, à medida que diminui o valor de $\boldsymbol{s}$ para o caráter PE. Neste caso fica evidente que a perda de GL para a fonte de variação CEC causada pela redução de $\boldsymbol{s}$ influenciou na detecção de significância. Em Uberlândia detectou-se diferença significativa $(p<0,01)$ na CEC para $\boldsymbol{s}$ igual a 6, 5 e 4, e não significância $(p<0,456)$ para $\boldsymbol{s}$ igual a 3 para o caráter PE. Para AP esses valores foram $(p<0,001)$ para $s$ igual a 6 ; $(p<0,003)$ para $s$ igual a $5 ;(p<0,014)$ para $s$ igual a 4 e $(p<0,035)$ para $s$ igual a 3. Esses valores confirmam o prejuízo causado para a detecção de significância para CEC com a redução do $\boldsymbol{s}$.

Os quadrados médios da CGC foram superiores aos da CEC. Considerando $s=6$ os quadrados médios da CGC foram $130 \%$ e $150 \%$ superiores aos quadrados médios da CEC para PE, respectivamente para os locais Piracicaba e Uberlândia. Estes valores são superiores aos obtidos no DPCI (A), provavelmente provocado por algumas combinações específicas deste dialelo. 


\subsection{Efeitos da capacidade geral e específica de combinação}

\subsection{1 $\mathrm{DPCl}(\mathrm{A})$}

Nas Tabelas 14, 15 e 18 encontram-se as médias observadas e os respectivos componentes dessas médias $\left(\mu, g_{i}, g_{j}\right.$ e $\left.s_{i j}\right)$ em unidades e em porcentagens dos 30 híbridos mais produtivos avaliados em Piracicaba, Uberlândia e Jataí, respectivamente. Nota-se que os efeitos da CEC foram positivos na maioria dos híbridos. Em mais de 50\% desses híbridos à contribuição do $s_{j}$ foi maior que pelo menos um dos g's em Piracicaba. Neste local, detectou-se diferença significativa para esta fonte de variação em todos os tamanhos de $\boldsymbol{s}$ (Tabela 9). Em Uberlândia e Jataí esses valores foram de 43,33 e $66,66 \%$ respectivamente. Estes valores reforçam a estratégia dos melhoristas em utilizar grupos heteróticos, pois apesar dos efeitos aditivos serem mais importantes que os não aditivos na cultura do milho conforme já comentado, estes são fundamentais para maximizar o potencial produtivo do híbrido. Valores significativos de CEC também foram relatados por Araújo (2000); Martins e Miranda Filho (1997) e Hoegemeyer e Hallauer (1976). No trabalho de Araújo (2000), dos dez híbridos mais produtivos, oito deles tiveram a média aumentada significativamente pelos altos valores de CEC. Neste trabalho, utilizando $s=4$, os valores da $C E C$ foram mais expressivos.

Estes resultados são diferentes dos encontrados por Andrade (1995) que trabalhando com as populações SUWAN e ESALQ-PB1 não encontrou valores tão significativos para CEC entre as melhores combinações que estudou. Provavelmente isto se deve devido ao pequeno número de cruzamentos por parental usado $(\mathrm{s}=3)$. Como será visto e explicado posteriormente, com a diminuição do valor de $\mathbf{s}$, diminui a amplitude de variação das estimativas de CEC, levando a uma falsa interpretação da sua importância. 
Entre as estimativas da CGC foi comum pelo menos um dos g's apresentar valor negativo, porém pouco expressivo na maioria dos híbridos em todos os locais. Uma alternativa apresentada por Araújo (2000) para minimizar este problema foi de selecionar mais dois grupos de linhagens de cada grupo com estimativas de g's próximas de zero, mas que fossem importantes para outras características, como por exemplo, acamamento, doenças, altura de planta e de espiga. Estas linhagens seriam então cruzadas com as linhagens que apresentaram elevadas estimativas de CGC positiva para o caráter PE, respeitando sempre os respectivos grupos heteróticos.

Observou-se em alguns híbridos, como por exemplo, 17x19'; 37x40'; em

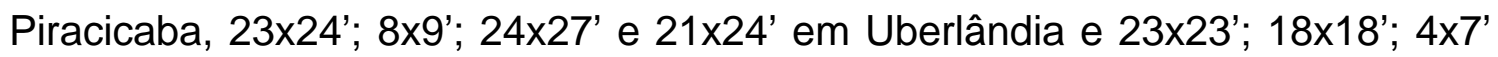
em Jataí, apresentaram estimativas de CGC próximas de zero e até mesmo negativas nos dois g's. Na prática este tipo de cruzamento não é interessante, pois o desempenho per se da linhagem está diretamente relacionada com seus efeitos aditivos. Na confecção do híbrido pelo menos uma das linhagens deve apresentar boa produtividade de grãos e a outra produção de pólen para que possa ser viabilizado comercialmente. Quanto mais produtiva for a linhagem fêmea mais viável é comercialmente o híbrido $O$ cruzamento entre duas linhagens pouco produtivas diminui muita a chance de viabilizar o híbrido, mesmo que esse seja produtivo.

Em alguns híbridos, o valor negativo de um dos g's neutralizou o efeito positivo do outro, como os híbridos 42x42'; 9x14'; $21 \times 22$ ' e $46 \times 49^{\prime}$ em

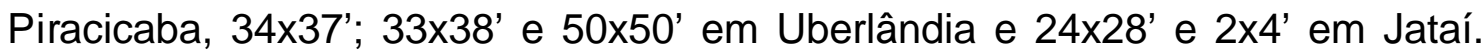
Esses casos são exemplos de híbridos perdidos quando for feita a predição dos não realizados com base nos g's $\left(\hat{Y}_{i j}=\hat{\mu}+\hat{g}_{i}+\hat{g}_{j}\right)$, mesmo adotando a alternativa proposta por Araújo (2000). Estas perdas são aceitáveis e não invalidam o processo de predição com base nos g's, pois mesmo com essas 
perdas, o melhorista terá chance de selecionar bons híbridos fazendo a predição.

Nas Tabelas 19 e 20; encontram-se as estimativas da CGC das linhagens da população GN-03 e GN-04 para o caráter PE dos três locais. As variações para a população GN-03 foram de 1,18 a $-1,50 ; 0,75$ a -0,81 e 0,78 a $-0,75$ tha para os locais Piracicaba, Uberlândia e Jataí, respectivamente. Para a população GN-04 esses valores foram 1,11 a -1,11; 1,29 a -0,72 e 0,81 a $-0,88$ para os respectivos locais. Considerando que as médias gerais foram de 8,23; 4,32 e 4,1 estes valores representam uma amplitude de variação de 33, 36 e 37\% para a população GN-03 e 27, 46 e 40\% para a população GN-04 para os respectivos locais. Estes valores são semelhantes aos encontrados por Andrade (1995) e superiores aos encontrados por Araújo (2000) que trabalharam com $s$ menores, evidenciando uma situação favorável à seleção. Porém, esta comparação deve ser vista com ressalvas, pois com a diminuição do s, a amplitude aumenta, principalmente quando o s utilizado é igual a 3. Analisando a classificação das estimativas, nota-se que mesmo em se tratando de locais contrastantes é possível identificar linhagens estáveis em Piracicaba e Uberlândia. Porém a condição de safrinha, representada pelo local Jataí, levou a classificação das estimativas em direção oposta aos locais de época de plantio verão. A primeira vista, este resultado serve de alerta, para necessidade de se selecionar linhagens específicas para esta condição.

As estimativas da variável AP para os locais Piracicaba e Uberlândia estão apresentadas nas Tabelas 23 e 24. Para GN-03 as variações foram de 15,50 a $-17,37$ e 11,33 a $-15,46$. Para GN-04 esses valores foram de 13,90 a $-23,42$ e 9,30 a-18,01 para os respectivos locais.

As médias para esta variável foram de 229,22 e 174,47. Assim, as amplitudes de variação foram de $14 \%$ e $15 \%$ para GN-03 e de $16 \%$ para GN-04 e para os respectivos locais. Esses valores são um pouco maiores do que os encontrados por Araújo (2000) e Andrade (1995). No entanto, por serem 
extremos, são pouco expressivos no sentido de aumentar ou diminuir a expressão do caráter em relação àmédia.

\subsubsection{DPCl (B)}

Nas Tabelas 15 e 17 encontram-se as médias observadas e os respectivos componentes dessas médias $\left(\hat{\mu}+\hat{g}_{i}+\hat{g}_{j}+\hat{s}_{i j}\right)$ em unidades e em porcentagem dos 30 híbridos mais produtivos, avaliados em Piracicaba e Uberlândia respectivamente. Para este conjunto de linhagens cerca de 33 e $40 \%$ das estimativas de $\mathrm{s}_{\mathrm{j}}$ foram superiores a pelo menos um dos g's para os locais Piracicaba e Uberlândia, respectivamente. Em Piracicaba, esse valor foi inferior ao obtido no $\operatorname{DPCl}(\mathrm{A})$. De fato a significância para esta fonte de variação foi detectada somente com $s=6$, evidenciando que as estimativas de $\mathrm{s}_{\mathrm{ij}}$ para este conjunto foram menos expressivas que no DPCI (A) considerando este local.

Neste grupo de linhagens foi possível identificar cruzamentos entre linhagens específicas resultando em bons híbridos. São exemplos neste sentido os cruzamentos entre as linhagens 79x79' e 83x88' em Piracicaba e 94x97'em Uberlândia. Vale a pena ressaltar que nestes casos a freqüência de alelos favoráveis nas linhagens é baixa e que o bom desempenho do cruzamento é creditado ao alto grau de complementaridade dos locos que controlam o caráter. Do ponto de vista prático do melhoramento é necessário que pelo menos uma das linhagens tenha CGC alta e que a exclusão de cruzamentos específicos em que esta não ocorre é perfeitamente recomendado.

Casos de híbridos em que o efeito negativo de um dos g's neutralizou o efeito positivo também ocorreram. Dentre os 30 mais produtivos este fato ocorreu em dois híbridos em Piracicaba (92x97' e 52x 56') e quatro em Uberlândia (75x75'; 96x51'; 66x70' e 90x94'). Como nesse trabalho o s=6 e 
$\mathrm{n}=50$, é possível predizer, utilizando o modelo reduzido, 2200 híbridos. Casos como os cruzamentos acima devem ocorrer também entre os 2200 e que não serão detectados na seleção com base nos g's.

Cabem aqui alguns comentários a respeito dessas linhagens com estimativas negativas e altas de CGC. O seu uso ficará restrito a utiliza-la como macho na confecção do híbrido, pois pelo que indica deve ser pouco produtiva. Um outro questionamento refere-se ao seu comportamento quando o grau de endogamia aumentar, podendo inviabilizar inclusive a sua manutenção. Esses cruzamentos podem também ser considerados como específicos, pois dificilmente estas linhagens chegarão ao patamar das denominadas linhagens elites do programa.

Geralmente no final de um processo de endogamia-hibridação uma alta intensidade de seleção é realizada, e poucos híbridos chegarão a ser comercializados. Além disto, deseja-se encontrar linhagens que concentrem atributos desejáveis, como por exemplo, alta CGC, resistência a doenças, acamamento etc. O objetivo do uso de "top-cross" ou do DPCl é excluir precocemente híbridos e linhagens menos promissores a avançar com aqueles com maiores chances de preencher a vaga de híbrido comercial ou de linhagem elite. Por estes motivos as perdas de combinações específicas não deve ser vista como limitante na predição dos não observados pelo modelo reduzido $\left(\hat{\mathrm{Y}}_{\mathrm{ij}}=\hat{\mu}+\hat{g}_{\mathrm{i}}+\hat{g}_{\mathrm{j}}\right)$, conforme já demonstrado nos trabalhos de Dantas (1988), Dantas (1992), Andrade (1995) e Araújo (2000).

Nas Tabelas 21 e 22 encontram-se as estimativas da CGC das populações GN-03 e GN-04 para o caráter PE nos locais Piracicaba e Uberlândia. Para a população GN-03 as variações foram 1,21 a -1,52 e 1,31 a $-1,06$ e para GN-04 de 1,51 a $-1,71$ e 0,93 a $-0,78$ para os respectivos locais. As médias dos respectivos locais foram 8,23 e 3,87 t/ha e as amplitudes de variação para a população GN-03 foram 33\% e 61\% e de 39\% e 44\% para GN- 
04. Andrade (1995) trabalhando com as populações ESALQ-PB1 e Suwan, obteve valores $37 \%$ e $45 \%$ respectivamente, semelhante aos aqui obtidos, porém com $\mathrm{s}=3$.

Para o caráter AP (Tabelas 29 e 30) as amplitudes dos g's para a população GN-03 para os locais Piracicaba e Uberlândia foram de 16\% e 17\% e de $19 \%$ e $20 \%$ para GN-04.

Ao analisar as linhagens com melhores g's para PE verifica-se que estas não foram æ̀ mesmas com características de redução na AP. Este resultado associado à baixa amplitude de variação encontrada tanto neste trabalho como nos de Araújo (2000) e Andrade (1995) depreende-se que a confecção de híbridos com baixa AP deve-se partir de populações com baixa média para este caráter.

\subsection{Influência do número s de cruzamentos nas estimativas de CGC}

Neste trabalho o valor máximo de $s$ adotado foi 6 . Esse valor não significa ser o melhor, mas sim um valor de referencia, pois, valores maiores tornam-se inviável o procedimento. Assim, esta foi utilizada para comparar com as demais amostragens de $\mathrm{s}(5,4$ e 3$)$.

\subsubsection{DPCl (A)}

As Figuras 1, 2 e 3 mostram as dispersões das estimativas de CGC para PE da população GN-03, de s iguais a 6 e 5; 6 e 4 e 6 e 3, assim como suas correlações para os locais Piracicaba, Uberlândia e Jataí, respectivamente.

Percebe-se que ocorre uma diminuição gradativa nas correlações das estimativas. A melhor situação foi encontrada entre as estimativas obtidas com $s$ iguais a 6 e 5 . Os coeficientes de correlação encontrados foram de 0,935, 
0,919 e 0,947 para os respectivos locais. Estes valores são considerados elevados e satisfatórios.

Entre as estimativas obtidas com $s$ iguais a 6 e 4 os valores de $r$ foram 0,697, 0,602 e 0,393. Esta diminuição de correlação é nítida, quando se observa a dispersão gráfica das estimativas. Entre $s=6$ e 3 , a correlação apresenta valores de $r$ iguais a 0,526, 0,207 e 0,031. Nesta situação a dispersão foi ainda maior, descaracterizando totalmente a associação entre as estimativas.

A mesma tendência de dispersão das estimativas de CGC ocorreram para o composto GN-04 (Figuras 4, 5 e 6), apresentando menores correlações com a diminuição do tamanho de $\mathrm{s}$, como era esperado. Novamente $0 \mathrm{~s}=5$ apresentou estimativas de correlações de CGC e erro considerados satisfatórios entre os s estudados.

$\mathrm{Na}$ Figura 7, encontram-se os gráficos com os erros associados æ̀̀ estimativas para os diferentes valores de $\mathrm{s}$. Em termos de porcentagem os erros referentes aos s iguais a 5, 4 e 3 foram $24 \%, 69 \%$ e $157 \%$ superiores em relação ao $s=6$, respectivamente. Nota-se que a curva é descendente, contudo o menor valor de $s$ que apresenta boa correlação com $s=6$ e menor erro das estimativas ocorreu para s igual a 5.

A variável AP avaliada em Piracicaba e Uberlândia, apresentou mesma tendência no que diz respeito à correlação entre estimativas de $g_{i}$ e $g_{j}$ obtidas com $s=6$ e aquelas referentes a outros valores de $s(s=3,4,5)$ (Figuras 8, 9, 10 e 11). A diferença foi de que apesar da diminuição da correlação ser descendente, esta foi menos pronunciada. Os valores de $r$ para a população GN-03 foram, 0840, 0,704 e 0,653 em Piracicaba e de 0,811, 0,568 e 0,573 em Uberlândia. Para a população GN-04 esses valores foram 0840, 0,718 e 0,670 e de 0,794, 0,621 e 0,596 para os respectivos locais. Os erros associados às estimativas de CGC para AP seguiram o modelo descendente (Figura 12), semelhantemente ao que ocorreu para o caráter PE. 


\subsubsection{DPCl (B)}

Os gráficos de dispersão das estimativas de CGC para diferentes tamanhos de $\mathrm{s}$, assim como os coeficientes de correlações ( $r$ ) do composto GN03 para o caráter PE nos locais Piracicaba e Uberlândia estão apresentadas nas Figuras 13 e 14. Os valores de $r$ entre $s$ iguais a 6 e 5 foi 0,935 em Piracicaba e 0,906 em Uberlândia. Entre s iguais a 6 e 4 esses valores foram 0,620 e 0,550 e entre 6 e 3, 0,270 e 0,241. Para a população GN-04 os valores de $r$ foram 0,876 e 0,882 para 6 e 5; 0,682 e 0,582 para 6 e 4 e 0,424 e 0,202 para 6 e 3 (Figuras 15 e 16). Semelhante ao DPCI (A), aqui as correlações também diminuíram com os valores de s, como era esperado.

Observando os valores de coeficiente correlação, juntamente com as respectivas dispersões das estimativas plotadas nos gráficos, verifica-se que de maneira geral o valor de $s=5$ foi o que melhor se correlacionou com $s=6$. Tanto no DPCI (A) como no DPCl (B) essas correlações foram maiores que 0,9. As únicas exceções ocorreram entre as estimativas obtidas nas populações GN-04 no $\mathrm{DPCl}(\mathrm{B})$, cujos valores foram 0,876 e 0,882 .

As Figuras 17 a 20 mostram os gráficos das estimativas para o caráter AP para os s estudados e suas correlações nos locais Piracicaba e Uberlândia respectivamente. Considerando os respectivos locais, os valores de r entre os 6 e 5 foram 0,949 e 0,937 para a população GN-03 e 0,945 e 0,936 para GN-04. Entre $\mathbf{s}$ iguais a 6 e 4 estes valores foram 0,897 e 0,736 para GN-03 e 0,932 e 0,787 para GN-04. Entre 6 e 3 tem-se 0,553 e 0,584 para GN-03 e 0,675 e 0,627 para GN-04.

Os gráficos com os erros associados æ̀ estimativas de $g$ e $g_{j}$ estão apresentados na Figuras 21 e 22 para PE e AP respectivamente. Quando comparado ao $\mathrm{s}=6$ os erros foram $27 \%, 71 \%$ e $177 \%$ superiores para $\mathrm{s}$ iguais a 5,4 e 3. 
Nota-se novamente que $s=5$ foi o menor valor capaz de descriminar 0 mérito de uma linhagem candidata em relação a sua CGC com boa precisão e coerência em todos os locais, dialelos e populações. Com $s=4$, ainda não se visualiza altas correlações em todos os casos. Apesar de que, com exceção do resultado obtido em Jataí para a população GN-03 e GN-04, em que a correlações encontradas foram de 0,393 e 0,480 respectivamente, os demais apresentaram valores entre 0,550 a 0,721 para o caráter PE. Para o caráter AP esses valores variaram de 0,568 a 0,932. Contudo, deprende-se que os resultados aqui encontrados não foram suficientes para garantir o uso de $s=4$, tanto pela falta de correlação em alguns casos, como pelo erro associado æ̀s estimativas.

O uso de $s=3$ ficou totalmente descartado quando para descriminar as linhagens quanto ao seu mérito em outros cruzamentos. Isso equivale a dizer que utilizando $s=3$ não foi possível predizer os demais não observados com boa precisão.

Esses resultados são para os compostos utilizados, sendo possível que para outras populações os valores de $s=4$ ou $s=3$ possam ser conveniente.

\subsection{Influência do número s de cruzamentos nas estimativas de CEC}

Como já ressaltado neste trabalho, um dos objetivos do DPCl é de predizer os híbridos não observados pelo modelo reduzido. Contudo, isso somente é possível se a CEC não for mais importante que a CGC. Apesar da CGC predominar em relação a CEC na cultura do milho como neste trabalho e em outros, como os de Andrade (1995) e Araújo (2000), ficou claro que tanto pela significância observada pelo teste de $F$, como pela sua participação no melhores híbridos, que a CEC é importante para maximizar o potencial de um híbrido. 
A maneira utilizada nos trabalhos que Andrade (1995) e Araújo (2000) e outros para testar a hipótese de que a predição dos não observados poderia ter ou não sucesso, foi a de correlacionar os híbridos observados $\left(Y_{i j}=\mu+g_{i}+g_{j}+s_{i j}+\bar{e}_{i j}\right)$ com aqueles preditos somente com base nos g's, ou seja, pelo modelo reduzido $\left(\hat{Y}_{i j}=\hat{\mu}+\hat{g}_{i}+\hat{g}_{j}\right)$. É oportuno salientar que os valores preditos e observados são por natureza correlacionados e que o coeficiente de correlação ( $r$ ) obtido é superestimado.

$\mathrm{Na}$ Tabela 27 encontra-se esses valores para PE nos três locais e para os tamanhos de s iguais a 3, 4, 5 e 6 . Percebe-se que de maneira contrária do que era esperado, as maiores correlações foram observadas com tamanho de $\mathrm{s}=3$. Nota-se também que apesar de não ser de grande magnitude esta redução ocorreu àmedida que o número s diminuiu.

$\mathrm{Na}$ Tabela 28, estão estes valores de correlações para a variável AP. Novamente as mesmas observações feitas para PE são validas para este caráter.

Utilizando um $s=3$, os valores encontrados por Andrade (1995) variaram de 0,82 a 0,96 para PE. Utilizando um valor de $s=4$, Araújo (2000) encontrou valor de $r$ de 0,86 para este mesmo caráter. Pela pouca expressão dos efeitos da CGC na altura de planta, a predição e conseqüentemente as correlações no foram realizadas.

As amplitudes de variação entre as estimativas de CGC para os DPCI (A) e (B),nos três locais para os diferentes tamanhos de s, para o caráter PE e para a população GN-03 está apresentada na Tabela 29. Esses valores evidenciam que a amplitude das estimativas da CGC assim como seus valores aumentam com a diminuição do tamanho de s. Esse aumento é também visualizado na Tabela 30, para o caráter PE e população GN-04 e nas Tabelas 32 e 33 para as populações GN-03 e GN-04 para o caráter AP respectivamente. 
Isso ocorre devido que com a redução de s as estimativas de CGC são mais erráticas e estão sujeita a uma maior variação e conseqüentemente ocorre uma maior oscilação das estimativas, tanto para mais como para menos.

Pelo fato das estimativas de CEC serem um desvio daquilo que é esperado em relação aos g's, ocorre o inverso com as estimativas de CEC, como pode ser visualizado nas Tabelas 31 para PE e na Tabela 34 para AP. As amplitudes diminuem com a redução de $s$, bem como a sua importância no desempenho do híbrido. Conseqüentemente levará a uma falsa interpretação a respeito de sua importância na predição, bem como no comportamento dos melhores híbridos.

Este fato explica o porque das correlações entre o predito e o observado serem superiores com a diminuição no tamanho de s. Com menores valores de CEC os valores preditos ficam mais bem correlacionados com os observados, apesar de estar ocorrendo uma flutuação maior das estimativas de CEC. Considerando ainda o fato de que as estimativas de CGC serem menos precisas com a diminuição de $\mathrm{s}$, as predições dos híbridos não observados serão ainda mais afetadas, diminuindo sua eficiência.

Com o objetivo de comparar as estimativas comuns de CEC obtidas com $s$ iguais a 6 e 5; 6 e 4; e 6 e 3 foram feitas correlações entre essas estimativas. As Figuras 23, 24 e 25 encontram-se os dados do DPCI (A) para o caráter PE e suas correlações nos locais Piracicaba, Uberlândia e Jataí. As correlações entre $s$ iguais a $6 / 5$ foram $0,96,0,94$ e 0,96 . Para $6 / 4$ os valores foram $0,86,0,86$ e 0,88 e para $6 / 3$ 0,70, 0,73 e 0,72 para os respectivos locais.

Para o caráter AP os valores de $r$ foram 0,94 e 0,92 para $s$ iguais a 6/5; 0,89 e 0,80 para $6 / 4$ e 0,75 e 0,69 para $6 / 3$ para os respectivos locais Piracicaba e Uberlândia (Figuras 26 e 27).

Situação semelhante ocorreu no DPCI (B) avaliados em Piracicaba e Uberlândia. Para o caráter PE os valores de $r$ foram 0,90 e 0,94 para $s$ iguais a $6 / 5,0,86$ e 0,85 para $6 / 4$ e 0,59 e 0,68 para $6 / 3$, para os respectivos locais 
(Figuras 28 e 29). Para o caráter AP os valores foram 0,93 e 0,94 para s iguais a 6/5, 0,84 e 0,82 para 6/4 e 0,62 e 0,63 para 6/3 (Figuras 30 e 31).

Em todos os locais e dialelos analisados, como para os caracteres avaliados, as correlações decresceram com a diminuição de s. Esses resultados evidenciam que com a diminuição de $s$ as estimativas de CEC são menos precisas e sujeitas a oscilações.

É importante frisar que as elevadas correlações observadas entre os valores preditos e observados tanto neste trabalho, como nos de Andrade (1995) e Araújo (2000), não são indicativos a priori de que a CEC não é importante. Portanto, ignora-la para predizer os híbridos não realizados poderá levar a uma seleção equivocada, principalmente quando $s$ utilizado for menor ou igual a 3.

De maneira geral o melhor procedimento seria predizer os melhores híbridos primeiramente com base nas melhores CGC's. Para isso deve-se cruzar a linhagem candidata com pelo menos cinco outras, para que essa predição seja bem feita. Os melhores não serão necessariamente os mais produtivos. Portanto devem ser refeitos e testados na tentativa de encontrar aqueles que expressem o máximo a CEC.

\subsection{Estimativas de parâmetros genéticos}

\subsection{Com base nas análises de linhas e diagonais}

A metodologia do DPCI proposta por Miranda Filho e Vencovsky (1999), permite estimar componentes de variância pelo método da análise de variância ou também chamado de método dos momentos.

Apesar do método não ter sido proposto especificamente para esse fim, a estimação de tais parâmetros são úteis, pois permitem inferir a respeito do 
controle genético do caráter, além do monitoramento da variabilidade das populações utilizadas.

Não é objetivo deste trabalho estudar a influência de $s$ nas magnitudes das estimativas de componentes de variância. Porém, com a diminuição de s, espera-se que as estimativas sejam menos precisas.

As estimativas de componentes de variância foram estimadas apenas para $s=6$, por ser esta o melhor tamanho de $s$ analisado.

Pelos quadrados médios apresentados nas Tabelas 35 e 36, foram obtidas as variâncias aditivas $\left(\hat{\sigma}_{\mathrm{A}(12)}^{2}\right)$ e de dominância $\hat{\sigma}_{\mathrm{D}(12)}^{2}$ interpopulacionais para o caráter PE.

Estas estimativas estão apresentadas na Tabela 37. Os valores encontrados para $\hat{\sigma}_{\mathrm{A}(12)}^{2}$ foram 120,56, 61,92 e $38,44(\mathrm{~g} / \mathrm{plt})^{2}$ para os locais Piracicaba, Uberlândia e Jataí respectivamente. A diferença na magnitude destas estimativas está relacionada com a média de cada ambiente. No entanto outros fatores bióticos e abióticos podem também influenciar nos valores das estimativas. A densidade de plantio utilizada foi de 55000 plantas por hectare nos locais Piracicaba e Jataí e de 62500 plantas por hectare em Uberlândia.

As estimativas de variância genética aditiva $\left(\hat{\sigma}_{A}\right)$ ao nível intrapopulacional do primeiro ciclo de seleção dos compostos GN-03 e GN-04 foram relatados por Nass et al. (1999). Os compostos apresentaram ampla variabilidade genética, sendo considerados promissoras para programas de melhoramento de milho. No segundo ciclo de seleção, as estimativas de $\hat{\sigma}_{\mathrm{A}}$ foram inferiores a do primeiro ciclo, com valores de $134,60(\mathrm{~g} / \mathrm{pl})^{2}$ para GN-03 e 99,20 (g/pl) ${ }^{2}$ para GN-04. Segundo os autores esta redução era esperada devido à intensidade de seleção (10\%) praticada nos compostos.

Ao nível interpopulacional, diversos autores relataram estimativas de variância aditiva $\hat{\sigma}_{\mathrm{A}(12)}^{2}$, expressas em $(\mathrm{g} / \mathrm{planta})^{2}$. Andrade (1995) encontrou 
valores de $\hat{\sigma}_{A(12)}^{2}$ para o caráter peso de grãos de 40,85 para o sistema de autofecundação e de 72,25 para os cruzamentos fraternais. Segundo o autor, Souza Junior (1983) trabalhando com progênies de meios irmãos das mesmas populações encontrou valor de 260,50, sendo este 6,38 e 3,73 vezes maior que os obtidos em seu trabalho. Obilana et al (1979) para as populações de origem temperada BS 10 e BS 11 obtiveram um valor de 178,70 com o esquema de Comstock e Robinson (1948). Miranda Filho e Paterniani ((1983) obtiveram o valor de 158,02 com progênies de meios irmãos das populações Piramex e Cateto. Os resultados encontrados por Araújo (2000) em três locais foram 111,55; 165,03 e 63,09 para as populações IAPAR26 e BR 106 utilizando o mesmo esquema do presente trabalho.

Para a variância de dominância interpopulacional $\left(\hat{\sigma}_{\mathrm{D}_{(12)}}^{2}\right)$, segundo Araújo (2000), existem poucos dados na literatura. $A \hat{\sigma}_{D_{(12)}}^{2}$ foi superior a $\hat{\sigma}_{A_{(12)}}^{2}$ em ambos os dialelos e em todos os locais. A relação entre a $\sigma_{D}^{2} / \sigma_{A}^{2}$ permite inferir em relação ao tipo de controle do caráter. Neste trabalho as relações encontradas foram 6,05, 4,30 e 7,15 para os locais Piracicaba, Uberlândia e Jataí, respectivamente evidenciando a importância dos efeitos não aditivos entre as populações. De fato segundo Nass et al. (1999) as populações GN-03 e GN-04 foram sintetizadas visando maximizar a heterose. No trabalho de Andrade (1995) foram obtidos valores de 96 para o sistema de autofecundação e 69,30 para cruzamentos fraternais. O autor concluiu que o $s=3$ não ser 0 suficiente para uma boa precisão. As relações encontradas por Araújo (2000), usando as populações BR 106 e IAPAR foram 0,24, 0,77 e 0,51. Esses resultados mostram que as populações utilizadas não são de grupos heteróticos contrastantes e que os efeitos não aditivos são pouco expressivos.

Esses resultados ressaltam a importância de se trabalhar com grupos heteróticos no sistema de endogamia - hibridação, pois essa variabilidade pode 
ser explorada nos híbridos obtidos através de linhagem. Ressalta também a importância da CEC, pois essa variabilidade será explorada nas combinações em que a heterozigose for elevada

\subsection{Considerações finais}

A utilização do esquema de cruzamentos dialelico circulante interpopulacional (DPCl) requer a definição do número (s) de vezes que uma linhagem é cruzada com linhagens da população contrastante. Neste contexto, o presente trabalho propôs estudar a influência do número s nas estimativas e significância da capacidade geral de combinação (CGC) e capacidade especifica de combinação (CEC).

O esquema DPCI, conforme utilizado neste trabalho, mostrou-se bastante promissor para a avaliação de linhagens e predição de combinações híbridas. De fato, utilizando 100 linhas $S_{1}$ de cada uma das populações (GN-03 e GN-04) e $\mathrm{s}=6$, foram obtidas e avaliadas 579 híbridos $\mathrm{S}_{1} \times \mathrm{S}_{1}$. Deste modo, com as estimativas dos efeitos (média geral e CGC) é possível predizer o comportamento de 9421 híbridos não avaliados. Na prática, a seleção dos melhores híbridos se faz com base nos melhores efeitos de CGC ( $g_{i}$ e $\left.g_{j}\right)$. De qualquer modo, a pressão de seleção é muito forte; por exemplo, a seleção dos 50 melhores híbridos representa uma intensidade de seleção 50/1000 =0,005 ou $0,5 \%$.

As populações GN-03 e GN-04 sintetizadas no departamento de Genética da ESALQ/USP, mostraram alto potencial de produtividade e promissoras para a extração de linhagens.

Embora as precisões experimentais dos experimentos avaliados em Uberlândia terem sido inferiores aos de Piracicaba e Jataí, levaram aos mesmos resultados. 
Os efeitos aditivos predominaram em relação aos não aditivos. No entanto, verificou-se que a CEC foi fundamental para a maximização da produção.

As magnitudes dos efeitos da CGC e CEC para o caráter altura de planta, levaram a concluir que a seleção de híbridos com baixa altura de planta, deve-se partir de populações com baixa média para este caráter.

$\mathrm{Na}$ época de plantio safrinha a média dos 297 híbridos avaliados, foi maior que a média da testemunha. Este fato, aliado ao comportamento diferencial das estimativas de CGC em relação à época de plantio normal, indica que a seleção de linhagens e de híbridos específicos para esta época pode levar a resultados significativos.

O menor valor de s que garantiu boa precisão das estimativas de CGC e CEC nos dois dialelos nos três locais foi igual a 5 . $O$ uso de $s=4$ foi satisfatório em alguns casos, mas não em todos os locais e dialelos analisados. O uso de $\mathrm{s}=3$ ficou totalmente descartado pois não se mostrou adequado para avaliar a CGC das linhagens. Entretanto, o uso de $s=3$ pode ser viável em outros pares de populações com estrutura genética diferente das utilizadas no presente trabalho.

As estimativas de CEC estão diretamente relacionadas com as da CGC. Observou-se que com a diminuição de $s$, ocorre uma maior oscilação das estimativas de CGC e conseqüentemente a uma diminuição da importância da CEC. Este fato levou a uma melhor correlação entre os híbridos preditos e observados com a diminuição de $\mathbf{s}$ induzindo a uma falsa interpretação de que a CEC não é importante. Pela importância da CEC, principalmente quando se trabalha com grupos heteróticos, esses resultados reforçam a conclusão de que o valor de $s$ deve ser maior ou igual a 5 para que se possa obter estimativas de CEC significativas e mais realistas. 
As estimativas da variância aditiva obtidas ao nível interpopulacional mostrou magnitude semelhante à obtidas ao nível intrapopulacional, indicando a validade das estimativas obtidas pelo método.

A relação $\sigma_{D}^{2} / \sigma_{A}^{2}$ indicou a presença de sobredominância no controle do caráter peso de espigas. Apesar do DPCI não ser o mais indicado para este estudo, esses resultados servem de alerta para a importância dos efeitos não aditivos, bem como ao uso de grupos heteróticos na confecção de híbridos altamente produtivos. 


\section{CONCLUSÕES}

De acordo com o que foi apresentado o presente trabalho permite fazer as seguintes conclusões:

1 Os compostos GN-03 e GN-04 confirmaram pertencer a diferentes grupos heteróticos. As altas médias e a amplitude de variação dos híbridos avaliados evidenciam que esses compostos são promissores tanto para programas de híbridos de linhagens, como para fins de seleção recorrente.

2 Com redução no número de $\mathrm{s}$, e conseqüentemente a perda de graus de liberdade, diminuiu o poder do teste de $F$, podendo não detectar diferenças significativas para a fonte de variação CEC.

3 A redução de s levou a uma maior variância das estimativas de CGC e conseqüentemente uma maior amplitude dos efeitos. Este fato acarretou uma perda na precisão das estimativas de CEC, bem como na redução da amplitude, ocasionando uma maior correlação entre os valores preditos e observados com a redução de s.

4 Para os compostos utilizados com o mínimo de cinco cruzamentos por parental $(s=5)$, pode-se obter estimativas significativas e adequadas de CGC e CEC. 
5 As estimativas da variância aditiva obtidas ao nível interpopulacional mostrou magnitude semelhante às obtidas ao nível intrapopulacional.

6 A variância de dominância foi superior a variância aditiva ao nível interpopulacional. Os resultados ressaltaram a importância de se trabalhar com grupos heteróticos em programas de melhoramento de milho. 
ANEXOS 
Tabela 7. Média e coeficiente de variação (CV\%) para os caracteres peso de espigas (PE) e altura de planta (AP). Piracicaba, 2001/02; Uberlândia, 2001/02 e Jataí, 2002.

\begin{tabular}{|c|c|c|c|c|c|}
\hline \multirow{2}{*}{ Experimentos } & \multirow{2}{*}{$\mathrm{NH}^{1 /}$} & \multicolumn{2}{|c|}{$\mathrm{PE}$ (t/ha) } & \multicolumn{2}{|c|}{$\mathrm{AP}(\mathrm{cm})$} \\
\hline & & MÉDIA & CV\% & MÉDIA & CV\% \\
\hline \multicolumn{6}{|c|}{ PIRACICABA } \\
\hline 1 & 50 & 8,23 & 15,38 & 226,56 & 6,00 \\
\hline 2 & 50 & 7,90 & 12,71 & 217,90 & 4,16 \\
\hline 3 & 50 & 8,68 & 13,91 & 231,03 & 4,91 \\
\hline 4 & 50 & 8,20 & 12,38 & 233,90 & 5,01 \\
\hline 5 & 50 & 9,07 & 10,97 & 226,27 & 4,18 \\
\hline 6 & 47 & 8,43 & 13,86 & 226,47 & 4,36 \\
\hline 7 & 50 & 9,05 & 12,40 & 232,07 & 3,80 \\
\hline 8 & 50 & 8,60 & 13,12 & 220,57 & 4,91 \\
\hline 9 & 50 & 7,85 & 16,05 & 215,50 & 5,56 \\
\hline 10 & 50 & 7,86 & 15,61 & 216,42 & 5,32 \\
\hline 11 & 50 & 7,85 & 13,70 & 217,02 & 5,52 \\
\hline 12 & 32 & 7,33 & 12,60 & 219,39 & 4,55 \\
\hline \multicolumn{6}{|c|}{ UBERLÂNDIA } \\
\hline 1 & 50 & 4,15 & 23,53 & 169,72 & 8,17 \\
\hline 2 & 50 & 3,90 & 24,16 & 162,32 & 10,68 \\
\hline 3 & 50 & 4,09 & 23,24 & 165,54 & 9,32 \\
\hline 4 & 50 & 4,88 & 17,96 & 175,93 & 7,56 \\
\hline 5 & 50 & 4,70 & 16,81 & 179,65 & 7,72 \\
\hline 6 & 47 & 4,53 & 16,93 & 183,86 & 8,69 \\
\hline 7 & 50 & 3,82 & 21,08 & 165,10 & 7,49 \\
\hline 8 & 50 & 4,61 & 20,83 & 177,24 & 9,03 \\
\hline 9 & 50 & 3,68 & 19,32 & 164,12 & 6,89 \\
\hline 10 & 50 & 3,34 & 23,89 & 147,22 & 8,80 \\
\hline 11 & 50 & 3,91 & 22,45 & 162,37 & 8,18 \\
\hline 12 & 32 & 3,92 & 22,72 & 176,64 & 8,61 \\
\hline \multicolumn{6}{|c|}{ JATAÍ } \\
\hline 1 & 50 & 4,00 & 16,00 & - & - \\
\hline 2 & 50 & 4,24 & 17,31 & - & - \\
\hline 3 & 50 & 4,30 & 14,94 & - & - \\
\hline 4 & 50 & 3,94 & 14,79 & - & - \\
\hline 5 & 50 & 4,18 & 14,40 & - & - \\
\hline 6 & 47 & 3,92 & 14,95 & - & - \\
\hline
\end{tabular}

11-número de híbridos $\mathrm{S}_{1} \times \mathrm{S}_{1}$ avaliados. 
Tabela 8. Média dos híbridos $S_{1} \times S_{1}$ e das testemunhas para os caracteres peso de espigas (PE) em t/ha e altura de planta (AP) em $\mathrm{cm}$ em três locais. Piracicaba, SP 2001/02; Uberlândia, MG 2001/02 e Jataí, GO 2002.

\begin{tabular}{|c|c|c|c|c|c|c|}
\hline Variáveis & $\mathrm{DPCl}$ & $\begin{array}{c}\text { Média } \\
\text { S1 x S1 }\end{array}$ & $\mathrm{T} 1^{1 /}$ & $\mathrm{T} 2^{2} \underline{1}$ & $\begin{array}{c}\text { Médias } \\
\text { testemunhas }\end{array}$ & Relação 3 - \\
\hline \multicolumn{7}{|c|}{ PIRACICABA } \\
\hline PE & $\begin{array}{l}A \\
B \\
A \\
B \\
\end{array}$ & $\begin{array}{c}8,40 \\
8,05 \\
229,22 \\
221,80 \\
\end{array}$ & $\begin{array}{r}8,57 \\
8,45 \\
211,42 \\
207,03 \\
\end{array}$ & $\begin{array}{c}9,22 \\
8,64 \\
222,13 \\
217,93 \\
\end{array}$ & $\begin{array}{c}8,90 \\
8,55 \\
216,78 \\
212,48 \\
\end{array}$ & $\begin{array}{l}0,94 \\
0,94 \\
1,06 \\
1,04 \\
\end{array}$ \\
\hline \multicolumn{7}{|c|}{ UBERLÂNDIA } \\
\hline AP & $\begin{array}{l}\mathrm{A} \\
\mathrm{B} \\
\mathrm{A} \\
\mathrm{B} \\
\end{array}$ & $\begin{array}{c}4,32 \\
3,87 \\
174,47 \\
165,43 \\
\end{array}$ & $\begin{array}{c}4,48 \\
3,63 \\
160,71 \\
156,06 \\
\end{array}$ & $\begin{array}{c}4,73 \\
4,20 \\
171,41 \\
165,93 \\
\end{array}$ & $\begin{array}{c}4,61 \\
3,92 \\
166,06 \\
161,00 \\
\end{array}$ & $\begin{array}{l}0,94 \\
0,99 \\
1.05 \\
1,03 \\
\end{array}$ \\
\hline \multicolumn{7}{|c|}{ JATAÍ } \\
\hline $\begin{array}{l}\mathrm{PE} \\
\text { testemun } \\
\text { relacão }\end{array}$ & $\begin{array}{l}\mathrm{A} \\
\mathrm{A} 255 \\
\end{array}$ & $\frac{4,10}{\text { em Pir }}$ & 3,50 & - & $\begin{array}{r}3,50 \\
2,1 \text { tectc }\end{array}$ & $\frac{1,17}{12560 ;}$ \\
\hline
\end{tabular}


Tabela 9. Quadro da análise de variância ao nível de médias do DPCI (A) para diferentes tamanhos de $\mathbf{s}$ para as variáveis peso de espiga (PE) e altura de planta (AP). Piracicaba, 2001/02.

\begin{tabular}{|c|c|c|c|c|c|}
\hline \multirow{2}{*}{ FV } & \multirow{2}{*}{$\mathrm{GL}$} & \multicolumn{2}{|c|}{ PE (t/ha) } & \multicolumn{2}{|c|}{$\mathrm{AP}(\mathrm{cm})$} \\
\hline & & QM & $\mathrm{P}^{1 /}$ & QM & $\mathrm{P}$ \\
\hline & \multicolumn{5}{|c|}{$s=6$} \\
\hline HÍBRIDOS & 296 & 0,836 & 0,000 & 147,66 & 0,000 \\
\hline CGC & 98 & 1,185 & 0,000 & 339,06 & 0,000 \\
\hline CGC $(\mathrm{I})^{\underline{2} /}$ & 49 & 1,170 & 0,000 & 340,62 & 0,000 \\
\hline CGC (II $)^{3 /}$ & 49 & 1,201 & 0,000 & 337,49 & 0,000 \\
\hline CEC & 198 & 0,663 & 0,000 & 52,92 & 0,005 \\
\hline \multirow[t]{2}{*}{ ERRO } & 750 & 0,420 & & 40,09 & \\
\hline & \multicolumn{5}{|c|}{$s=5$} \\
\hline HÍBRIDOS & 246 & 0,829 & 0,000 & 145,73 & 0,000 \\
\hline CGC & 98 & 1,006 & 0,000 & 285,29 & 0,000 \\
\hline CGC (I) & 49 & 1,073 & 0,000 & 283,70 & 0,000 \\
\hline CGC (II) & 49 & 0,940 & 0,000 & 286,87 & 0,000 \\
\hline CEC & 148 & 0,712 & 0,000 & 53,32 & 0,010 \\
\hline \multirow{2}{*}{ ERRO } & 750 & 0,420 & & 40,09 & \\
\hline & \multicolumn{5}{|c|}{$\mathrm{S}=4$} \\
\hline HÍBRIDOS & 196 & 0,813 & 0,000 & 143,78 & 0,000 \\
\hline CGC & 98 & 0,920 & 0,000 & 228,38 & 0,000 \\
\hline CGC (I) & 49 & 1,155 & 0,000 & 204,29 & 0,000 \\
\hline CGC (II) & 49 & 0,684 & 0,005 & 252,46 & 0,000 \\
\hline CEC & 98 & 0,705 & 0,000 & 59,19 & 0,003 \\
\hline \multirow[t]{2}{*}{ ERRO } & 750 & 0,420 & & 40,09 & \\
\hline & \multicolumn{5}{|c|}{$s=3$} \\
\hline HÍBRIDOS & 147 & 0,817 & 0,000 & 151,21 & 0,000 \\
\hline CGC & 98 & 0,898 & 0,000 & 194,59 & 0,000 \\
\hline CGC (I) & 49 & 0,621 & 0,020 & 173,51 & 0,000 \\
\hline CGC (II) & 49 & 1,174 & 0,000 & 215,66 & 0,000 \\
\hline CEC & 49 & 0,656 & 0,009 & 64,45 & 0,006 \\
\hline ERRO & 750 & 0,420 & & 40,09 & \\
\hline
\end{tabular}

11 nível de significância pelo teste de $\mathrm{F} ;{ }^{2} / \mathrm{GN}-03$ e ${ }^{3} / \mathrm{GN}-04$. 
Tabela 10. Quadro da análise de variância ao nível de médias do DPCI (B) para diferentes tamanhos de $\mathbf{s}$ para as variáveis peso de espiga (PE) e altura de planta (AP). Piracicaba, 2001/02.

\begin{tabular}{|c|c|c|c|c|c|}
\hline \multirow{2}{*}{ FV } & \multirow{2}{*}{$\mathrm{GL}$} & \multicolumn{2}{|c|}{$\mathrm{PE}(\mathrm{t} / \mathrm{ha})$} & \multicolumn{2}{|c|}{$\mathrm{AP}(\mathrm{cm})$} \\
\hline & & QM & $\mathrm{P}^{1 /}$ & $\mathrm{QM}$ & $\mathrm{P}$ \\
\hline & \multicolumn{5}{|c|}{$s=6$} \\
\hline HÍBRIDOS & 281 & 0,835 & 0,000 & 140,00 & 0,000 \\
\hline CGC & 98 & 1,321 & 0,000 & 281,36 & 0,000 \\
\hline CGC $(I)^{\underline{2} /}$ & 49 & 1,022 & 0,000 & 270,05 & 0,000 \\
\hline CGC (II) $)^{3 /}$ & 49 & 1,620 & 0,000 & 292,67 & 0,000 \\
\hline CEC & 183 & 0,575 & 0,006 & 64,30 & 0,000 \\
\hline \multirow[t]{2}{*}{ ERRO } & 714 & 0,432 & & 40,08 & \\
\hline & \multicolumn{5}{|c|}{$S=5$} \\
\hline HÍBRIDOS & 232 & 0,737 & 0,000 & 137,38 & 0,000 \\
\hline CGC & 98 & 1,087 & 0,000 & 241,14 & 0,000 \\
\hline CGC (I) & 49 & 0,926 & 0,000 & 208,95 & 0,000 \\
\hline CGC (II) & 49 & 1,247 & 0,000 & 273,32 & 0,000 \\
\hline CEC & 134 & 0,481 & 0,201 & 61,50 & 0,000 \\
\hline \multirow[t]{2}{*}{ ERRO } & 714 & 0,432 & & 40,08 & \\
\hline & \multicolumn{5}{|c|}{$\mathrm{S}=4$} \\
\hline HÍBRIDOS & 185 & 0,781 & 0,000 & 147,38 & 0,000 \\
\hline CGC & 98 & 1,013 & 0,000 & 223,56 & 0,000 \\
\hline CGC (I) & 49 & 0,804 & 0,000 & 183,16 & 0,000 \\
\hline CGC (II) & 49 & 1,223 & 0,000 & 263,95 & 0,000 \\
\hline CEC & 87 & 0,520 & 0,112 & 61,56 & 0,002 \\
\hline \multirow[t]{2}{*}{ ERRO } & 714 & 0,432 & & 40,08 & \\
\hline & \multicolumn{5}{|c|}{$s=3$} \\
\hline HÍBRIDOS & 138 & 0,778 & 0,000 & 150,74 & 0,000 \\
\hline CGC & 98 & 0,934 & 0,000 & 189,59 & 0,000 \\
\hline CGC - 1 & 49 & 0,488 & 0,257 & 113,74 & 0,000 \\
\hline CGC - 2 & 49 & 1,379 & 0,000 & 265,45 & 0,000 \\
\hline CEC & 40 & 0,397 & 0,615 & 55,55 & 0,060 \\
\hline ERRO & 714 & 0,432 & & 40,08 & \\
\hline
\end{tabular}

11 nível de significância pelo teste de $\mathrm{F} ;{ }^{2}$ GN-03 e ${ }^{3}$ GN-04. 
Tabela 11. Quadro da análise de variância ao nível de médias do DPCl (A) para diferentes tamanhos de $\mathbf{s}$ para as variáveis peso de espiga (PE) e altura de planta (AP). Uberlândia, 2001/02.

\begin{tabular}{|c|c|c|c|c|c|}
\hline \multirow{2}{*}{$\mathrm{FV}$} & \multirow{2}{*}{ GL } & \multicolumn{2}{|c|}{$\mathrm{PE}$ (t/ha) } & \multicolumn{2}{|c|}{$\mathrm{AP}(\mathrm{cm})$} \\
\hline & & QM & $\mathrm{P}^{1 /}$ & QM & $\mathrm{P}$ \\
\hline & \multicolumn{5}{|c|}{$s=6$} \\
\hline HÍBRIDOS & 296 & 0,370 & 0,000 & 113,51 & 0,000 \\
\hline CGC & 98 & 0,547 & 0,000 & 178,41 & 0,000 \\
\hline CGC $(I)^{\underline{2} /}$ & 49 & 0,504 & 0,000 & 153,47 & 0,000 \\
\hline CGC (II) $)^{3 /}$ & 49 & 0,590 & 0,000 & 203,36 & 0,000 \\
\hline CEC & 198 & 0,283 & 0,079 & 81,38 & 0,237 \\
\hline \multirow[t]{2}{*}{ ERRO } & 582 & 0,241 & & 75,08 & \\
\hline & \multicolumn{5}{|c|}{$s=5$} \\
\hline HÍBRIDOS & 246 & 0,377 & 0,000 & 112,26 & 0,000 \\
\hline CGC & 98 & 0,539 & 0,000 & 171,49 & 0,000 \\
\hline CGC (I) & 49 & 0,455 & 0,000 & 174,10 & 0,000 \\
\hline CGC (II) & 49 & 0,623 & 0,000 & 168,88 & 0,000 \\
\hline CEC & 148 & 0,269 & 0,187 & 73,04 & 0,573 \\
\hline \multirow[t]{2}{*}{ ERRO } & 582 & 0,241 & & 75,08 & \\
\hline & \multicolumn{5}{|c|}{$\mathrm{S}=4$} \\
\hline HÍBRIDOS & 196 & 0,387 & 0,000 & 113,82 & 0,000 \\
\hline CGC & 98 & 0,496 & 0,000 & 162,09 & 0,000 \\
\hline CGC (I) & 49 & 0,285 & 0,192 & 133,28 & 0,001 \\
\hline CGC (II) & 49 & 0,707 & 0,000 & 190,90 & 0,000 \\
\hline CEC & 98 & 0,277 & 0,166 & 65,56 & 0,796 \\
\hline \multirow[t]{2}{*}{ ERRO } & 582 & 0,241 & & 75,08 & \\
\hline & \multicolumn{5}{|c|}{$s=3$} \\
\hline HÍBRIDOS & 147 & 0,402 & 0,000 & 117,60 & 0,000 \\
\hline CGC & 98 & 0,455 & 0,000 & 139,92 & 0,000 \\
\hline CGC (I) & 49 & 0,292 & 0,158 & 79,38 & 0,372 \\
\hline CGC (II) & 49 & 0,619 & 0,000 & 200,45 & 0,000 \\
\hline CEC & 49 & 0,294 & 0,151 & 72,97 & 0,530 \\
\hline ERRO & 582 & 0,241 & & 75,08 & \\
\hline
\end{tabular}


Tabela 12. Quadro da análise de variância ao nível de médias do DPCl (B) para diferentes tamanhos de $\mathbf{s}$ para as variáveis peso de espiga (PE) e altura de planta (AP). Uberlândia, 2001/02.

\begin{tabular}{|c|c|c|c|c|c|}
\hline \multirow{2}{*}{$\mathrm{FV}$} & \multirow{2}{*}{$\mathrm{GL}$} & \multicolumn{2}{|c|}{$\mathrm{PE}$ (t/ha) } & \multicolumn{2}{|c|}{$\mathrm{AP}(\mathrm{cm})$} \\
\hline & & QM & $\mathrm{P}^{1 /}$ & QM & $\mathrm{P}$ \\
\hline & \multicolumn{5}{|c|}{$s=6$} \\
\hline HÍBRIDOS & 281 & 0,500 & 0,000 & 116,00 & 0,000 \\
\hline CGC & 98 & 0,821 & 0,000 & 173,59 & 0,000 \\
\hline CGC $(\mathrm{I})^{\underline{2} /}$ & 49 & 0,868 & 0,000 & 163,16 & 0,000 \\
\hline CGC (II) ${ }^{3 /}$ & 49 & 0,775 & 0,000 & 184,03 & 0,000 \\
\hline CEC & 183 & 0,328 & 0,000 & 85,15 & 0,001 \\
\hline \multirow[t]{2}{*}{ ERRO } & 552 & 0,206 & & 58,96 & \\
\hline & \multicolumn{5}{|c|}{$s=5$} \\
\hline HÍBRIDOS & 232 & 0,525 & 0,000 & 113,26 & 0,000 \\
\hline CGC & 98 & 0,789 & 0,000 & 153,29 & 0,000 \\
\hline CGC (I) & 49 & 0,933 & 0,000 & 153,21 & 0,000 \\
\hline CGC (II) & 49 & 0,645 & 0,000 & 153,36 & 0,000 \\
\hline CEC & 134 & 0,333 & 0,000 & 83,99 & 0,003 \\
\hline \multirow[t]{2}{*}{ ERRO } & 552 & 0,206 & & 58,96 & \\
\hline & \multicolumn{5}{|c|}{$\mathrm{S}=4$} \\
\hline HÍBRIDOS & 185 & 0,556 & 0,000 & 117,17 & 0,000 \\
\hline CGC & 98 & 0,770 & 0,000 & 147,66 & 0,000 \\
\hline CGC (I) & 49 & 0,631 & 0,000 & 98,75 & 0,004 \\
\hline CGC (II) & 49 & 0,910 & 0,000 & 196,58 & 0,000 \\
\hline CEC & 87 & 0,314 & 0,003 & 82,81 & 0,014 \\
\hline \multirow[t]{2}{*}{ ERRO } & 552 & 0,206 & & 58,96 & \\
\hline & \multicolumn{5}{|c|}{$s=3$} \\
\hline HÍBRIDOS & 138 & 0,535 & 0,000 & 127,12 & 0,000 \\
\hline CGC & 98 & 0,645 & 0,000 & 143,72 & 0,000 \\
\hline CGC (I) & 49 & 0,598 & 0,000 & 107,33 & 0,001 \\
\hline CGC (II) & 49 & 0,692 & 0,000 & 180,11 & 0,000 \\
\hline CEC & 40 & 0,265 & 0,115 & 86,44 & 0,035 \\
\hline ERRO & 552 & 0,206 & & 58,96 & \\
\hline
\end{tabular}

11 nível de significância pelo teste de F; ${ }^{2}$ GN-03 e ${ }^{3}$ GN-04. 
Tabela 13. Quadro da análise de variância ao nível de médias do DPCl (A) para diferentes tamanhos de $\mathbf{s}$ para a variável peso de espiga (PE) em t/ha. Jataí, 2002.

\begin{tabular}{|c|c|c|c|}
\hline FV & $\mathrm{GL}$ & QM & $\mathrm{P}^{1 /}$ \\
\hline & \multicolumn{3}{|c|}{$s=6$} \\
\hline HÍBRIDOS & 296 & 0,289 & 0,000 \\
\hline CGC & 98 & 0,438 & 0,000 \\
\hline CGC $(I)^{2}$ & 49 & 0,428 & 0,000 \\
\hline CGC (II) ${ }^{3 /}$ & 49 & 0,447 & 0,000 \\
\hline CEC & 198 & 0,215 & 0,000 \\
\hline \multirow[t]{2}{*}{ ERRO } & 294 & 0,132 & \\
\hline & \multicolumn{3}{|c|}{$s=5$} \\
\hline HÍBRIDOS & 246 & 0,294 & 0,000 \\
\hline CGC & 98 & 0,385 & 0,000 \\
\hline CGC (I) & 49 & 0,386 & 0,000 \\
\hline CGC (II) & 49 & 0,383 & 0,000 \\
\hline CEC & 148 & 0,235 & 0,000 \\
\hline \multirow[t]{2}{*}{ ERRO } & 294 & 0,132 & \\
\hline & \multicolumn{3}{|c|}{$S=4$} \\
\hline HÍBRIDOS & 196 & 0,308 & 0,000 \\
\hline CGC & 98 & 0,375 & 0,000 \\
\hline CGC (I) & 49 & 0,280 & 0,000 \\
\hline CGC (II) & 49 & 0,470 & 0,000 \\
\hline CEC & 98 & 0,241 & 0,000 \\
\hline \multirow[t]{2}{*}{ ERRO } & 294 & 0,132 & \\
\hline & \multicolumn{3}{|c|}{$s=3$} \\
\hline HÍBRIDOS & 147 & 0,321 & 0,000 \\
\hline CGC & 98 & 0,356 & 0,000 \\
\hline CGC (I) & 49 & 0,185 & 0,050 \\
\hline CGC (II) & 49 & 0,526 & 0,000 \\
\hline CEC & 49 & 0,252 & 0,001 \\
\hline ERRO & 294 & 0,132 & \\
\hline
\end{tabular}

1] nível de significância pelo teste de F; ${ }^{2} \mathrm{GN}-03$ e ${ }^{3 /} \mathrm{GN}-04$. 
Tabela 14. Estimativas dos parâmetros do modelo utilizado para o caráter peso de espigas (t/ha) dos 30 melhores híbridos, avaliados no DPCI (A) com s igual a 6. Piracicaba, 2001/02.

\begin{tabular}{|c|c|c|c|c|c|c|c|c|c|}
\hline \multirow{2}{*}{ Híbrido } & \multicolumn{5}{|c|}{ Em t/ha } & \multicolumn{4}{|c|}{$\mathrm{Em} \%$} \\
\hline & $\hat{\mathrm{m}} \mathbb{1}$ & $\hat{\mu}^{\underline{2}}$ & $\hat{g}_{i}{ }^{3 /}$ & $\hat{g}_{\mathrm{j}}{ }^{4 l}$ & $\hat{s}_{i j} \frac{5 /}{2}$ & $\mu \%$ & $g_{i} \%$ & $g_{j} \%$ & $s_{i j} \%$ \\
\hline $19 \times 21$ & 10,98 & 8,23 & $-0,46$ & 1,09 & 2,12 & 74,95 & $-4,19$ & 9,93 & 19,31 \\
\hline $5 \times 7$ & 10,78 & 8,23 & 0,24 & 0,87 & 1,44 & 76,35 & 2,23 & 8,07 & 13,36 \\
\hline $37 \times 40^{\circ}$ & 10,45 & 8,23 & 0,2 & 0,21 & 1,81 & 78,76 & 1,91 & 2,01 & 17,32 \\
\hline $6 \times 10^{\prime}$ & 10,39 & 8,23 & $-0,41$ & 0,88 & 1,69 & 79,21 & $-3,95$ & 8,47 & 16,27 \\
\hline $47 \times 11^{\circ}$ & 10,33 & 8,23 & 0,57 & $-0,04$ & 1,57 & 79,67 & 5,52 & $-0,39$ & 15,20 \\
\hline $50 \times 3$ & 10,22 & 8,23 & 0,64 & 0,22 & 1,13 & 80,53 & 6,26 & 2,15 & 11,06 \\
\hline $19 \times 23$ & 10,02 & 8,23 & $-0,46$ & 1,1 & 1,15 & 82,14 & $-4,59$ & 10,98 & 11,48 \\
\hline $31 \times 32$ & 10,02 & 8,23 & 0,33 & 0,06 & 1,4 & 82,14 & 3,29 & 0,60 & 13,97 \\
\hline $30 \times 34$ & 9,92 & 8,23 & 0,32 & 0,44 & 0,93 & 82,96 & 3,23 & 4,44 & 9,38 \\
\hline $33 \times 34$ & 9,91 & 8,23 & 0,86 & 0,44 & 0,38 & 83,05 & 8,68 & 4,44 & 3,83 \\
\hline $2 \times 7$ & 9,83 & 8,23 & 0,6 & 0,87 & 0,13 & 83,72 & 6,10 & 8,85 & 1,32 \\
\hline $36 \times 38^{\prime}$ & 9,71 & 8,23 & 1,18 & 0,22 & 0,08 & 84,76 & 12,15 & 2,27 & 0,82 \\
\hline $22 \times 22$ & 9,64 & 8,23 & 0,23 & 0,82 & 0,35 & 85,37 & 2,39 & 8,51 & 3,63 \\
\hline $42 \times 42^{\prime}$ & 9,61 & 8,23 & 0,22 & $-0,46$ & 1,62 & 85,64 & 2,29 & $-4,79$ & 16,86 \\
\hline $36 \times 39^{\circ}$ & 9,6 & 8,23 & 1,18 & $-0,06$ & 0,24 & 85,73 & 12,29 & $-0,63$ & 2,50 \\
\hline $29 \times 29^{\circ}$ & 9,6 & 8,23 & 0,13 & 0,5 & 0,73 & 85,73 & 1,35 & 5,21 & 7,60 \\
\hline $9 \times 14$ & 9,59 & 8,23 & $-0,4$ & 0,71 & 1,05 & 85,82 & $-4,17$ & 7,40 & 10,95 \\
\hline $36 \times 37^{-}$ & 9,57 & 8,23 & 1,18 & $-0,08$ & 0,23 & 86,00 & 12,33 & $-0,84$ & 2,40 \\
\hline $36 \times 40^{\circ}$ & 9,56 & 8,23 & 1,18 & 0,21 & $-0,06$ & 86,09 & 12,34 & 2,20 & $-0,63$ \\
\hline $24 \times 29^{\circ}$ & 9,55 & 8,23 & 0,6 & 0,5 & 0,22 & 86,18 & 6,28 & 5,24 & 2,30 \\
\hline $46 \times 47^{-}$ & 9,55 & 8,23 & 0,94 & $-0,63$ & 1,01 & 86,18 & 9,84 & $-6,60$ & 10,58 \\
\hline $8 \times 12$ & 9,53 & 8,23 & $-0, \mathrm{~b} 08$ & 0,09 & 1,28 & 86,36 & $-0,84$ & 0,94 & 13,43 \\
\hline $21 \times 22$ & 9,53 & 8,23 & $-0,75$ & 0,82 & 1,22 & 86,36 & $-7,87$ & 8,60 & 12,80 \\
\hline $33 \times 36^{\prime}$ & 8,86 & 8,23 & 0,86 & $-0,31$ & 0,08 & 92,89 & 9,71 & $-3,50$ & 0,90 \\
\hline $3 \times 8^{\prime}$ & 9,47 & 8,23 & $-0,16$ & 1,11 & 0,29 & 86,91 & $-1,69$ & 11,72 & 3,06 \\
\hline $46 \times 49^{\circ}$ & 9,46 & 8,23 & 0,94 & $-0,81$ & 1,09 & 87,00 & 9,94 & $-8,56$ & 11,52 \\
\hline $17 \times 19^{\circ}$ & 9,07 & 8,23 & $-0,08$ & $-0,13$ & 1,05 & 90,74 & $-0,88$ & $-1,43$ & 11,58 \\
\hline $33 \times 37^{`}$ & 9,43 & 8,23 & 0,86 & $-0,08$ & 0,41 & 87,27 & 9,12 & $-0,85$ & 4,35 \\
\hline $1 \times 3$ & 9,43 & 8,23 & 0,54 & 0,22 & 0,44 & 87,27 & 5,73 & 2,33 & 4,67 \\
\hline $2 \times 2$ & 9,42 & 8,23 & 0,6 & 0,09 & 0,49 & 87,37 & 6,37 & 0,96 & 5,20 \\
\hline
\end{tabular}


Tabela 15. Estimativas dos parâmetros do modelo utilizado para o caráter peso de espigas (t/ha) dos 30 melhores híbridos, avaliados no DPCl (B) com s igual a 6. Piracicaba, 2001/02.

\begin{tabular}{|c|c|c|c|c|c|c|c|c|c|}
\hline \multirow{2}{*}{ Híbrido } & \multicolumn{5}{|c|}{ Em tha } & \multicolumn{4}{|c|}{ Em \% } \\
\hline & $\hat{\mathrm{m}} \stackrel{\mathbb{1}}{ }$ & $\hat{\mu}^{\underline{2}}$ & $\hat{g}_{\mathrm{i}}{ }^{3 /}$ & $\hat{g}_{\mathrm{j}}{ }^{4 l}$ & $\hat{s}_{\mathrm{ij}}{ }^{5 /}$ & $\mu \%$ & $g_{i} \%$ & $g_{j} \%$ & $\mathrm{~s}_{\mathrm{ij}} \%$ \\
\hline $70 \times 73^{\prime}$ & 10,45 & 8,22 & 1,21 & 0,11 & 0,9 & 78,66 & 11,58 & 1,05 & 8,61 \\
\hline $98 \times 52$ & 10,44 & 8,22 & 0,61 & 1,28 & 0,32 & 78,74 & 5,84 & 12,26 & 3,07 \\
\hline $67 \times 71^{\prime}$ & 10,38 & 8,22 & 0,66 & $-0,16$ & 1,66 & 79,19 & 6,36 & $-1,54$ & 15,99 \\
\hline $53 \times 58^{\prime}$ & 10,31 & 8,22 & 0,12 & 0,91 & 1,06 & 79,73 & 1,16 & 8,83 & 10,28 \\
\hline $79 \times 79^{\circ}$ & 10,3 & 8,22 & 0,26 & $-0,08$ & 1,89 & 79,81 & 2,52 & $-0,78$ & 18,35 \\
\hline $53 \times 54$ & 10,12 & 8,22 & 0,12 & 0,73 & 1,04 & 81,23 & 1,19 & 7,21 & 10,28 \\
\hline $75 \times 80^{\circ}$ & 10,11 & 8,22 & 1,17 & $-0,17$ & 0,89 & 81,31 & 11,57 & $-1,68$ & 8,80 \\
\hline $100 \times 53$ & 10,03 & 8,22 & $-0,34$ & 0,47 & 1,68 & 81,95 & $-3,39$ & 4,69 & 16,75 \\
\hline $94 \times 94^{\prime}$ & 9,97 & 8,22 & $-0,83$ & 1,51 & 1,07 & 82,45 & $-8,32$ & 15,15 & 10,73 \\
\hline $75 \times 77^{\prime}$ & 9,79 & 8,22 & 1,17 & 0,21 & 0,19 & 83,96 & 11,95 & 2,15 & 1,94 \\
\hline $86 \times 87^{-}$ & 9,79 & 8,22 & 0,38 & 0,12 & 1,06 & 83,96 & 3,88 & 1,23 & 10,83 \\
\hline $64 \times 64$ & 9,76 & 8,22 & 1,06 & 0,28 & 0,2 & 84,22 & 10,86 & 2,87 & 2,05 \\
\hline $75 \times 75$ & 9,72 & 8,22 & 1,17 & $-0,81$ & 1,13 & 84,57 & 12,04 & $-8,33$ & 11,63 \\
\hline $92 \times 97^{\prime}$ & 9,63 & 8,22 & $-0,7$ & 0,68 & 1,43 & 85,36 & $-7,27$ & 7,06 & 14,85 \\
\hline $82 \times 85^{\prime}$ & 9,6 & 8,22 & 0,25 & 0,78 & 0,35 & 85,63 & 2,60 & 8,13 & 3,65 \\
\hline $58 \times 60^{\circ}$ & 9,57 & 8,22 & 0,13 & 0,62 & 0,6 & 85,89 & 1,36 & 6,48 & 6,27 \\
\hline $73 \times 77^{1}$ & 9,52 & 8,22 & 0,93 & 0,21 & 0,15 & 86,34 & 9,77 & 2,21 & 1,58 \\
\hline $80 \times 85$ & 9,51 & 8,22 & $-0,01$ & 0,78 & 0,52 & 86,44 & $-0,11$ & 8,20 & 5,47 \\
\hline $98 \times 51^{\prime}$ & 9,49 & 8,22 & 0,61 & 0,69 & $-0,03$ & 86,62 & 6,43 & 7,27 & $-0,32$ \\
\hline $81 \times 85$ & 9,48 & 8,22 & $-0,15$ & 0,78 & 0,62 & 86,71 & $-1,58$ & 8,23 & 6,54 \\
\hline $60 \times 60^{\circ}$ & 9,48 & 8,22 & 0,18 & 0,62 & 0,46 & 86,71 & 1,90 & 6,54 & 4,85 \\
\hline $62 \times 65$ & 9,47 & 8,22 & 0,77 & $-0,36$ & 0,83 & 86,80 & 8,13 & $-3,80$ & 8,76 \\
\hline $98 \times 53$ & 9,45 & 8,22 & 0,61 & 0,47 & 0,15 & 86,98 & 6,46 & 4,97 & 1,59 \\
\hline $62 \times 64^{-}$ & 9,42 & 8,22 & 0,77 & 0,28 & 0,15 & 87,26 & 8,17 & 2,97 & 1,59 \\
\hline $95 \times 97^{\prime}$ & 9,34 & 8,22 & 0,32 & 0,68 & 0,12 & 88,01 & 3,43 & 7,28 & 1,28 \\
\hline $55 \times 58^{\circ}$ & 9,3 & 8,22 & $-0,36$ & 0,91 & 0,53 & 88,39 & $-3,87$ & 9,78 & 5,70 \\
\hline $52 \times 56^{\prime}$ & 9,29 & 8,22 & $-0,39$ & 0,62 & 0,83 & 88,48 & $-4,20$ & 6,67 & 8,93 \\
\hline $99 \times 52^{\prime}$ & 9,28 & 8,22 & $-0,23$ & 1,28 & 0 & 88,58 & $-2,48$ & 13,79 & 0,00 \\
\hline $70 \times 71^{-}$ & 9,27 & 8,22 & 1,21 & $-0,16$ & 0 & 88,67 & 13,05 & $-1,73$ & 0,00 \\
\hline $83 \times 88^{\prime}$ & 9,27 & 8,22 & $-0,18$ & 0,26 & 0,98 & 88,67 & $-1,94$ & 2,80 & 10,57 \\
\hline
\end{tabular}

1/média observada; '2/média estimada; ${ }^{3 / C G C ~ d a ~ p o p u l a c ̧ a ̃ o ~ G N-03 ; ~}{ }^{4 / C G C ~ d a ~}$ população GN-04; ${ }^{5}$ CEC do híbrido “ij”. 
Tabela 16. Estimativas dos parâmetros do modelo utilizado para o caráter peso de espigas (t/ha) dos 30 melhores híbridos, avaliados no DPCI (A) com $s$ igual a 6 . Uberlândia, 2001/02.

\begin{tabular}{|c|c|c|c|c|c|c|c|c|c|}
\hline \multirow{2}{*}{ Híbrido } & \multicolumn{5}{|c|}{ Em t/ha } & \multicolumn{4}{|c|}{ Em \% } \\
\hline & $\hat{\mathrm{m}}^{1 /}$ & $\hat{\mu}^{\underline{2}}$ & $\hat{g}_{i}{ }^{3 /}$ & $\hat{g}_{j}{ }^{4 l}$ & $\hat{s}_{i j}{ }^{5 /}$ & $\mu \%$ & $g_{i} \%$ & $g_{j} \%$ & $s_{i j} \%$ \\
\hline $36 \times 36^{\prime}$ & 6,28 & 4,32 & 0,49 & 1,29 & 0,18 & 68,79 & 7,80 & 20,54 & 2,87 \\
\hline $32 \times 36^{\prime}$ & 6,16 & 4,32 & $-0,10$ & 1,29 & 0,65 & 70,13 & $-1,62$ & 20,94 & 10,55 \\
\hline $36 \times 37^{\circ}$ & 6,01 & 4,32 & 0,49 & 0,91 & 0,29 & 71,88 & 8,15 & 15,14 & 4,83 \\
\hline $26 \times 29^{\circ}$ & 5,72 & 4,32 & 0,01 & 0,28 & 1,11 & 75,52 & 0,17 & 4,90 & 19,41 \\
\hline $28 \times 31^{\prime}$ & 5,61 & 4,32 & 0,32 & $-0,08$ & 1,04 & 77,01 & 5,70 & $-1,43$ & 18,54 \\
\hline $43 \times 43^{\prime}$ & 5,60 & 4,32 & 0,04 & 0,32 & 0,91 & 77,14 & 0,71 & 5,71 & 16,25 \\
\hline $32 \times 34^{-}$ & 5,60 & 4,32 & $-0,10$ & 0,49 & 0,89 & 77,14 & $-1,79$ & 8,75 & 15,89 \\
\hline $25 \times 28$ & 5,59 & 4,32 & 0,75 & 0,12 & 0,40 & 77,28 & 13,42 & 2,15 & 7,16 \\
\hline $25 \times 29^{\circ}$ & 5,58 & 4,32 & 0,75 & 0,28 & 0,23 & 77,42 & 13,44 & 5,02 & 4,12 \\
\hline $9 \times 13^{\prime}$ & 5,58 & 4,32 & 0,66 & $-0,20$ & 0,80 & 77,42 & 11,83 & $-3,58$ & 14,34 \\
\hline $42 \times 47^{\prime}$ & 5,58 & 4,32 & 0,47 & 0,25 & 0,53 & 77,42 & 8,42 & 4,48 & 9,50 \\
\hline $36 \times 38^{`}$ & 5,48 & 4,32 & 0,49 & 0,32 & 0,34 & 78,83 & 8,94 & 5,84 & 6,20 \\
\hline $9 \times 12$ & 5,44 & 4,32 & 0,66 & 0,10 & 0,36 & 79,41 & 12,13 & 1,84 & 6,62 \\
\hline $4 \times 5^{\prime}$ & 5,38 & 4,32 & 0,40 & 0,06 & 0,61 & 80,30 & 7,43 & 1,12 & 11,34 \\
\hline $34 \times 37^{\prime}$ & 5,38 & 4,32 & $-0,63$ & 0,91 & 0,77 & 80,30 & $-11,71$ & 16,91 & 14,31 \\
\hline $23 \times 24$ & 5,36 & 4,32 & 0,11 & 0,25 & 0,67 & 80,60 & 2,05 & 4,66 & 12,50 \\
\hline $35 \times 36^{\prime}$ & 5,35 & 4,32 & $-0,30$ & 1,29 & 0,04 & 80,75 & $-5,61$ & 24,11 & 0,75 \\
\hline $10 \times 15$ & 5,34 & 4,32 & 0,42 & 0,36 & 0,23 & 80,90 & 7,87 & 6,74 & 4,31 \\
\hline $10 \times 14$ & 5,31 & 4,32 & 0,42 & $-0,01$ & 0,57 & 81,36 & 7,91 & $-0,19$ & 10,73 \\
\hline $8 \times 9^{\prime}$ & 5,31 & 4,32 & 0,09 & 0,00 & 0,90 & 81,36 & 1,69 & 0,00 & 16,95 \\
\hline $21 \times 23$ & 5,27 & 4,32 & $-0,02$ & 0,32 & 0,65 & 81,97 & $-0,38$ & 6,07 & 12,33 \\
\hline $33 \times 36^{\prime}$ & 5,25 & 4,32 & $-0,27$ & 1,29 & $-0,09$ & 82,29 & $-5,14$ & 24,57 & $-1,71$ \\
\hline $33 \times 38$ & 5,23 & 4,32 & $-0,27$ & 0,32 & 0,85 & 82,60 & $-5,16$ & 6,12 & 16,25 \\
\hline $25 \times 30^{-}$ & 5,23 & 4,32 & 0,75 & $-0,22$ & 0,38 & 82,60 & 14,34 & $-4,21$ & 7,27 \\
\hline $37 \times 37^{\circ}$ & 5,21 & 4,32 & $-0,32$ & 0,91 & 0,30 & 82,92 & $-6,14$ & 17,47 & 5,76 \\
\hline $46 \times 47^{\circ}$ & 5,20 & 4,32 & 0,44 & 0,25 & 0,19 & 83,08 & 8,46 & 4,81 & 3,65 \\
\hline $50 \times 50^{\circ}$ & 5,20 & 4,32 & 0,36 & $-0,48$ & 0,99 & 83,08 & 6,92 & $-9,23$ & 19,04 \\
\hline $24 \times 27$ & 5,18 & 4,32 & 0,24 & 0,12 & 0,50 & 83,40 & 4,63 & 2,32 & 9,65 \\
\hline $25 \times 27^{-}$ & 5,18 & 4,32 & 0,75 & 0,12 & $-0,01$ & 83,40 & 14,48 & 2,32 & $-0,19$ \\
\hline $21 \times 24$ & 5,16 & 4,32 & $-0,02$ & 0,25 & 0,60 & 83,72 & $-0,39$ & 4,84 & 11,63 \\
\hline
\end{tabular}

1/média observada; '2/média estimada; ${ }^{3 / C G C}$ da população GN-03; ${ }^{4 / C G C ~ d a ~}$ população GN-04; ${ }^{5}$ CEC do híbrido “ij”. 
Tabela 17. Estimativas dos parâmetros do modelo utilizado para o caráter peso de espigas (t/ha) dos 30 melhores híbridos, avaliados no DPCI (B) com s igual a 6. Uberlândia, 2001/02.

\begin{tabular}{|c|c|c|c|c|c|c|c|c|c|}
\hline \multirow{2}{*}{ Híbrido } & \multicolumn{5}{|c|}{ Em tha } & \multicolumn{4}{|c|}{ Em \% } \\
\hline & $\hat{\mathrm{m}} \stackrel{1}{ }$ & $\hat{\mu}^{\underline{2}}$ & $\hat{g}_{\mathrm{i}}{ }^{3 /}$ & $\hat{g}_{\mathrm{j}}{ }^{4 l}$ & $\hat{s}_{\mathrm{ij}}{ }^{5 /}$ & $\mu \%$ & $g_{i} \%$ & $g_{j} \%$ & $\mathrm{~s}_{\mathrm{ij}} \%$ \\
\hline $100 \times 53$ & 6,00 & 3,87 & 0,04 & 0,74 & 1,35 & 64,50 & 0,67 & 12,33 & 22,50 \\
\hline $83 \times 87^{`}$ & 5,81 & 3,87 & 0,21 & 0,36 & 1,37 & 66,61 & 3,61 & 6,20 & 23,58 \\
\hline $65 \times 65^{\circ}$ & 5,81 & 3,87 & 1,31 & 0,38 & 0,25 & 66,61 & 22,55 & 6,54 & 4,30 \\
\hline $65 \times 69^{\circ}$ & 5,66 & 3,87 & 1,31 & $-0,42$ & 0,90 & 68,37 & 23,14 & $-7,42$ & 15,90 \\
\hline $75 \times 77^{\circ}$ & 5,64 & 3,87 & 1,22 & 0,10 & 0,45 & 68,62 & 21,63 & 1,77 & 7,98 \\
\hline $75 \times 75$ & 5,62 & 3,87 & 1,22 & $-0,75$ & 1,28 & 68,86 & 21,71 & $-13,35$ & 22,78 \\
\hline $70 \times 73$ & 5,60 & 3,87 & 0,90 & 0,13 & 0,70 & 69,11 & 16,07 & 2,32 & 12,50 \\
\hline $55 \times 58$ & 5,51 & 3,87 & $-0,19$ & 0,93 & 0,89 & 70,24 & $-3,45$ & 16,88 & 16,15 \\
\hline $64 \times 64$ & 5,33 & 3,87 & 0,45 & 0,36 & 0,65 & 72,61 & 8,44 & 6,75 & 12,20 \\
\hline $82 \times 83^{\prime}$ & 5,33 & 3,87 & 0,50 & 0,17 & 0,79 & 72,61 & 9,38 & 3,19 & 14,82 \\
\hline $63 \times 64^{-}$ & 5,33 & 3,87 & 0,33 & 0,36 & 0,77 & 72,61 & 6,19 & 6,75 & 14,45 \\
\hline $75 \times 76^{\prime}$ & 5,19 & 3,87 & 1,22 & 0,32 & $-0,22$ & 74,57 & 23,51 & 6,17 & $-4,24$ \\
\hline $88 \times 91^{\prime}$ & 5,18 & 3,87 & 0,67 & $-0,24$ & 0,88 & 74,71 & 12,93 & $-4,63$ & 16,99 \\
\hline $95 \times 97^{-}$ & 5,17 & 3,87 & 0,24 & 0,03 & 1,04 & 74,85 & 4,64 & 0,58 & 20,12 \\
\hline $94 \times 97^{-}$ & 5,17 & 3,87 & $-0,01$ & 0,03 & 1,28 & 74,85 & $-0,19$ & 0,58 & 24,76 \\
\hline $100 \times 54$ & 5,08 & 3,87 & 0,04 & 0,72 & 0,45 & 76,18 & 0,79 & 14,17 & 8,86 \\
\hline $96 \times 51^{-}$ & 5,00 & 3,87 & $-0,25$ & 0,45 & 0,93 & 77,40 & $-5,00$ & 9,00 & 18,60 \\
\hline $65 \times 67^{`}$ & 5,00 & 3,87 & 1,31 & $-0,31$ & 0,13 & 77,40 & 26,20 & $-6,20$ & 2,60 \\
\hline $85 \times 87^{\prime}$ & 4,96 & 3,87 & 0,73 & 0,36 & 0,00 & 78,02 & 14,72 & 7,26 & 0,00 \\
\hline $57 \times 57^{\prime}$ & 4,89 & 3,87 & $-0,30$ & 0,67 & 0,64 & 79,14 & $-6,13$ & 13,70 & 13,09 \\
\hline $66 \times 70^{\prime}$ & 4,87 & 3,87 & 0,97 & $-0,77$ & 0,79 & 79,47 & 19,92 & $-15,81$ & 16,22 \\
\hline $73 \times 76^{\prime}$ & 4,86 & 3,87 & 0,22 & 0,32 & 0,45 & 79,63 & 4,53 & 6,58 & 9,26 \\
\hline $90 \times 95$ & 4,85 & 3,87 & 0,57 & 0,08 & 0,32 & 79,79 & 11,75 & 1,65 & 6,60 \\
\hline $88 \times 92$ & 4,85 & 3,87 & 0,67 & 0,53 & $-0,23$ & 79,79 & 13,81 & 10,93 & $-4,74$ \\
\hline $92 \times 96^{\prime}$ & 4,84 & 3,87 & $-0,22$ & 0,72 & 0,47 & 79,96 & $-4,55$ & 14,88 & 9,71 \\
\hline $85 \times 89^{\circ}$ & 4,83 & 3,87 & 0,73 & $-0,23$ & 0,46 & 80,12 & 15,11 & $-4,76$ & 9,52 \\
\hline $66 \times 67^{\circ}$ & 4,81 & 3,87 & 0,97 & $-0,31$ & 0,28 & 80,46 & 20,17 & $-6,44$ & 5,82 \\
\hline $77 \times 81^{\prime}$ & 4,79 & 3,87 & 0,50 & $-0,31$ & 0,73 & 80,79 & 10,44 & $-6,47$ & 15,24 \\
\hline $90 \times 94$ & 4,77 & 3,87 & 0,57 & 0,33 & 0,00 & 81,13 & 11,95 & 6,92 & 0,00 \\
\hline $95 \times 98^{\circ}$ & 4,75 & 3,87 & 0,24 & 0,50 & 0,15 & 81,47 & 5,05 & 10,53 & 3,16 \\
\hline
\end{tabular}

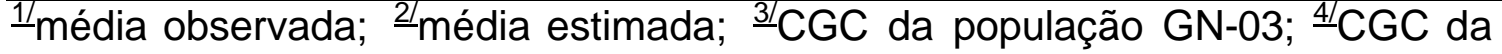
população GN-04; ${ }^{5}$ CEC do híbrido “ij”. 
Tabela 18. Estimativas dos parâmetros do modelo utilizado para o caráter peso de espigas (t/ha) dos 30 melhores híbridos, avaliados no DPCI (A) com $\boldsymbol{s}$ igual a 6. Jataí, 2001/02.

\begin{tabular}{|c|c|c|c|c|c|c|c|c|c|}
\hline \multirow{2}{*}{ Híbrido } & \multicolumn{5}{|c|}{ Em tha } & \multicolumn{4}{|c|}{$\mathrm{Em} \%$} \\
\hline & $\hat{\mathrm{m}} \mathbb{1}$ & $\hat{\mu}^{\underline{2}}$ & $\hat{g}_{\mathrm{i}}{ }^{3 /}$ & $\hat{g}_{\mathrm{j}}{ }^{4 l}$ & $\hat{s}_{\mathrm{ij}} \frac{5 /}{5}$ & $\mu \%$ & $g_{i} \%$ & $g_{j} \%$ & $\mathrm{~s}_{\mathrm{ij}} \%$ \\
\hline $9 \times 9^{\prime}$ & 5,82 & 4,10 & 0,78 & 0,81 & 0,14 & 70,45 & 13,40 & 13,92 & 2,41 \\
\hline $8 \times 9^{\prime}$ & 5,65 & 4,10 & 0,37 & 0,81 & 0,37 & 72,57 & 6,55 & 14,34 & 6,55 \\
\hline $11 \times 11^{\prime}$ & 5,40 & 4,10 & 0,37 & 0,28 & 0,65 & 75,93 & 6,85 & 5,19 & 12,04 \\
\hline $50 \times 2$ & 5,40 & 4,10 & 0,21 & 0,54 & 0,55 & 75,93 & 3,89 & 10,00 & 10,19 \\
\hline $35 \times 36^{\prime}$ & 5,32 & 4,10 & 0,06 & 0,47 & 0,70 & 77,07 & 1,13 & 8,83 & 13,16 \\
\hline $18 \times 18$ & 5,26 & 4,10 & 0,09 & 0,11 & 0,96 & 77,95 & 1,71 & 2,09 & 18,25 \\
\hline $46 \times 49^{\circ}$ & 5,25 & 4,10 & 0,18 & 0,40 & 0,57 & 78,10 & 3,43 & 7,62 & 10,86 \\
\hline $12 \times 14$ & 5,22 & 4,10 & 0,70 & $-0,15$ & 0,58 & 78,54 & 13,41 & $-2,87$ & 11,11 \\
\hline $4 \times 7^{\prime}$ & 5,19 & 4,10 & 0,03 & 0,10 & 0,96 & 79,00 & 0,58 & 1,93 & 18,50 \\
\hline $6 \times 11^{\circ}$ & 5,18 & 4,10 & 0,15 & 0,28 & 0,65 & 79,15 & 2,90 & 5,41 & 12,55 \\
\hline $31 \times 36^{\prime}$ & 5,10 & 4,10 & 0,29 & 0,47 & 0,24 & 80,39 & 5,69 & 9,22 & 4,71 \\
\hline $6 \times 9^{\prime}$ & 5,09 & 4,10 & 0,15 & 0,81 & 0,03 & 80,55 & 2,95 & 15,91 & 0,59 \\
\hline $4 \times 9^{\circ}$ & 5,08 & 4,10 & 0,03 & 0,81 & 0,14 & 80,71 & 0,59 & 15,94 & 2,76 \\
\hline $10 \times 10$ & 5,04 & 4,10 & 0,33 & $-0,01$ & 0,62 & 81,35 & 6,55 & $-0,20$ & 12,30 \\
\hline $41 \times 46^{\prime}$ & 5,04 & 4,10 & 0,25 & 0,05 & 0,65 & 81,35 & 4,96 & 0,99 & 12,90 \\
\hline $31 \times 34$ & 5,03 & 4,10 & 0,29 & 0,20 & 0,45 & 81,51 & 5,77 & 3,98 & 8,95 \\
\hline $15 \times 20^{\prime}$ & 5,01 & 4,10 & 0,44 & 0,07 & 0,40 & 81,84 & 8,78 & 1,40 & 7,98 \\
\hline $26 \times 30^{\circ}$ & 4,98 & 4,10 & 0,24 & 0,23 & 0,41 & 82,33 & 4,82 & 4,62 & 8,23 \\
\hline $46 \times 47^{\prime}$ & 4,98 & 4,10 & 0,18 & 0,31 & 0,39 & 82,33 & 3,61 & 6,22 & 7,83 \\
\hline $20 \times 22$ & 4,98 & 4,10 & 0,49 & $-0,14$ & 0,54 & 82,33 & 9,84 & $-2,81$ & 10,84 \\
\hline $29 \times 30^{\circ}$ & 4,94 & 4,10 & 0,11 & 0,23 & 0,50 & 83,00 & 2,23 & 4,66 & 10,12 \\
\hline $20 \times 24$ & 4,93 & 4,10 & 0,49 & 0,22 & 0,13 & 83,16 & 9,94 & 4,46 & 2,64 \\
\hline $24 \times 28^{\circ}$ & 4,93 & 4,10 & 0,25 & $-0,17$ & 0,75 & 83,16 & 5,07 & $-3,45$ & 15,21 \\
\hline $23 \times 23$ & 4,92 & 4,10 & $-0,06$ & $-0,15$ & 1,04 & 83,33 & $-1,22$ & $-3,05$ & 21,14 \\
\hline $47 \times 48^{\prime}$ & 4,92 & 4,10 & $-0,03$ & 0,05 & 0,80 & 83,33 & $-0,61$ & 1,02 & 16,26 \\
\hline $24 \times 24$ & 4,92 & 4,10 & 0,25 & 0,22 & 0,36 & 83,33 & 5,08 & 4,47 & 7,32 \\
\hline $9 \times 10^{\circ}$ & 4,92 & 4,10 & 0,78 & $-0,01$ & 0,06 & 83,33 & 15,85 & $-0,20$ & 1,22 \\
\hline $14 \times 19^{\prime}$ & 4,90 & 4,10 & 0,52 & $-0,33$ & 0,61 & 83,67 & 10,61 & $-6,73$ & 12,45 \\
\hline $2 \times 4^{\prime}$ & 4,88 & 4,10 & $-0,31$ & 0,40 & 0,69 & 84,02 & $-6,35$ & 8,20 & 14,14 \\
\hline $30 \times 31^{-}$ & 4,80 & 4,10 & 0,01 & 0,04 & 0,65 & 85,42 & 0,21 & 0,83 & 13,54 \\
\hline
\end{tabular}

1'-média observada; "2/média estimada; ${ }^{3 / C G C}$ da população GN-03; ${ }^{4}$ CGC da população GN-04; ${ }^{5}$ CEC do híbrido "ij”". 
Tabela 19. Estimativas da capacidade geral de combinação da população GN-03 para o caráter peso de espigas (t/ha) em três locais para o $\mathrm{DPCl}(\mathrm{A})$ e suas respectivas posições em ordem decrescente.

\begin{tabular}{|c|c|c|c|c|c|c|}
\hline \multirow{2}{*}{ GENITOR } & \multicolumn{3}{|c|}{ CGC - $1^{1 /}$} & \multicolumn{3}{|c|}{ Classificação } \\
\hline & Local $1 \stackrel{2}{1}$ & Local $2^{3 /}$ & Local 34 & Local 1 & Local 2 & Local 3 \\
\hline 36 & 1,18 & 0,49 & $-0,34$ & 1 & 3 & 43 \\
\hline 46 & 0,94 & 0,44 & 0,18 & 2 & 5 & 16 \\
\hline 33 & 0,86 & $-0,27$ & $-0,20$ & 3 & 39 & 34 \\
\hline 45 & 0,70 & 0,20 & $-0,49$ & 4 & 16 & 47 \\
\hline 50 & 0,64 & 0,36 & 0,21 & 5 & 9 & 15 \\
\hline 2 & 0,60 & 0,42 & $-0,31$ & 6 & 7 & 42 \\
\hline 48 & 0,60 & 0,32 & $-0,27$ & 7 & 11 & 40 \\
\hline 24 & $0,6 \mathrm{~b} 0$ & 0,24 & 0,25 & 8 & 15 & 12 \\
\hline 47 & 0,57 & 0,19 & $-0,03$ & 9 & 17 & 27 \\
\hline 1 & 0,54 & $-0,10$ & $-0,24$ & 10 & 30 & 39 \\
\hline 44 & 0,53 & 0,24 & $-0,39$ & 11 & 14 & 46 \\
\hline 31 & 0,33 & $-0,81$ & 0,29 & 12 & 50 & 10 \\
\hline 35 & 0,32 & $-0,30$ & 0,06 & 13 & 40 & 23 \\
\hline 30 & 0,32 & $-0,66$ & 0,01 & 14 & 49 & 26 \\
\hline 27 & 0,29 & $-0,19$ & $-0,15$ & 15 & 35 & 32 \\
\hline 5 & 0,24 & 0,18 & $-0,37$ & 16 & 19 & 44 \\
\hline 22 & 0,23 & $-0,61$ & 0,10 & 17 & 47 & 20 \\
\hline 42 & 0,22 & 0,47 & $-0,22$ & 18 & 4 & 36 \\
\hline 37 & 0,20 & $-0,32$ & $-0,12$ & 19 & 42 & 30 \\
\hline 29 & 0,13 & $-0,12$ & 0,11 & 20 & 32 & 19 \\
\hline 32 & 0,09 & $-0,10$ & $-0,75$ & 21 & 31 & 50 \\
\hline 26 & 0,09 & 0,01 & 0,24 & 22 & 25 & 14 \\
\hline 34 & 0,08 & $-0,63$ & $-0,49$ & 23 & 48 & 48 \\
\hline 12 & 0,03 & $-0,15$ & 0,70 & 24 & 33 & 2 \\
\hline 25 & 0,03 & 0,75 & 0,12 & 25 & 1 & 18 \\
\hline 49 & $-0,03$ & 0,30 & $-0,59$ & 26 & 12 & 49 \\
\hline 38 & $-0,05$ & $-0,34$ & $-0,10$ & 27 & 43 & 29 \\
\hline 23 & $-0,07$ & 0,11 & $-0,06$ & 28 & 20 & 28 \\
\hline 17 & $-0,08$ & $-0,32$ & $-0,23$ & 29 & 41 & 38 \\
\hline
\end{tabular}


Tabela 19. Estimativas da capacidade geral de combinação da população GN-03 para o caráter peso de espigas (t/ha) em três locais para o $\mathrm{DPCl}(\mathrm{A})$ e suas respectivas posições em ordem decrescente.

\begin{tabular}{|c|c|c|c|c|c|c|}
\hline \multirow{2}{*}{ GENITOR } & \multicolumn{3}{|c|}{ CGC $-1^{1 /}$} & \multicolumn{3}{|c|}{ Classificação } \\
\hline & Local $1 \underline{2 l}$ & Local $2^{3 /}$ & Local $3^{4 !}$ & Local 1 & Local 2 & Local 3 \\
\hline 8 & $-0,08$ & 0,09 & 0,37 & 30 & 22 & 7 \\
\hline 10 & $-0,08$ & 0,42 & 0,33 & 31 & 6 & 9 \\
\hline 43 & $-0,10$ & 0,04 & 0,04 & 32 & 24 & 24 \\
\hline 16 & $-0,12$ & 0,10 & $-0,22$ & 33 & 21 & 35 \\
\hline 3 & $-0,16$ & 0,08 & $-0,22$ & 34 & 23 & 37 \\
\hline 39 & $-0,17$ & $-0,42$ & 0,06 & 35 & 45 & 22 \\
\hline 11 & $-0,18$ & $-0,09$ & 0,37 & 36 & 29 & 6 \\
\hline 40 & $-0,21$ & $-0,42$ & $-0,20$ & 37 & 46 & 33 \\
\hline 13 & $-0,28$ & 0,29 & 0,34 & 38 & 13 & 8 \\
\hline 15 & $-0,32$ & $-0,22$ & 0,44 & 39 & 36 & 5 \\
\hline 41 & $-0,39$ & $-0,24$ & 0,25 & 40 & 38 & 11 \\
\hline 9 & $-0,40$ & 0,66 & 0,78 & 41 & 2 & 1 \\
\hline 6 & $-0,41$ & $-0,08$ & 0,15 & 42 & 28 & 17 \\
\hline 19 & $-0,46$ & $-0,06$ & $-0,28$ & 43 & 27 & 41 \\
\hline 7 & $-0,52$ & 0,18 & $-0,37$ & 44 & 18 & 45 \\
\hline 20 & $-0,68$ & $-0,17$ & 0,49 & 45 & 34 & 4 \\
\hline 21 & $-0,75$ & $-0,02$ & 0,24 & 46 & 26 & 13 \\
\hline 14 & $-0,91$ & $-0,23$ & 0,52 & 47 & 37 & 3 \\
\hline 28 & $-0,96$ & 0,32 & $-0,13$ & 48 & 10 & 31 \\
\hline 4 & $-1,46$ & 0,40 & 0,03 & 49 & 8 & 25 \\
\hline 18 & $-1,50$ & $-0,42$ & 0,09 & 50 & 44 & 21 \\
\hline
\end{tabular}

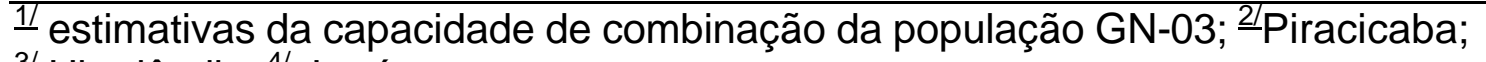
3/ Uberlândia; $\stackrel{4}{\text { J Jataí. }}$ 
Tabela 20. Estimativas da capacidade geral de combinação da população GN-04 para o caráter peso de espigas (t/ha) em três locais para o $\mathrm{DPCl}(\mathrm{A})$ e suas respectivas posições em ordem decrescente.

\begin{tabular}{|c|c|c|c|c|c|c|}
\hline \multirow[b]{2}{*}{ GENITOR } & \multicolumn{3}{|c|}{$C G C-2^{1 /}$} & \multicolumn{3}{|c|}{ Classificação } \\
\hline & Local 1 니 & Local $2^{3 /}$ & Local 3 $\frac{4 !}{}$ & Local 1 & Local 2 & Local 3 \\
\hline 8 & 1,11 & $-0,16$ & $-0,22$ & 1 & 34 & 40 \\
\hline 23 & 1,10 & 0,32 & $-0,15$ & 2 & 10 & 36 \\
\hline $21^{\prime}$ & 1,09 & 0,42 & $-0,04$ & 3 & 5 & 29 \\
\hline $10^{`}$ & 0,88 & 0,16 & $-0,01$ & 4 & 16 & 27 \\
\hline 7 & 0,87 & 0,06 & 0,10 & 5 & 21 & 20 \\
\hline $18^{\prime}$ & 0,87 & $-0,16$ & 0,11 & 6 & 33 & 18 \\
\hline 22 & 0,82 & $-0,15$ & $-0,14$ & 7 & 31 & 33 \\
\hline 20 & 0,75 & $-0,43$ & 0,07 & 8 & 45 & 21 \\
\hline 14 & 0,71 & $-0,01$ & $-0,15$ & 9 & 26 & 34 \\
\hline $29^{\circ}$ & 0,50 & 0,28 & $-0,30$ & 10 & 11 & 42 \\
\hline 34 & 0,44 & 0,49 & 0,20 & 11 & 3 & 16 \\
\hline $36^{\prime}$ & 0,32 & 1,29 & 0,47 & 12 & 1 & 4 \\
\hline $19^{\prime}$ & 0,25 & $-0,07$ & $-0,33$ & 13 & 27 & 45 \\
\hline 3 & 0,22 & $-0,46$ & 0,20 & 14 & 46 & 15 \\
\hline $38^{\prime}$ & 0,22 & 0,32 & 0,30 & 15 & 8 & 10 \\
\hline $40^{\circ}$ & 0,21 & 0,34 & $-0,01$ & 16 & 7 & 26 \\
\hline $24^{\prime}$ & 0,16 & 0,25 & 0,22 & 17 & 12 & 14 \\
\hline 12 & 0,09 & 0,10 & $-0,88$ & 18 & 19 & 50 \\
\hline $2^{\prime}$ & 0,09 & $-0,24$ & 0,54 & 19 & 38 & 2 \\
\hline $6^{\prime}$ & 0,06 & $-0,43$ & $-0,13$ & 20 & 43 & 31 \\
\hline $43^{\prime}$ & 0,06 & 0,32 & $-0,31$ & 21 & 9 & 43 \\
\hline $32^{\prime}$ & 0,06 & 0,07 & 0,38 & 22 & 20 & 8 \\
\hline $45^{\prime}$ & $-0,03$ & $-0,07$ & 0,51 & 23 & 28 & 3 \\
\hline 1 & $-0,04$ & $-0,41$ & $-0,13$ & 24 & 42 & 30 \\
\hline $11^{\prime}$ & $-0,06$ & $-0,43$ & 0,28 & 25 & 44 & 11 \\
\hline $39^{\circ}$ & $-0,06$ & 0,19 & 0,13 & 26 & 14 & 17 \\
\hline $15^{`}$ & $-0,07$ & 0,36 & $-0,35$ & 27 & 6 & 46 \\
\hline $37^{\prime}$ & $-0,08$ & 0,91 & $-0,16$ & 28 & 2 & 37 \\
\hline $13^{\prime}$ & $-0,13$ & $-0,20$ & $-0,70$ & 29 & 36 & 49 \\
\hline $16^{`}$ & $-0,13$ & $-0,17$ & $-0,65$ & 30 & 35 & 48 \\
\hline
\end{tabular}


Tabela 20. Estimativas da capacidade geral de combinação da população GN-04 para o caráter peso de espigas (t/ha) em três locais para o $\mathrm{DPCl}(\mathrm{A})$ e suas respectivas posições em ordem decrescente.

\begin{tabular}{|c|c|c|c|c|c|c|}
\hline \multirow{2}{*}{ GENITOR } & \multicolumn{3}{|c|}{$C G C-2^{1 /}$} & \multicolumn{3}{|c|}{ Classificação } \\
\hline & Local 1 $1 \underline{21}$ & Local $2^{3 /}$ & Local 34 & Local 1 & Local 2 & Local 3 \\
\hline $26^{\prime}$ & $-0,13$ & $-0,29$ & $-0,19$ & 31 & 39 & 39 \\
\hline $17^{\prime}$ & $-0,13$ & 0,00 & $-0,57$ & 32 & 24 & 47 \\
\hline $44^{`}$ & $-0,27$ & $-0,72$ & $-0,33$ & 33 & 50 & 44 \\
\hline $31^{\prime}$ & $-0,31$ & $-0,08$ & 0,04 & 34 & 29 & 24 \\
\hline $27^{\prime}$ & $-0,31$ & 0,12 & $-0,01$ & 35 & 17 & 25 \\
\hline $33^{\circ}$ & $-0,31$ & 0,16 & 0,10 & 36 & 15 & 19 \\
\hline $28^{\prime}$ & $-0,40$ & 0,12 & $-0,17$ & 37 & 18 & 38 \\
\hline $41^{\circ}$ & $-0,40$ & $-0,09$ & 0,23 & 38 & 30 & 13 \\
\hline $25^{`}$ & $-0,41$ & $-0,15$ & $-0,28$ & 39 & 32 & 41 \\
\hline $30^{\circ}$ & $-0,43$ & $-0,22$ & 0,23 & 40 & 37 & 12 \\
\hline 42 & $-0,46$ & 0,05 & 0,39 & 41 & 23 & 7 \\
\hline $9^{\prime}$ & $-0,48$ & 0,00 & 0,81 & 42 & 25 & 1 \\
\hline 5 & $-0,50$ & 0,06 & $-0,13$ & 43 & 22 & 32 \\
\hline 4 & $-0,59$ & $-0,55$ & 0,40 & 44 & 49 & 6 \\
\hline $47^{\circ}$ & $-0,63$ & 0,25 & 0,31 & 45 & 13 & 9 \\
\hline $50^{`}$ & $-0,73$ & $-0,48$ & $-0,02$ & 46 & 47 & 28 \\
\hline $49^{\circ}$ & $-0,81$ & $-0,35$ & 0,40 & 47 & 41 & 5 \\
\hline $48^{\circ}$ & $-0,92$ & $-0,29$ & 0,05 & 48 & 40 & 22 \\
\hline $35^{`}$ & $-0,99$ & 0,46 & $-0,15$ & 49 & 4 & 35 \\
\hline $46^{\prime}$ & $-1,11$ & $-0,50$ & 0,05 & 50 & 48 & 23 \\
\hline
\end{tabular}

프 estimativas da capacidade de combinação da população GN-04; ${ }^{2 /}$ Piracicaba;

3/ Uberlândia; ${ }^{4 /}$ Jataí. 
Tabela 21. Estimativas da capacidade geral de combinação da população GN-03 para o caráter peso de espigas em três locais para o DPCl (B) e suas respectivas posições em ordem decrescente.

\begin{tabular}{|c|c|c|c|c|}
\hline \multirow{2}{*}{ GENITOR } & \multicolumn{2}{|c|}{$C G C-1 \frac{1 /}{1}$} & \multicolumn{2}{|c|}{ Classificação } \\
\hline & 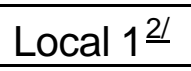 & Local 2 $\frac{3 /}{2}$ & Local 1 & Local 2 \\
\hline 70 & 1,21 & 0,90 & 1 & 4 \\
\hline 75 & 1,17 & 1,22 & 2 & 2 \\
\hline 64 & 1,06 & 0,45 & 3 & 11 \\
\hline 65 & 0,95 & 1,31 & 4 & 1 \\
\hline 73 & 0,93 & 0,22 & 5 & 15 \\
\hline 62 & 0,77 & $-0,25$ & 6 & 35 \\
\hline 63 & 0,70 & 0,33 & 7 & 12 \\
\hline 67 & 0,66 & 0,03 & 8 & 21 \\
\hline 66 & 0,63 & 0,97 & 9 & 3 \\
\hline 61 & 0,62 & $-0,08$ & 10 & 26 \\
\hline 98 & 0,61 & $-0,58$ & 11 & 44 \\
\hline 68 & 0,59 & 0,50 & 12 & 10 \\
\hline 77 & 0,42 & 0,50 & 13 & 8 \\
\hline 86 & 0,38 & $-0,44$ & 14 & 41 \\
\hline 74 & 0,38 & $-0,16$ & 15 & 30 \\
\hline 95 & 0,32 & 0,24 & 16 & 14 \\
\hline 79 & 0,26 & 0,25 & 17 & 13 \\
\hline 71 & 0,25 & $-0,05$ & 18 & 25 \\
\hline 82 & 0,25 & 0,50 & 19 & 9 \\
\hline 60 & 0,18 & $-0,11$ & 20 & 27 \\
\hline 57 & 0,13 & $-0,30$ & 21 & 37 \\
\hline 58 & 0,13 & $-0,48$ & 22 & 42 \\
\hline 53 & 0,12 & $-0,70$ & 23 & 48 \\
\hline 59 & 0,07 & $-1,06$ & 24 & 50 \\
\hline 80 & $-0,01$ & 0,17 & 25 & 17 \\
\hline 56 & $-0,03$ & $-0,86$ & 26 & 49 \\
\hline 78 & $-0,03$ & $-0,23$ & 27 & 34 \\
\hline 81 & $-0,15$ & 0,16 & 28 & 18 \\
\hline 69 & $-0,16$ & 0,12 & 29 & 19 \\
\hline 83 & $-0,18$ & 0,21 & 30 & 16 \\
\hline
\end{tabular}


Tabela 21. Estimativas da capacidade geral de combinação da população GN-03 para o caráter peso de espigas em três locais para o DPCl (B) e suas respectivas posições em ordem decrescente.

\begin{tabular}{|c|c|c|c|c|}
\hline \multirow{2}{*}{ GENITOR } & \multicolumn{2}{|c|}{$\mathrm{CGC}-1^{1 /}$} & \multicolumn{2}{|c|}{ Classificação } \\
\hline & Local 1 $\underline{2 !}$ & Local $2^{3 /}$ & Local 1 & Local 2 \\
\hline 72 & $-0,22$ & $-0,05$ & 31 & 24 \\
\hline 99 & $-0,23$ & $-0,39$ & 32 & 40 \\
\hline 89 & $-0,25$ & $-0,16$ & 33 & 31 \\
\hline 100 & $-0,34$ & 0,04 & 34 & 20 \\
\hline 55 & $-0,36$ & $-0,19$ & 35 & 32 \\
\hline 52 & $-0,39$ & $-0,68$ & 36 & 47 \\
\hline 76 & $-0,41$ & $-0,13$ & 37 & 29 \\
\hline 85 & $-0,42$ & 0,73 & 38 & 5 \\
\hline 87 & $-0,43$ & $-0,11$ & 39 & 28 \\
\hline 51 & $-0,51$ & $-0,56$ & 40 & 43 \\
\hline 90 & $-0,54$ & 0,57 & 41 & 7 \\
\hline 96 & $-0,68$ & $-0,25$ & 42 & 36 \\
\hline 92 & $-0,70$ & $-0,22$ & 43 & 33 \\
\hline 93 & $-0,77$ & $-0,30$ & 44 & 38 \\
\hline 94 & $-0,83$ & $-0,01$ & 45 & 22 \\
\hline 84 & $-0,84$ & $-0,04$ & 46 & 23 \\
\hline 91 & $-0,86$ & $-0,64$ & 47 & 45 \\
\hline 54 & $-0,93$ & $-0,67$ & 48 & 46 \\
\hline 97 & $-0,99$ & $-0,36$ & 49 & 39 \\
\hline 88 & $-1,52$ & 0,67 & 50 & 6 \\
\hline
\end{tabular}


Tabela 22. Estimativas da capacidade geral de combinação da população GN-04 para o caráter peso de espigas (t/ha) em três locais para o DPCI (B) e suas respectivas posições em ordem decrescente .

\begin{tabular}{|c|c|c|c|c|}
\hline \multirow[b]{2}{*}{ GENITOR } & \multicolumn{2}{|c|}{$C G C-2^{1 /}$} & \multicolumn{2}{|c|}{ Classificação } \\
\hline & Local $1^{2 !}$ & Local $2^{\underline{3}}$ & Local 1 & Local 2 \\
\hline 94 & 1,51 & 0,33 & 1 & 16 \\
\hline 52 & 1,28 & 0,64 & 2 & 9 \\
\hline $96^{`}$ & 1,07 & 0,72 & 3 & 5 \\
\hline $95^{`}$ & 0,97 & 0,08 & 4 & 23 \\
\hline $58^{\prime}$ & 0,91 & 0,93 & 5 & 1 \\
\hline $85^{`}$ & 0,78 & $-0,16$ & 6 & 28 \\
\hline $54^{`}$ & 0,73 & 0,72 & 7 & 6 \\
\hline $93^{\prime}$ & 0,72 & $-0,12$ & 8 & 26 \\
\hline $51^{\prime}$ & 0,69 & 0,45 & 9 & 12 \\
\hline $97^{\circ}$ & 0,68 & 0,03 & 10 & 25 \\
\hline $56^{\prime}$ & 0,62 & 0,73 & 11 & 4 \\
\hline $60^{\prime}$ & 0,62 & 0,27 & 12 & 18 \\
\hline $98^{\prime}$ & 0,54 & 0,50 & 13 & 11 \\
\hline $89^{\circ}$ & 0,54 & $-0,23$ & 14 & 31 \\
\hline $53^{\prime}$ & 0,47 & 0,74 & 15 & 3 \\
\hline 92 & 0,39 & 0,53 & 16 & 10 \\
\hline $91^{\prime}$ & 0,38 & $-0,24$ & 17 & 32 \\
\hline $64^{\circ}$ & 0,28 & 0,36 & 18 & 14 \\
\hline $88^{\prime}$ & 0,26 & $-0,32$ & 19 & 36 \\
\hline $59^{\prime}$ & 0,24 & 0,68 & 20 & 7 \\
\hline $77^{`}$ & 0,21 & 0,10 & 21 & 22 \\
\hline 82 & 0,15 & $-0,44$ & 22 & 40 \\
\hline $87^{\circ}$ & 0,12 & 0,36 & 23 & 15 \\
\hline $73^{\prime}$ & 0,11 & 0,13 & 24 & 21 \\
\hline $83^{`}$ & 0,06 & 0,17 & 25 & 20 \\
\hline $79^{\circ}$ & $-0,08$ & $-0,30$ & 26 & 33 \\
\hline $57^{\prime}$ & $-0,08$ & 0,67 & 27 & 8 \\
\hline $81^{\prime}$ & $-0,10$ & $-0,31$ & 28 & 35 \\
\hline $84^{\circ}$ & $-0,10$ & $-0,16$ & 29 & 27 \\
\hline $90^{`}$ & $-0,11$ & $-0,39$ & 30 & 37 \\
\hline
\end{tabular}


Tabela 22. Estimativas da capacidade geral de combinação da população GN-04 para o caráter peso de espigas (t/ha) em três locais para o $\mathrm{DPCl}(\mathrm{B})$ e suas respectivas posições em ordem decrescente.

\begin{tabular}{|c|c|c|c|c|}
\hline \multirow{2}{*}{ GENITOR } & \multicolumn{2}{|c|}{$C G C-2^{1 /}$} & \multicolumn{2}{|c|}{ Classificação } \\
\hline & Local $1 \underline{2}$ & Local $2^{3 /}$ & Local 1 & Local 2 \\
\hline $71^{\circ}$ & $-0,16$ & $-0,59$ & 31 & 43 \\
\hline $80^{`}$ & $-0,17$ & $-0,76$ & 32 & 48 \\
\hline $65^{`}$ & $-0,36$ & 0,38 & 33 & 13 \\
\hline $74^{\prime}$ & $-0,39$ & $-0,71$ & 34 & 45 \\
\hline $86^{`}$ & $-0,44$ & $-0,18$ & 35 & 30 \\
\hline $78^{\prime}$ & $-0,46$ & 0,04 & 36 & 24 \\
\hline $61^{\circ}$ & $-0,48$ & 0,21 & 37 & 19 \\
\hline $62^{\prime}$ & $-0,49$ & $-0,40$ & 38 & 38 \\
\hline $100^{\circ}$ & $-0,52$ & $-0,52$ & 39 & 42 \\
\hline 72 & $-0,58$ & $-0,45$ & 40 & 41 \\
\hline $76^{`}$ & $-0,63$ & 0,32 & 41 & 17 \\
\hline $55^{\circ}$ & $-0,68$ & 0,79 & 42 & 2 \\
\hline $67^{`}$ & $-0,78$ & $-0,31$ & 43 & 34 \\
\hline $75^{\circ}$ & $-0,81$ & $-0,75$ & 44 & 47 \\
\hline $66^{\prime}$ & $-0,87$ & $-0,72$ & 45 & 46 \\
\hline $70^{`}$ & $-0,93$ & $-0,77$ & 46 & 49 \\
\hline $63^{`}$ & $-1,02$ & $-0,16$ & 47 & 29 \\
\hline $69^{\circ}$ & $-1,06$ & $-0,42$ & 48 & 39 \\
\hline $99^{\circ}$ & $-1,31$ & $-0,70$ & 49 & 44 \\
\hline $68^{\circ}$ & $-1,71$ & $-0,78$ & 50 & 50 \\
\hline
\end{tabular}


Tabela 23. Estimativas da capacidade geral de combinação da população GN-03 para o caráter altura de planta $(\mathrm{cm})$ em dois locais para 0 $\mathrm{DPCl}(\mathrm{A})$ e suas respectivas posições em ordem decrescente.

\begin{tabular}{|c|c|c|c|c|}
\hline \multirow[b]{2}{*}{ GENITOR } & \multicolumn{2}{|c|}{$\mathrm{CGC}-1 \frac{1 /}{1}$} & \multicolumn{2}{|c|}{ Classificação } \\
\hline & Local $1 \stackrel{21}{ }$ & Local $2^{\frac{33}{1}}$ & Local 1 & Local 2 \\
\hline 32 & 15,10 & 5,04 & 1 & 9 \\
\hline 2 & 14,04 & 6,26 & 2 & 4 \\
\hline 15 & 12,71 & 7,74 & 3 & 3 \\
\hline 46 & 11,36 & $-0,88$ & 4 & 32 \\
\hline 45 & 11,20 & $-0,33$ & 5 & 29 \\
\hline 49 & 10,99 & 3,32 & 6 & 13 \\
\hline 31 & 10,98 & $-0,96$ & 7 & 33 \\
\hline 37 & 8,98 & $-0,34$ & 8 & 30 \\
\hline 1 & 8,66 & 1,81 & 9 & 21 \\
\hline 36 & 6,20 & 0,29 & 10 & 26 \\
\hline 10 & 5,69 & 11,33 & 11 & 1 \\
\hline 23 & 5,17 & 5,33 & 12 & 6 \\
\hline 5 & 4,74 & 5,82 & 13 & 5 \\
\hline 22 & 4,62 & 0,10 & 14 & 27 \\
\hline 21 & 4,49 & 2,43 & 15 & 15 \\
\hline 3 & 3,96 & 4,19 & 16 & 10 \\
\hline 16 & 3,67 & 2,18 & 17 & 18 \\
\hline 13 & 3,62 & 5,28 & 18 & 7 \\
\hline 17 & 3,11 & $-3,47$ & 19 & 42 \\
\hline 9 & 1,79 & $-0,07$ & 20 & 28 \\
\hline 40 & 0,83 & $-4,99$ & 21 & 43 \\
\hline 18 & 0,82 & 0,80 & 22 & 25 \\
\hline 26 & 0,35 & 1,49 & 23 & 23 \\
\hline 34 & 0,34 & $-1,18$ & 24 & 35 \\
\hline 47 & 0,03 & $-0,62$ & 25 & 31 \\
\hline 35 & $-0,61$ & 1,95 & 26 & 19 \\
\hline 24 & $-1,36$ & 8,39 & 27 & 2 \\
\hline 48 & $-1,70$ & $-1,95$ & 28 & 40 \\
\hline 27 & $-1,92$ & $-0,98$ & 29 & 34 \\
\hline 39 & $-2,54$ & $-6,08$ & 30 & 44 \\
\hline 30 & $-2,70$ & 1,71 & 31 & 22 \\
\hline
\end{tabular}


Tabela 23. Estimativas da capacidade geral de combinação da população GN03 para o caráter altura de planta $(\mathrm{cm})$ em dois locais para o DPCI (A) e suas respectivas posições em ordem decrescente.

\begin{tabular}{|c|c|c|c|c|}
\hline \multirow{2}{*}{ GENITOR } & \multicolumn{2}{|c|}{$C G C-1 \frac{1}{\prime}$} & \multicolumn{2}{|c|}{ Classificação } \\
\hline & 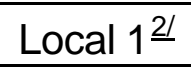 & Local $2^{3 /}$ & Local 1 & Local 2 \\
\hline 7 & $-2,86$ & 2,34 & 32 & 16 \\
\hline 44 & $-2,86$ & 5,13 & 33 & 8 \\
\hline 50 & $-3,12$ & 1,44 & 34 & 24 \\
\hline 41 & $-3,70$ & $-1,88$ & 35 & 37 \\
\hline 33 & $-3,70$ & 3,01 & 36 & 14 \\
\hline 19 & $-4,54$ & 1,87 & 37 & 20 \\
\hline 29 & $-4,77$ & 2,33 & 38 & 17 \\
\hline 25 & $-4,85$ & 3,33 & 39 & 12 \\
\hline 20 & $-5,88$ & 3,82 & 40 & 11 \\
\hline 43 & $-6,21$ & $-1,69$ & 41 & 36 \\
\hline 11 & $-6,37$ & $-8,97$ & 42 & 46 \\
\hline 6 & $-6,52$ & $-10,39$ & 43 & 47 \\
\hline 14 & $-6,80$ & $-2,75$ & 44 & 41 \\
\hline 42 & $-7,26$ & $-1,92$ & 45 & 39 \\
\hline 38 & $-9,71$ & $-10,90$ & 46 & 48 \\
\hline 8 & $-14,26$ & $-7,36$ & 47 & 45 \\
\hline 4 & $-15,01$ & $-13,65$ & 48 & 49 \\
\hline 12 & $-16,83$ & $-15,46$ & 49 & 50 \\
\hline 28 & $-17,37$ & $-1,89$ & 50 & 38 \\
\hline
\end{tabular}


Tabela 24. Estimativas da capacidade geral de combinação da população GN-04 para o caráter altura de planta $(\mathrm{cm})$ em dois locais para 0 $\mathrm{DPCl}(\mathrm{A})$ e suas respectivas posições em ordem decrescente.

\begin{tabular}{|c|c|c|c|c|}
\hline \multirow[b]{2}{*}{ GENITOR } & \multicolumn{2}{|c|}{$C G C-2^{1 /}$} & \multicolumn{2}{|c|}{ Classificação } \\
\hline & Local $1^{2} \underline{1}$ & Local $2^{\underline{3 !}}$ & Local 1 & Local 2 \\
\hline 8 & 13,90 & 7,00 & 1 & 8 \\
\hline $40^{\circ}$ & 11,30 & 8,43 & 2 & 4 \\
\hline $50^{`}$ & 10,48 & 8,51 & 3 & 3 \\
\hline $26^{\prime}$ & 10,46 & 2,98 & 4 & 17 \\
\hline 14 & 9,16 & 8,68 & 5 & 2 \\
\hline 12 & 8,41 & 8,21 & 6 & 5 \\
\hline 1 & 8,03 & 2,44 & 7 & 20 \\
\hline $45^{`}$ & 7,71 & 1,85 & 8 & 22 \\
\hline $24^{\circ}$ & 7,22 & $-4,66$ & 9 & 41 \\
\hline $33^{\prime}$ & 7,11 & $-1,91$ & 10 & 33 \\
\hline $18^{\prime}$ & 7,02 & 4,43 & 11 & 13 \\
\hline $21^{\prime}$ & 6,50 & 0,01 & 12 & 26 \\
\hline $43^{\prime}$ & 6,39 & 9,30 & 13 & 1 \\
\hline $37^{\circ}$ & 6,21 & 5,93 & 14 & 12 \\
\hline $29^{\circ}$ & 5,82 & 7,03 & 15 & 7 \\
\hline $10^{\circ}$ & 5,40 & 2,58 & 16 & 19 \\
\hline $6^{\prime}$ & 4,37 & $-0,74$ & 17 & 27 \\
\hline 7 & 3,74 & 2,40 & 18 & 21 \\
\hline 5 & 2,99 & 6,90 & 19 & 9 \\
\hline 22 & 2,87 & $-2,60$ & 20 & 35 \\
\hline 28 & 0,89 & $-1,69$ & 21 & 31 \\
\hline 2 & 0,73 & 2,92 & 22 & 18 \\
\hline $19^{\circ}$ & 0,69 & $-2,57$ & 23 & 34 \\
\hline $30^{\circ}$ & 0,64 & $-7,37$ & 24 & 44 \\
\hline 3 & 0,11 & 3,85 & 25 & 14 \\
\hline $47^{\circ}$ & 0,10 & 6,56 & 26 & 10 \\
\hline $39^{\circ}$ & $-0,06$ & 7,07 & 27 & 6 \\
\hline $34^{\circ}$ & $-0,07$ & $-2,70$ & 28 & 36 \\
\hline $27^{\circ}$ & $-0,27$ & $-3,36$ & 29 & 38 \\
\hline $15^{\circ}$ & $-0,44$ & 0,21 & 30 & 24 \\
\hline $41^{\circ}$ & $-0,74$ & 6,07 & 31 & 11 \\
\hline
\end{tabular}


Tabela 24. Estimativas da capacidade geral de combinação da população GN-04 para o caráter altura de planta $(\mathrm{cm})$ em dois locais para 0 DPCI (A) e suas respectivas posições em ordem decrescente.

\begin{tabular}{|c|c|c|c|c|}
\hline \multirow{2}{*}{ GENITOR } & \multicolumn{2}{|c|}{$C G C-2^{1 /}$} & \multicolumn{2}{|c|}{ Classificação } \\
\hline & Local 1리 & Local 2 $\frac{3 /}{1}$ & Local 1 & Local 2 \\
\hline 32 & $-0,97$ & $-0,91$ & 32 & 29 \\
\hline $31^{\prime}$ & $-1,06$ & $-1,71$ & 33 & 32 \\
\hline $13^{\prime}$ & $-2,52$ & $-8,69$ & 34 & 46 \\
\hline $17^{\prime}$ & $-3,35$ & 0,13 & 35 & 25 \\
\hline $11^{\prime}$ & $-3,46$ & $-2,84$ & 36 & 37 \\
\hline $38^{\prime}$ & $-3,48$ & $-5,06$ & 37 & 42 \\
\hline $36^{\prime}$ & $-4,13$ & 3,01 & 38 & 16 \\
\hline 42 & $-4,83$ & 3,11 & 39 & 15 \\
\hline $46^{\prime}$ & $-4,87$ & $-7,89$ & 40 & 45 \\
\hline $35^{\circ}$ & $-7,26$ & 1,77 & 41 & 23 \\
\hline $9^{\prime}$ & $-8,07$ & $-0,79$ & 42 & 28 \\
\hline $44^{\circ}$ & $-8,52$ & $-12,63$ & 43 & 49 \\
\hline 25 & $-8,58$ & $-3,95$ & 44 & 40 \\
\hline $48^{`}$ & $-8,72$ & $-11,66$ & 45 & 48 \\
\hline $16^{`}$ & $-10,21$ & $-0,99$ & 46 & 30 \\
\hline 23 & $-12,92$ & $-3,73$ & 47 & 39 \\
\hline $20{ }^{`}$ & $-13,93$ & $-18,01$ & 48 & 50 \\
\hline $49^{\circ}$ & $-16,36$ & $-5,33$ & 49 & 43 \\
\hline 4 & $-23,42$ & $-9,58$ & 50 & 47 \\
\hline
\end{tabular}


Tabela 25. Estimativas da capacidade geral de combinação da população GN-03 para o caráter altura de planta $(\mathrm{cm})$ em dois locais para 0 $\mathrm{DPCl}(\mathrm{B})$ e suas respectivas posições em ordem decrescente.

\begin{tabular}{|c|c|c|c|c|}
\hline \multirow[b]{2}{*}{ GENITOR } & \multicolumn{2}{|c|}{ CGC $-1 \frac{1 /}{1}$} & \multicolumn{2}{|c|}{ Classificação } \\
\hline & Local 1 $1 \stackrel{21}{ }$ & Local $2^{2 / 3}$ & Local 1 & Local 2 \\
\hline 64 & 16,37 & $-1,46$ & 1 & 32 \\
\hline 73 & 14,87 & 10,17 & 2 & 6 \\
\hline 55 & 14,44 & 6,50 & 3 & 14 \\
\hline 60 & 12,72 & 3,63 & 4 & 20 \\
\hline 63 & 11,98 & 4,67 & 5 & 18 \\
\hline 78 & 10,97 & 6,59 & 6 & 13 \\
\hline 68 & 10,59 & 8,18 & 7 & 11 \\
\hline 81 & 9,99 & 4,88 & 8 & 17 \\
\hline 75 & 9,93 & 10,82 & 9 & 3 \\
\hline 82 & 9,42 & 10,14 & 10 & 7 \\
\hline 62 & 7,12 & $-5,63$ & 11 & 38 \\
\hline 58 & 5,88 & $-4,75$ & 12 & 36 \\
\hline 74 & 5,40 & 8,29 & 13 & 10 \\
\hline 84 & 5,18 & $-0,82$ & 14 & 28 \\
\hline 57 & 5,15 & $-0,38$ & 15 & 26 \\
\hline 86 & 4,86 & $-0,44$ & 16 & 27 \\
\hline 67 & 4,81 & 1,90 & 17 & 25 \\
\hline 77 & 4,69 & 10,28 & 18 & 4 \\
\hline 70 & 4,21 & 11,40 & 19 & 2 \\
\hline 85 & 4,01 & 12,05 & 20 & 1 \\
\hline 99 & 3,28 & $-13,07$ & 21 & 46 \\
\hline 95 & 2,48 & 3,24 & 22 & 21 \\
\hline 79 & 0,86 & 8,74 & 23 & 8 \\
\hline 65 & 0,69 & 10,22 & 24 & 5 \\
\hline 76 & 0,41 & 8,30 & 25 & 9 \\
\hline 59 & 0,14 & $-13,96$ & 26 & 47 \\
\hline 72 & $-0,12$ & 2,28 & 27 & 24 \\
\hline 100 & $-0,58$ & $-0,87$ & 28 & 29 \\
\hline 69 & $-0,65$ & 2,89 & 29 & 22 \\
\hline 98 & $-1,66$ & $-8,36$ & 30 & 41 \\
\hline 80 & $-1,66$ & 4,50 & 31 & 19 \\
\hline
\end{tabular}


Tabela 25. Estimativas da capacidade geral de combinação da população GN-03 para o caráter altura de planta $(\mathrm{cm})$ em dois locais para o DPCI (B) e suas respectivas posições em ordem decrescente.

\begin{tabular}{|c|c|c|c|c|}
\hline \multirow{2}{*}{ GENITOR } & \multicolumn{2}{|c|}{$\mathrm{CGC}-1^{1 /}$} & \multicolumn{2}{|c|}{ Classificação } \\
\hline & Local 1 $2 /$ & Local 2 $\frac{3 /}{1}$ & Local 1 & Local 2 \\
\hline 66 & $-1,73$ & 7,03 & 32 & 12 \\
\hline 61 & $-3,29$ & 2,79 & 33 & 23 \\
\hline 83 & $-3,45$ & 5,56 & 34 & 15 \\
\hline 88 & $-4,30$ & $-1,19$ & 35 & 30 \\
\hline 97 & $-4,77$ & $-6,75$ & 36 & 39 \\
\hline 51 & $-5,48$ & $-8,83$ & 37 & 42 \\
\hline 53 & $-6,54$ & $-10,44$ & 38 & 43 \\
\hline 87 & $-7,93$ & $-4,11$ & 39 & 34 \\
\hline 56 & $-8,33$ & $-10,76$ & 40 & 44 \\
\hline 91 & $-8,42$ & 5,22 & 41 & 16 \\
\hline 93 & $-8,75$ & $-4,93$ & 42 & 37 \\
\hline 90 & $-9,52$ & $-2,12$ & 43 & 33 \\
\hline 71 & $-9,61$ & $-1,42$ & 44 & 31 \\
\hline 52 & $-13,21$ & $-15,32$ & 45 & 49 \\
\hline 89 & $-14,33$ & $-7,92$ & 46 & 40 \\
\hline 54 & $-14,47$ & $-15,63$ & 47 & 50 \\
\hline 94 & $-16,04$ & $-14,48$ & 48 & 48 \\
\hline 92 & $-17,17$ & $-4,70$ & 49 & 35 \\
\hline 96 & $-18,42$ & $-11,92$ & 50 & 45 \\
\hline
\end{tabular}


Tabela 26. Estimativas da capacidade geral de combinação da população GN-04 para o caráter altura de planta $(\mathrm{cm})$ em dois locais para 0 DPCI (B) e suas respectivas posições em ordem decrescente.

\begin{tabular}{|c|c|c|c|c|}
\hline \multirow[b]{2}{*}{ GENITOR } & \multicolumn{2}{|c|}{$C G C-2^{1 /}$} & \multicolumn{2}{|c|}{ Classificação } \\
\hline & Local $1^{2 !}$ & Local $2^{3 /}$ & Local 1 & Local 2 \\
\hline $95^{\prime}$ & 20,76 & 5,17 & 1 & 16 \\
\hline $94^{\circ}$ & 17,57 & 4,57 & 2 & 18 \\
\hline $97^{\circ}$ & 17,17 & 10,51 & 3 & 7 \\
\hline $93^{`}$ & 13,67 & 0,09 & 4 & 24 \\
\hline $92^{\prime}$ & 12,36 & 8,41 & 5 & 11 \\
\hline $71^{\circ}$ & 12,29 & $-1,97$ & 6 & 29 \\
\hline $61^{\circ}$ & 12,20 & 15,94 & 7 & 1 \\
\hline $98^{\circ}$ & 10,20 & 11,14 & 8 & 4 \\
\hline $96^{\circ}$ & 9,34 & 11,07 & 9 & 5 \\
\hline $53^{\prime}$ & 8,54 & 12,52 & 10 & 2 \\
\hline $88^{\circ}$ & 7,30 & 7,19 & 11 & 13 \\
\hline $79^{\circ}$ & 6,36 & 1,57 & 12 & 21 \\
\hline $59^{\circ}$ & 6,13 & 10,30 & 13 & 8 \\
\hline $77^{\circ}$ & 4,35 & $-4,83$ & 14 & 35 \\
\hline 52 & 4,35 & 11,90 & 15 & 3 \\
\hline $51^{\prime}$ & 3,84 & 10,94 & 16 & 6 \\
\hline $60^{\circ}$ & 3,81 & 5,07 & 17 & 17 \\
\hline $58^{\circ}$ & 3,67 & 4,28 & 18 & 19 \\
\hline $85^{`}$ & 2,83 & $-1,66$ & 19 & 27 \\
\hline $57^{\circ}$ & 0,87 & 8,25 & 20 & 12 \\
\hline $54^{\circ}$ & 0,62 & 6,87 & 21 & 15 \\
\hline $73^{`}$ & 0,24 & 0,00 & 22 & 25 \\
\hline $69^{\circ}$ & 0,11 & $-5,78$ & 23 & 38 \\
\hline $91^{\circ}$ & 0,01 & $-3,00$ & 24 & 32 \\
\hline $55^{\circ}$ & $-0,27$ & 7,12 & 25 & 14 \\
\hline $83^{\prime}$ & $-0,67$ & $-1,68$ & 26 & 28 \\
\hline $66^{\circ}$ & $-1,44$ & $-0,57$ & 27 & 26 \\
\hline $56^{\prime}$ & $-1,91$ & 8,44 & 28 & 9 \\
\hline $64^{\circ}$ & $-2,75$ & 8,42 & 29 & 10 \\
\hline $87^{\circ}$ & $-3,04$ & $-2,82$ & 30 & 31 \\
\hline $99^{\circ}$ & $-3,13$ & 1,24 & 31 & 22 \\
\hline
\end{tabular}


Tabela 26. Estimativas da capacidade geral de combinação da população GN-04 para o caráter altura de planta $(\mathrm{cm})$ em dois locais para 0 $\mathrm{DPCl}(\mathrm{B})$ e suas respectivas posições em ordem decrescente.

\begin{tabular}{|c|c|c|c|c|}
\hline \multirow{2}{*}{ GENITOR } & \multicolumn{2}{|c|}{$\mathrm{CGC}-2^{1 /}$} & \multicolumn{2}{|c|}{ Classificação } \\
\hline & Local 1 $2 /$ & Local 2 $\frac{3 /}{1}$ & Local 1 & Local 2 \\
\hline $90^{\circ}$ & $-3,14$ & $-7,76$ & 32 & 39 \\
\hline 72 & $-3,35$ & $-4,09$ & 33 & 34 \\
\hline $65^{\circ}$ & $-3,57$ & 3,94 & 34 & 20 \\
\hline 62 & $-3,96$ & 0,14 & 35 & 23 \\
\hline $86^{\prime}$ & $-4,37$ & $-2,32$ & 36 & 30 \\
\hline $84^{\circ}$ & $-4,59$ & $-5,39$ & 37 & 36 \\
\hline $89^{\circ}$ & $-6,08$ & $-4,06$ & 38 & 33 \\
\hline $68^{`}$ & $-6,76$ & $-8,32$ & 39 & 40 \\
\hline $100^{\circ}$ & $-7,57$ & $-5,46$ & 40 & 37 \\
\hline $76^{\prime}$ & $-8,25$ & $-8,72$ & 41 & 41 \\
\hline $80^{\circ}$ & $-8,48$ & $-12,69$ & 42 & 47 \\
\hline $70^{\circ}$ & $-8,66$ & $-10,13$ & 43 & 44 \\
\hline $81^{\circ}$ & $-9,08$ & $-12,93$ & 44 & 49 \\
\hline $75^{`}$ & $-10,21$ & $-9,29$ & 45 & 43 \\
\hline $78^{\prime}$ & $-11,27$ & $-11,79$ & 46 & 46 \\
\hline $74^{\circ}$ & $-12,01$ & $-12,91$ & 47 & 48 \\
\hline 82 & $-15,25$ & $-16,96$ & 48 & 50 \\
\hline $67^{\circ}$ & $-17,95$ & $-10,89$ & 49 & 45 \\
\hline $63^{`}$ & $-20,88$ & $-9,06$ & 50 & 42 \\
\hline
\end{tabular}


Tabela 27. Coeficientes de correlação entre os valores observados e preditos pelo modelo reduzido $\left(\hat{Y}_{i j}=\hat{\mu}+\hat{g}_{i}+\hat{g}_{j}\right)$ em três locais para diferentes valores de $s$ e para o caráter peso de espiga (t/ha).

\begin{tabular}{cccc}
\hline $\mathrm{s}^{\underline{1}}$ & Piracicaba-SP & Uberlândia-MG & Jataí-GO \\
\hline & & DPCI $(\mathrm{A})$ & \\
4 & 0,856 & 0,869 & 0,860 \\
5 & 0,752 & 0,800 & 0,780 \\
6 & 0,693 & 0,755 & 0,721 \\
& 0,685 & 0,700 & 0,708 \\
3 & & DPCI (B) & \\
4 & 0,923 & 0,925 & - \\
5 & 0,829 & 0,857 & - \\
6 & 0,789 & 0,796 & - \\
\hline
\end{tabular}

1'número de cruzamentos por parental.

Tabela 28. Coeficientes de correlação entre os valores observados e preditos pelo modelo reduzido $\left(\hat{Y}_{i j}=\hat{\mu}+\hat{g}_{i}+\hat{g}_{j}\right)$ em dois locais para diferentes valores de $\boldsymbol{s}$ e para o caráter altura de planta $(\mathrm{cm})$.

\begin{tabular}{cccc}
\hline $\mathrm{s}^{\underline{1}}$ & Piracicaba & Uberlândia \\
\hline 3 & 0,926 & $\mathrm{DPCl}(\mathrm{A})$ & \\
4 & 0,892 & & 0,891 \\
5 & 0,880 & & 0,844 \\
6 & 0,872 & & 0,780 \\
& & $\mathrm{DPCl}(\mathrm{B})$ & 0,721 \\
3 & 0,945 & & 0,896 \\
4 & 0,896 & & 0,817 \\
5 & 0,861 & 0,756 \\
6 & 0,837 & 0,722 \\
\hline
\end{tabular}

"1'número de cruzamentos por parental. 
Tabela 29. Limite superior (LS) e inferior (LI), e amplitude de variação (A) das estimativas de CGC da população GN-03 para valores de $\boldsymbol{s}$ iguais a $6,5,4$ e 3 obtidas em três locais para a variável peso de espigas (t/ha).

\begin{tabular}{|c|c|c|c|c|c|c|c|c|c|}
\hline \multirow[b]{2}{*}{$\mathrm{s}$} & \multicolumn{3}{|c|}{ LOCAL $1^{1 /}$} & \multicolumn{3}{|c|}{ LOCAL $2^{2 !}$} & \multicolumn{3}{|c|}{ LOCAL $3^{3 !}$} \\
\hline & LS & $\mathrm{LI}$ & A & LS & $\mathrm{LI}$ & $A$ & LS & $\mathrm{LI}$ & $A$ \\
\hline & \multicolumn{3}{|c|}{$\mathrm{DPCl}(\mathrm{A})$} & \multicolumn{3}{|c|}{$\overline{\mathrm{DPCl}}(\mathrm{A})$} & \multicolumn{3}{|c|}{$\mathrm{DPCl}(\mathrm{A})$} \\
\hline 6 & 1,18 & $-1,50$ & 2,68 & 0,75 & $-0,81$ & 1,56 & 0,78 & $-0,75$ & 1,53 \\
\hline 5 & 1,05 & $-1,52$ & 2,57 & 0,99 & $-1,01$ & 2,00 & 0,95 & $-0,91$ & 1,86 \\
\hline 4 & 1,63 & $-2,72$ & 4,35 & 0,83 & $-1,22$ & 2,05 & 0,90 & $-1,26$ & 2,16 \\
\hline \multirow{2}{*}{3} & 2,95 & $-2,62$ & 5,57 & 1,31 & $-1,23$ & 2,54 & 1,19 & $-1,50$ & 2,69 \\
\hline & \multicolumn{3}{|c|}{$\mathrm{DPCl}(\mathrm{B})$} & \multicolumn{3}{|c|}{$\mathrm{DPCl}(\mathrm{B})$} & \multicolumn{3}{|c|}{$\mathrm{DPCl}(\mathrm{B})$} \\
\hline 6 & 1,21 & $-1,52$ & 2,73 & 1,31 & $-1,06$ & 2,37 & - & - & - \\
\hline 5 & 1,09 & $-1,22$ & 2,31 & 1,25 & $-1,33$ & 2,58 & - & - & - \\
\hline 4 & 1,53 & $-1,11$ & 2,64 & 2,15 & $-2,60$ & 4,75 & - & - & - \\
\hline 3 & 3,07 & $-2,71$ & 5,78 & 1,82 & $-1,50$ & 3,32 & - & - & - \\
\hline
\end{tabular}

11/Piracicaba-SP; 2 Uberlândia-MG; $\stackrel{3}{-}$ Jataí-GO.

Tabela 30. Limite superior (LS) e inferior (LI), e amplitude de variação (A) das estimativas de CGC da população $\mathrm{GN}-04$ para valores de $\mathbf{s}$ iguais a $6,5,4$ e 3 obtidas em três locais para a variável peso de espigas (t/ha).

\begin{tabular}{|c|c|c|c|c|c|c|c|c|c|}
\hline \multirow[b]{2}{*}{$\mathrm{s}$} & \multicolumn{3}{|c|}{ LOCAL $1^{1 /}$} & \multicolumn{3}{|c|}{ LOCAL $2^{2 \underline{l}}$} & \multicolumn{3}{|c|}{ LOCAL $3^{3 /}$} \\
\hline & LS & $\mathrm{LI}$ & $\bar{A}$ & LS & $\mathrm{LI}$ & $A$ & LS & $\mathrm{LI}$ & $\mathrm{A}$ \\
\hline & \multicolumn{3}{|c|}{$\mathrm{DPCl}(\mathrm{A})$} & \multicolumn{3}{|c|}{$\mathrm{DPCl}(\mathrm{A})$} & \multicolumn{3}{|c|}{$\mathrm{DPCl}(\mathrm{A})$} \\
\hline 6 & 1,11 & $-1,11$ & 2,22 & 1,29 & $-0,72$ & 2.01 & 0,81 & $-0,88$ & 1,69 \\
\hline 5 & 1,11 & $-1,29$ & 2,40 & 1,64 & $-0,86$ & 2,50 & 0,82 & $-0,95$ & 1,77 \\
\hline 4 & 1,88 & $-1,58$ & 3,46 & 1,79 & $-1,45$ & 3,24 & 1,62 & $-0,92$ & 2,54 \\
\hline \multirow[t]{2}{*}{3} & 2,4 & $-3,50$ & 5,90 & 1,27 & $-1,46$ & 2,73 & 2,01 & $-1,18$ & 3,19 \\
\hline & \multicolumn{3}{|c|}{$\mathrm{DPCl}(\mathrm{B})$} & \multicolumn{3}{|c|}{$\mathrm{DPCl}(\mathrm{B})$} & \multicolumn{3}{|c|}{$\mathrm{DPCl}(\mathrm{B})$} \\
\hline 6 & 1,51 & $-1,71$ & 3,22 & 0,93 & $-0,78$ & 1,71 & - & - & - \\
\hline 5 & 1,56 & $-1,81$ & 3,37 & 1,26 & $-0,69$ & 1,95 & - & - & - \\
\hline 4 & 1,44 & $-1,39$ & 2,83 & 2,39 & $-1,81$ & 4,20 & - & - & - \\
\hline 3 & 2,89 & $-3,35$ & 6,24 & 1,59 & $-2,29$ & 3,88 & - & - & - \\
\hline
\end{tabular}


Tabela 31. Limite superior (LS) e inferior (LI), e amplitude de variação (A) das estimativas de CEC para valores de $\mathbf{s}$ iguais a 6, 5, 4 e 3 obtidas em três locais para a variável peso de espigas (t/ha).

\begin{tabular}{|c|c|c|c|c|c|c|c|c|c|}
\hline \multirow[b]{2}{*}{$\mathrm{s}$} & \multicolumn{3}{|c|}{ LOCAL $1^{1 /}$} & \multicolumn{3}{|c|}{ LOCAL $2^{\underline{2} /}$} & \multicolumn{3}{|c|}{ LOCAL $3^{3 /}$} \\
\hline & LS & $\mathrm{LI}$ & A & LS & $\mathrm{LI}$ & A & LS & $\mathrm{LI}$ & A \\
\hline & \multicolumn{3}{|c|}{$\mathrm{DPCl}(\mathrm{A})$} & \multicolumn{3}{|c|}{$\mathrm{DPCl}(\mathrm{A})$} & \multicolumn{3}{|c|}{$\mathrm{DPCl}(\mathrm{A})$} \\
\hline 6 & 2,12 & $-1,60$ & 3,72 & 1,11 & $-1,36$ & 2,47 & 1,04 & $-1,00$ & 2,04 \\
\hline 5 & 1,92 & $-1,49$ & 3,41 & 0,87 & $-1,40$ & 2,27 & 0,92 & $-0,90$ & 1,82 \\
\hline 4 & 2,16 & $-1,30$ & 3,46 & 0,95 & $-1,35$ & 2,30 & 0,83 & $-0,97$ & 1,80 \\
\hline 3 & 1,31 & $-1,28$ & 2,59 & 0,68 & $-0,97$ & 1,65 & 0,70 & $-0,78$ & 1,48 \\
\hline & \multicolumn{3}{|c|}{$\mathrm{DPCl}(\mathrm{B})$} & \multicolumn{3}{|c|}{$\mathrm{DPCl}(\mathrm{B})$} & \multicolumn{3}{|c|}{$\mathrm{DPCl}(\mathrm{B})$} \\
\hline 6 & 1,89 & $-2,85$ & 4,75 & 1,37 & $-1,33$ & 2,70 & - & - & - \\
\hline 5 & 1,82 & $-1,22$ & 3,04 & 1,27 & $-1,30$ & 2,57 & - & - & - \\
\hline 4 & 1,16 & $-1,24$ & 2,40 & 0,97 & $-0,98$ & 1,95 & - & - & - \\
\hline 3 & 0,93 & $-0,66$ & 1,59 & 0,80 & $-0,57$ & 1,37 & - & - & - \\
\hline
\end{tabular}

11/Piracicaba-SP; 느berlândia-MG; 3 -Jataí-GO.

Tabela 32. Limite superior (LS) e inferior (LI), e amplitude de variação (A) das estimativas de CGC da população $\mathrm{GN}-03$ para valores de $\mathbf{s}$ iguais a $6,5,4$ e 3 obtidas em dois locais para a variável altura de planta (cm).

\begin{tabular}{|c|c|c|c|c|c|c|}
\hline \multirow[b]{2}{*}{$\mathrm{s}$} & \multicolumn{3}{|c|}{ LOCAL $1^{1 /}$} & \multicolumn{3}{|c|}{ LOCAL $2^{2 / 1}$} \\
\hline & LS & $\mathrm{LI}$ & A & LS & $\mathrm{LI}$ & A \\
\hline & \multicolumn{3}{|c|}{$\mathrm{DPCl}(\mathrm{A})$} & \multicolumn{3}{|c|}{$\mathrm{DPCl}(\mathrm{A})$} \\
\hline 6 & 15,10 & $-17,37$ & 32,47 & 11,33 & $-15,46$ & 26,79 \\
\hline 5 & 17,08 & $-17,46$ & 34,54 & 15,91 & $-17,24$ & 33,15 \\
\hline 4 & 25,15 & $-21,79$ & 46,94 & 24,07 & $-25,06$ & 49,13 \\
\hline 3 & 29,86 & $-29,44$ & 59,30 & 25,08 & $-25,63$ & 50,71 \\
\hline & \multicolumn{3}{|c|}{$\mathrm{DPCl}(\mathrm{B})$} & \multicolumn{3}{|c|}{$\mathrm{DPCl}(\mathrm{B})$} \\
\hline 6 & 16,37 & $-18,42$ & 34,79 & 12,05 & $-15,63$ & 27,68 \\
\hline 5 & 14,50 & $-18,34$ & 32,84 & 12,47 & $-14,80$ & 27,27 \\
\hline 4 & 23,65 & $-32,89$ & 56,54 & 27,76 & $-31,98$ & 59,74 \\
\hline 3 & 26,06 & $-31,52$ & 57,58 & 26,88 & $-38,72$ & 65,60 \\
\hline
\end{tabular}

1/Piracicaba-SP; $\underline{2}$ Uberlândia-MG. 
Tabela 33. Limite superior (LS) e inferior (LI), e amplitude de variação (A) das estimativas de CGC da população GN-04 para valores de $\mathbf{s}$ iguais a $6,5,4$ e 3 obtidas em dois locais para a variável altura de planta (cm).

\begin{tabular}{|c|c|c|c|c|c|c|}
\hline \multirow[b]{2}{*}{$\mathrm{s}$} & \multicolumn{3}{|c|}{ LOCAL $1^{1 /}$} & \multicolumn{3}{|c|}{ LOCAL $2^{\underline{2 l}}$} \\
\hline & LS & $\mathrm{LI}$ & A & LS & $\mathrm{LI}$ & A \\
\hline & \multicolumn{3}{|c|}{$\mathrm{DPCl}(\mathrm{A})$} & \multicolumn{3}{|c|}{$\mathrm{DPCl}(\mathrm{A})$} \\
\hline 6 & 13,9 & $-23,42$ & 37,32 & 9,30 & $-18,01$ & 27,31 \\
\hline 5 & 19,58 & $-20,97$ & 40,55 & 16,99 & $-19,67$ & 36,66 \\
\hline 4 & 26,47 & $-25,74$ & 52,21 & 29,19 & $-31,39$ & 60,58 \\
\hline 3 & 30,79 & $-17,58$ & 48,37 & 38,17 & $-34,14$ & 72,31 \\
\hline & \multicolumn{3}{|c|}{$\mathrm{DPCl}(\mathrm{B})$} & \multicolumn{3}{|c|}{$\mathrm{DPCl}(\mathrm{B})$} \\
\hline 6 & 20,76 & $-20,88$ & 41,64 & 15,94 & $-16,96$ & 32,90 \\
\hline 5 & 19,85 & $-19,37$ & 39,22 & 15,05 & $-15,24$ & 30,29 \\
\hline 4 & 30,98 & $-25,40$ & 56,38 & 31,51 & $-30,10$ & 61,61 \\
\hline 3 & 20,63 & $-31,50$ & 52,13 & 40,21 & $-19,67$ & 59,88 \\
\hline
\end{tabular}

1/Piracicaba-SP; 느berlândia-MG.

Tabela 34. Limite superior (LS) e inferior (LI), e amplitude de variação (A) das estimativas de CEC para valores de $\mathbf{s}$ iguais a 6, 5, 4 e 3 obtidas em dois locais para a variável altura de planta $(\mathrm{cm})$.

\begin{tabular}{|c|c|c|c|c|c|c|}
\hline \multirow[b]{2}{*}{$\mathrm{s}$} & \multicolumn{3}{|c|}{ LOCAL $1^{1 / 1}$} & \multicolumn{3}{|c|}{ LOCAL $2^{2}$} \\
\hline & LS & LI & A & LS & LI & A \\
\hline & \multicolumn{3}{|c|}{$\mathrm{DPCl}(\mathrm{A})$} & \multicolumn{3}{|c|}{$\mathrm{DPCl}(\mathrm{A})$} \\
\hline 6 & 16,35 & $-16,36$ & 32,71 & 20,66 & $-19,95$ & 40,61 \\
\hline 5 & 13,48 & $-18,11$ & 31,59 & 14,45 & $-18,39$ & 32,84 \\
\hline 4 & 16,48 & $-18,54$ & 35,02 & 11,96 & $-19,09$ & 31,05 \\
\hline 3 & 10,98 & $-12,05$ & 23,03 & 11,95 & $-15,39$ & 27,34 \\
\hline & \multicolumn{3}{|c|}{$\mathrm{DPCl}(\mathrm{B})$} & \multicolumn{3}{|c|}{$\mathrm{DPCl}(\mathrm{B})$} \\
\hline 6 & 18,37 & $-22,15$ & 40,52 & 22,68 & $-24,46$ & 47,14 \\
\hline 5 & 17,29 & $-23,43$ & 40,72 & 18,87 & $-22,65$ & 41,52 \\
\hline 4 & 15,29 & $-21,43$ & 36,72 & 15,83 & $-19,41$ & 35,24 \\
\hline 3 & 10,51 & $-11,86$ & 22,37 & 12,38 & $-13,20$ & 25,58 \\
\hline
\end{tabular}

11/Piracicaba-SP; -Uberlândia-MG. 
Tabela 35. Quadrados médios da análise de variância agrupada (DPCI A e DPCI B) dos dois arranjos de diagonais, para o caráter peso de espigas (t/ha) em dois locais para estimação de parâmetros genéticos.

\begin{tabular}{lcccccc}
\hline \multirow{2}{*}{ FV } & \multirow{2}{*}{ GL } & \multicolumn{2}{c}{ PIRACICABA } & & \multicolumn{2}{c}{ UBERLÂNDIA } \\
\cline { 3 - 4 } \cline { 6 - 7 } & & $\mathrm{QM}^{1 /}$ & $\mathrm{QM}^{2 / 1}$ & & $\mathrm{QM}^{1 /}$ & $\mathrm{QM}^{2 / 1}$ \\
\hline DIAGONAL (D) & 10 & 0,876 & 0,876 & & 0,406 & 0,406 \\
LINHA (L) & 98 & 1,119 & 1,402 & & 0,755 & 0,688 \\
LXD & 490 & 0,742 & 0,685 & & 0,351 & 0,365 \\
ERRO & 750 & 0,425 & 0,425 & & 0,225 & 0,225 \\
HíBRIDOS/D & 594 & 0,812 & 0,812 & & 0,421 & 0,421 \\
\hline
\end{tabular}

11arranjo do grupo I; ㄹarranjo do grupo II.

Tabela 36. Quadrados médios da análise de variância dos dois arranjos de diagonais, para o caráter peso de espigas (t/ha) avaliados em Jataí-GO, para estimação de parâmetros genéticos do $\mathrm{DPCl}(\mathrm{A})$.

\begin{tabular}{lccc}
\hline \multicolumn{1}{c}{ FV } & GL & $\mathrm{QM}^{1 /}$ & $\mathrm{QM}^{1} \underline{\underline{2}}$ \\
\hline DIAGONAL (D) & 5 & 0,189 & 0,189 \\
LINHA (L) & 49 & 0,399 & 0,467 \\
LXD & 245 & 0,265 & 0,252 \\
ERRO & 750 & 0,130 & 0,130 \\
HíBRIDOS/D & 297 & 0,288 & 0,288 \\
\hline
\end{tabular}

11-arranjo do grupo I; 르arranjo do grupo II. 
Tabela 37. Estimativas das variâncias interpopulacionais, em (g/planta $)^{2}$, para a variável peso de espigas (t/ha) e para as populações GN-03 e GN04 em três locais.

\begin{tabular}{|c|c|c|c|c|c|c|}
\hline Local & $\bar{\sigma}_{H}^{2} \frac{11}{1}$ & $\hat{\sigma}_{g l}^{2} \underline{2}$ & $\hat{\sigma}_{g \mid l}^{2} \underline{3}$ & $\hat{\sigma}_{s}^{24 l}$ & $\hat{\sigma}_{A(12)}^{2}{ }^{5 /}$ & $\hat{\sigma}_{D(12)}^{2} \underline{6 /}$ \\
\hline Piracicaba & 242,70 & 20,78 & 39,50 & 182,42 & 120,56 & 729,68 \\
\hline Uberlândia & 97,56 & 17,23 & 13,81 & 66,53 & 61,92 & 266,13 \\
\hline Jataí & 87,92 & 7,37 & 11,85 & 68,71 & 38,44 & 274,84 \\
\hline $\begin{array}{l}\text { I/variância entre h } \\
\text { de combinação } \\
\text { combinação da } \\
\text { combinação; } \underline{5} \text { va } \\
\text { interpopulacional. }\end{array}$ & ado GN & e diagc & ais; $\stackrel{2}{v} v$ & riância c & capaci & ade gera \\
\hline
\end{tabular}



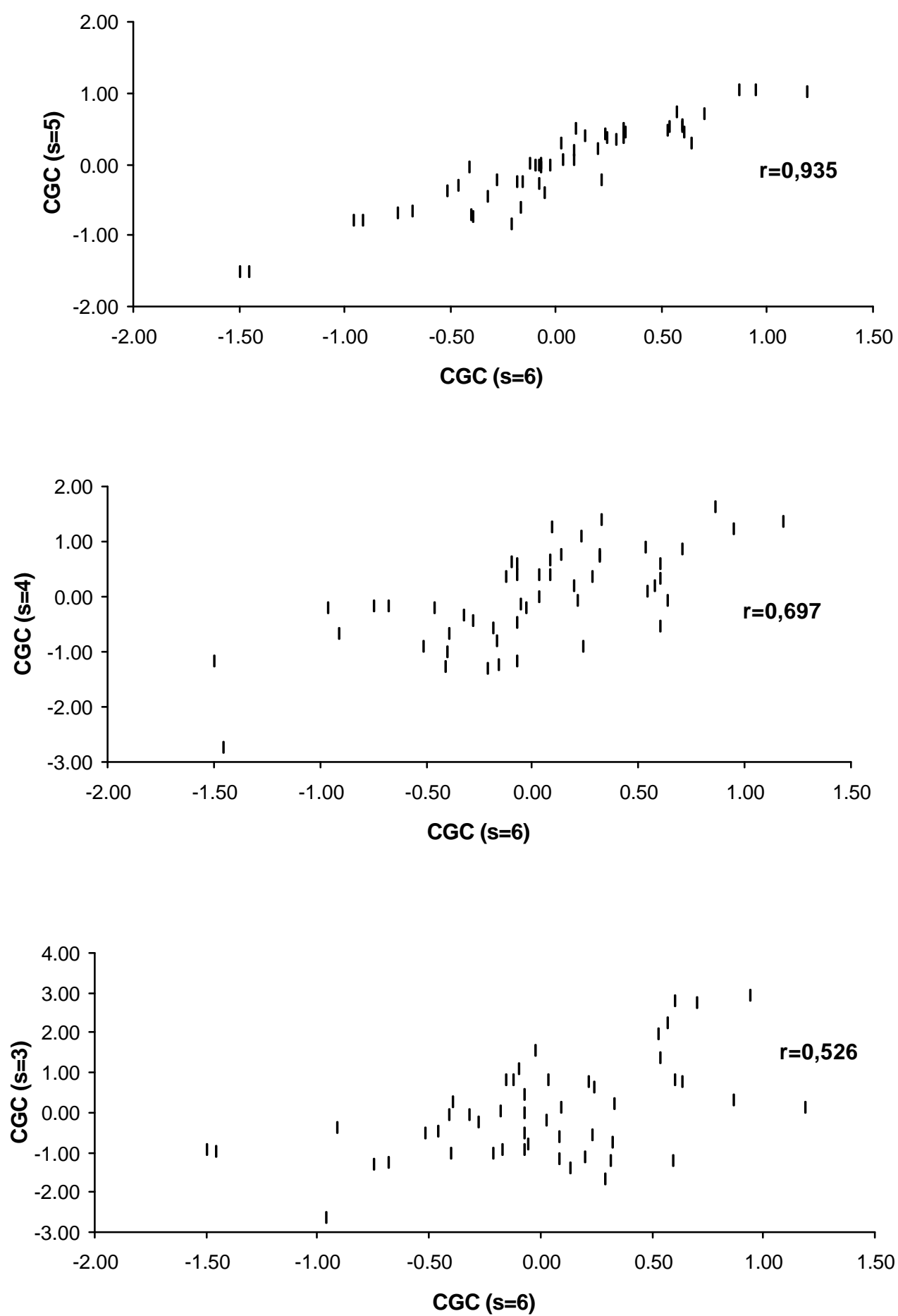

Figura 1 - Dispersão das estimativas obtidas para CGC do DPCI (A) da população GN03 , obtidas entre os valores de $s$ iguais à $6 / 5 ; 6 / 4$ e 6/3 e suas correlações para o caráter peso de espigas (t/ha). Piracicaba-SP, 2001/02. 

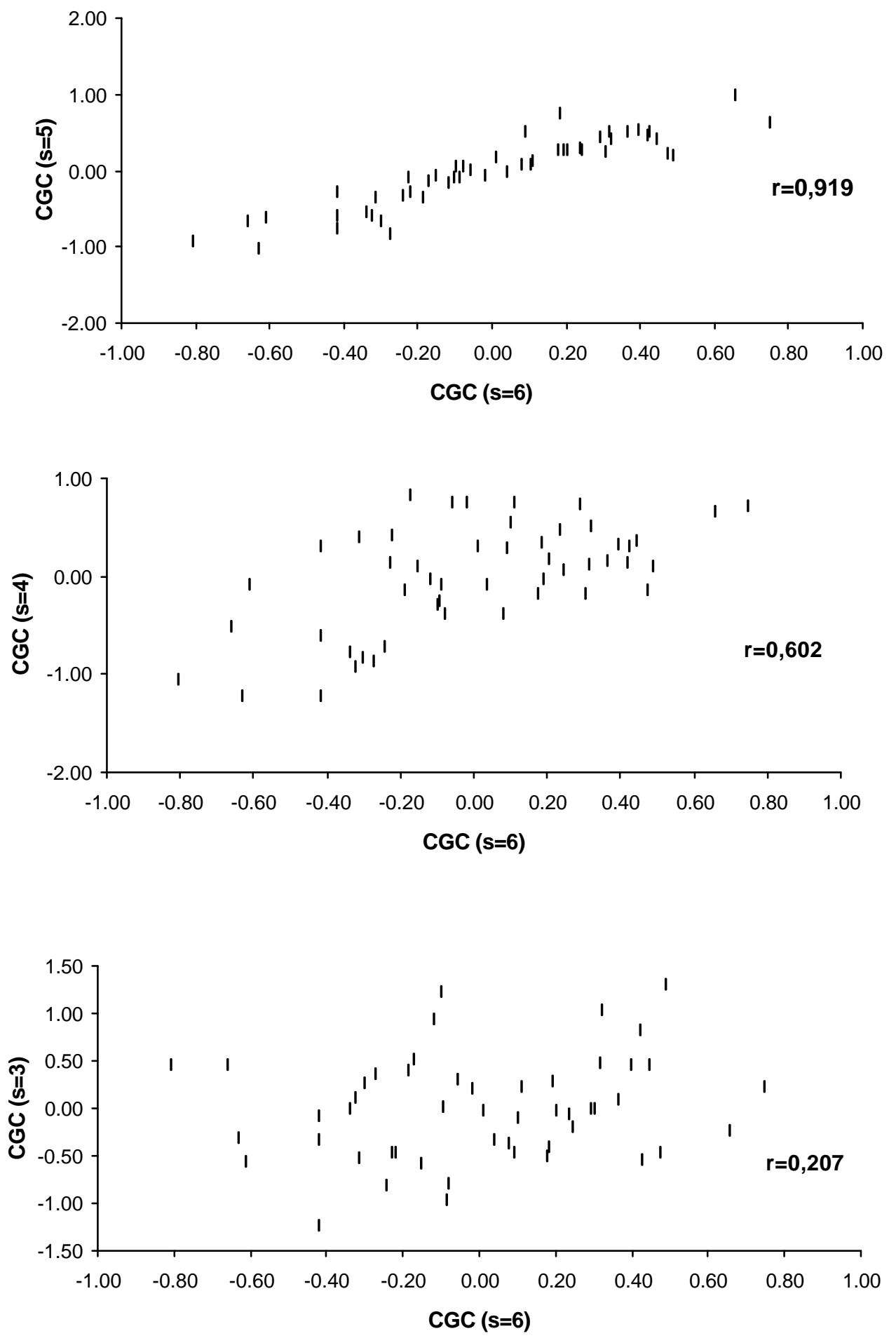

Figura 2 - Dispersão das estimativas obtidas para CGC do DPCI (A) da população GN03 , obtidas entre os valores de $s$ iguais à 6/5; 6/4 e 6/3 e suas correlações para o caráter peso de espigas (t/ha). Uberlândia-MG, 2001/02. 

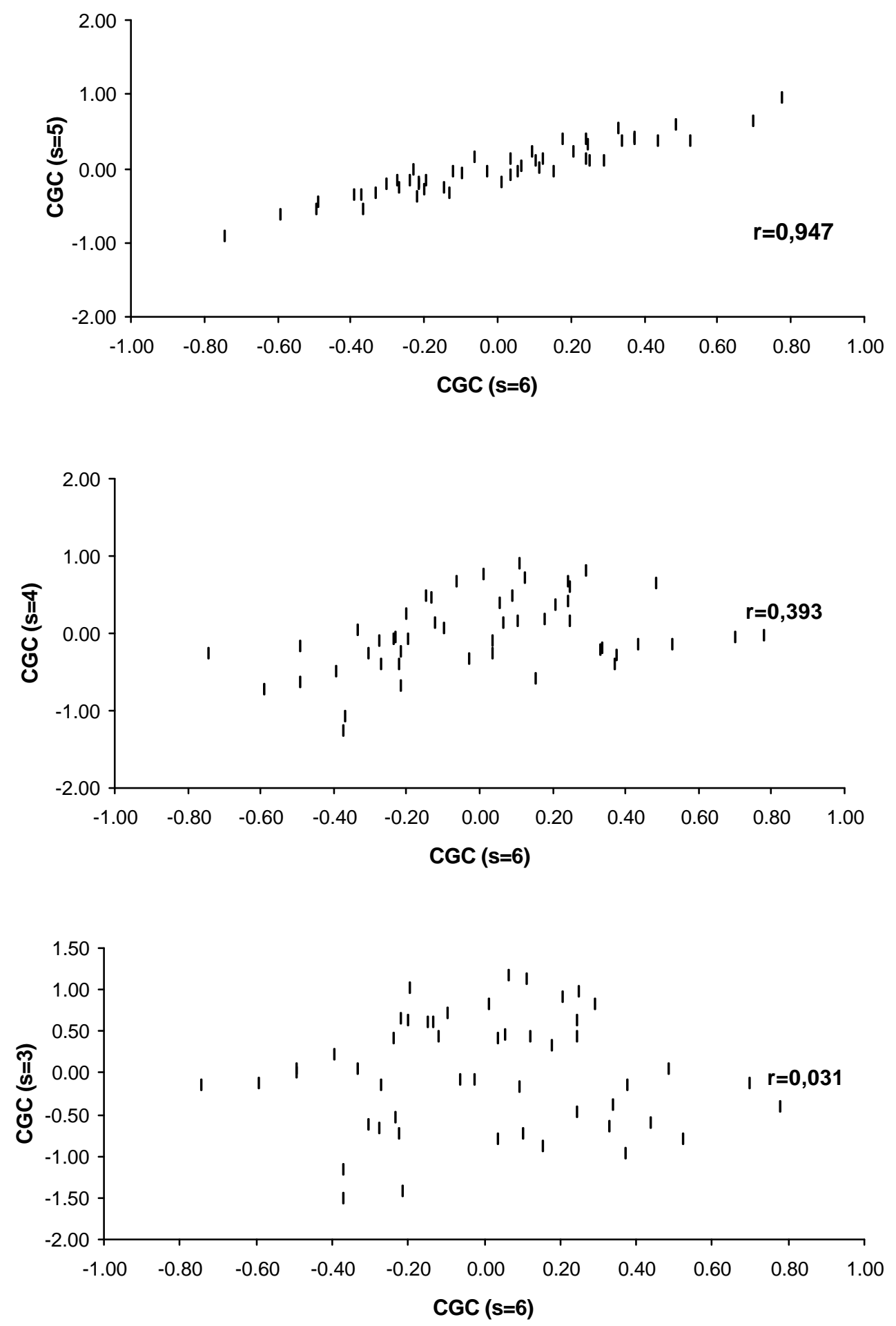

Figura 3 - Dispersão das estimativas obtidas para CGC do DPCI (A) da população GN03 , obtidas entre os valores de $s$ iguais à $6 / 5 ; 6 / 4$ e 6/3 e suas correlações para o caráter peso de espigas (t/ha). Jataí-GO, 2002. 

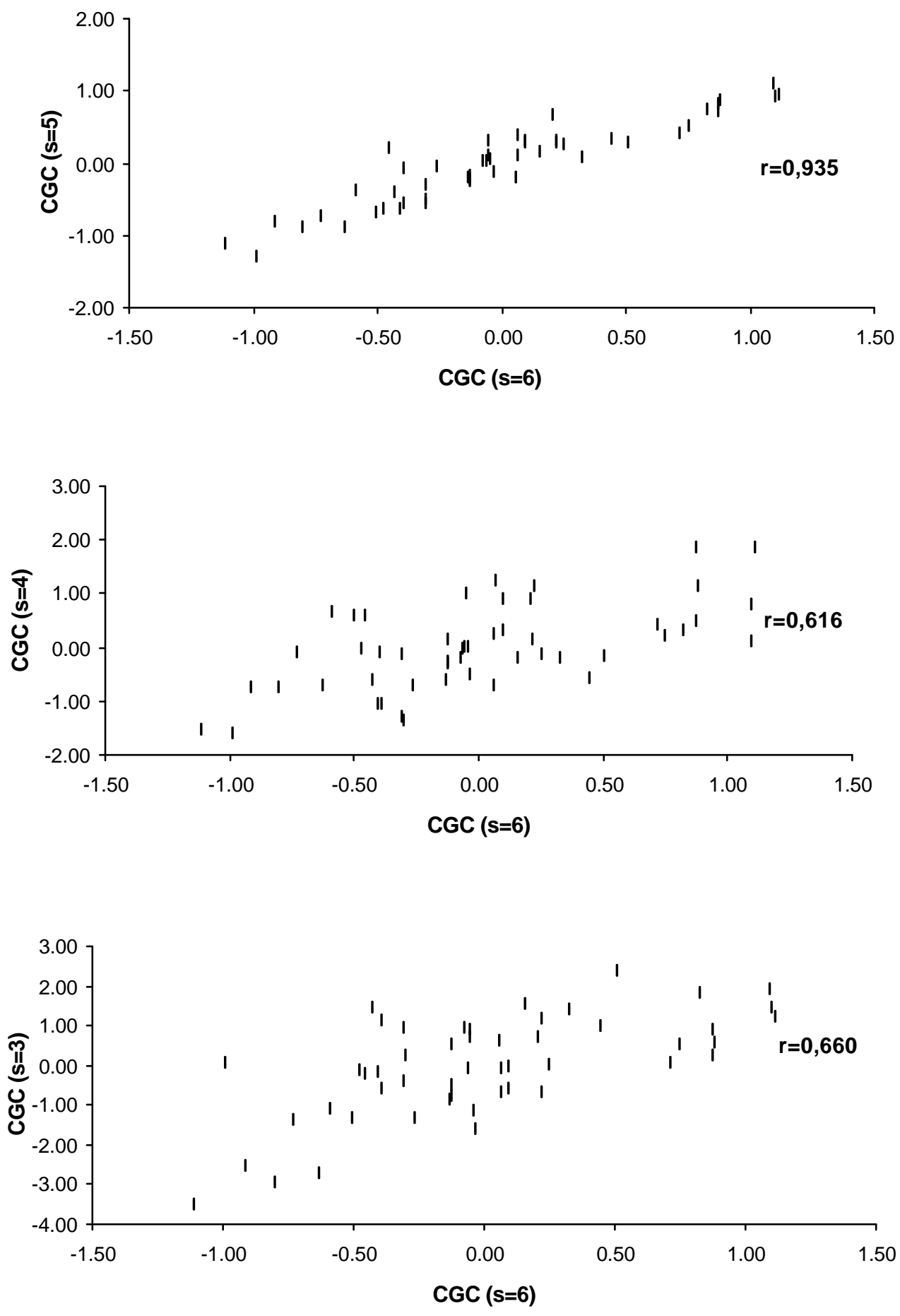

Figura 4 - Dispersão entre as estimativas obtidas para CGC do DPCI (A) da população GN-04, obtidas entre os valores de $s$ iguais à 6/5;6/4 e 6/3 e suas correlações para o caráter peso de espigas (t/ha). Piracicaba-SP, 2001/02. 

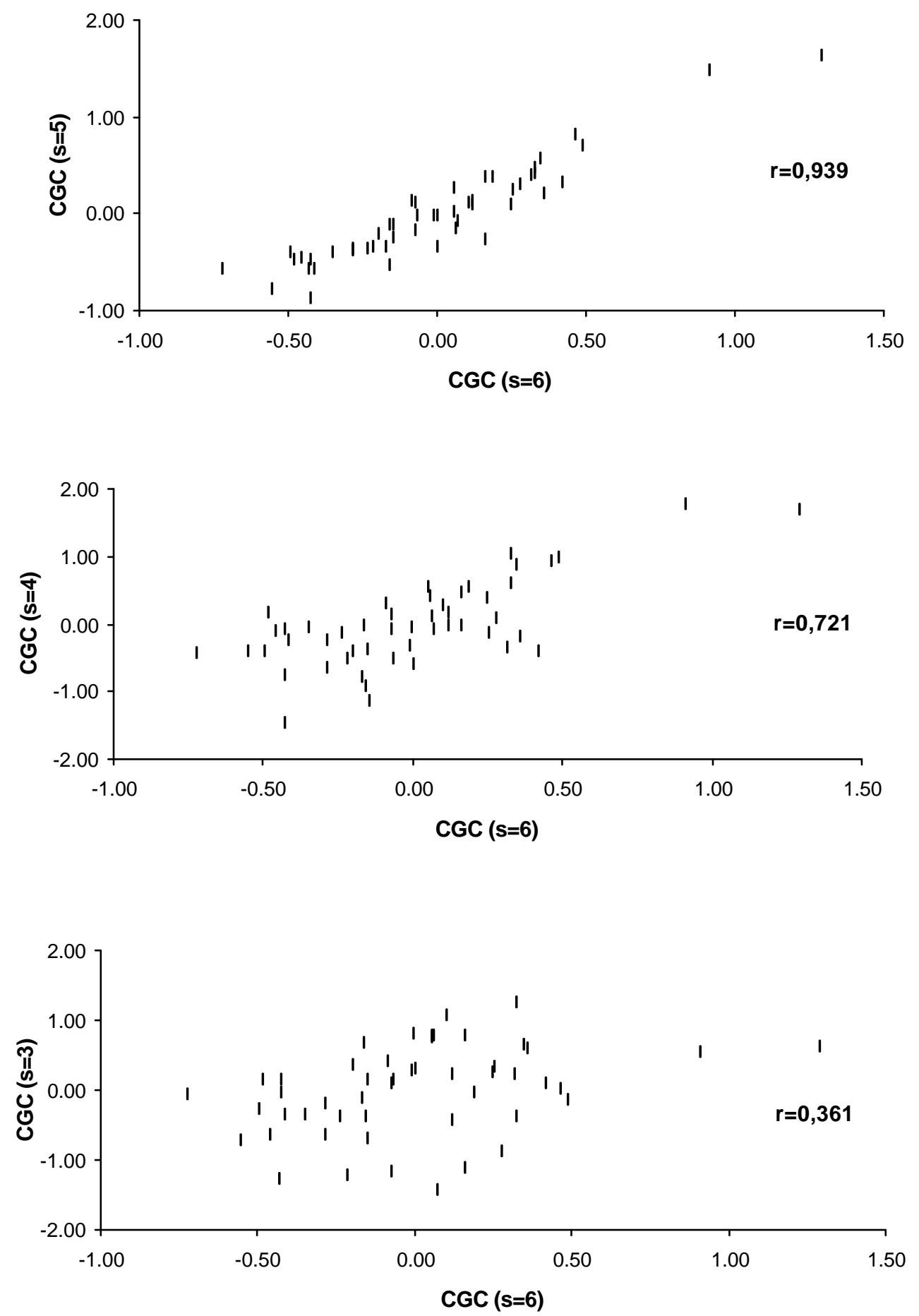

Figura 5 - Dispersão das estimativas obtidas para CGC do DPCI (A) da população GN04 , obtidas entre os valores de $s$ iguais à $6 / 5 ; 6 / 4$ e 6/3 e suas correlações para o caráter peso de espigas (t/ha). Uberlândia-MG, 2001/02. 

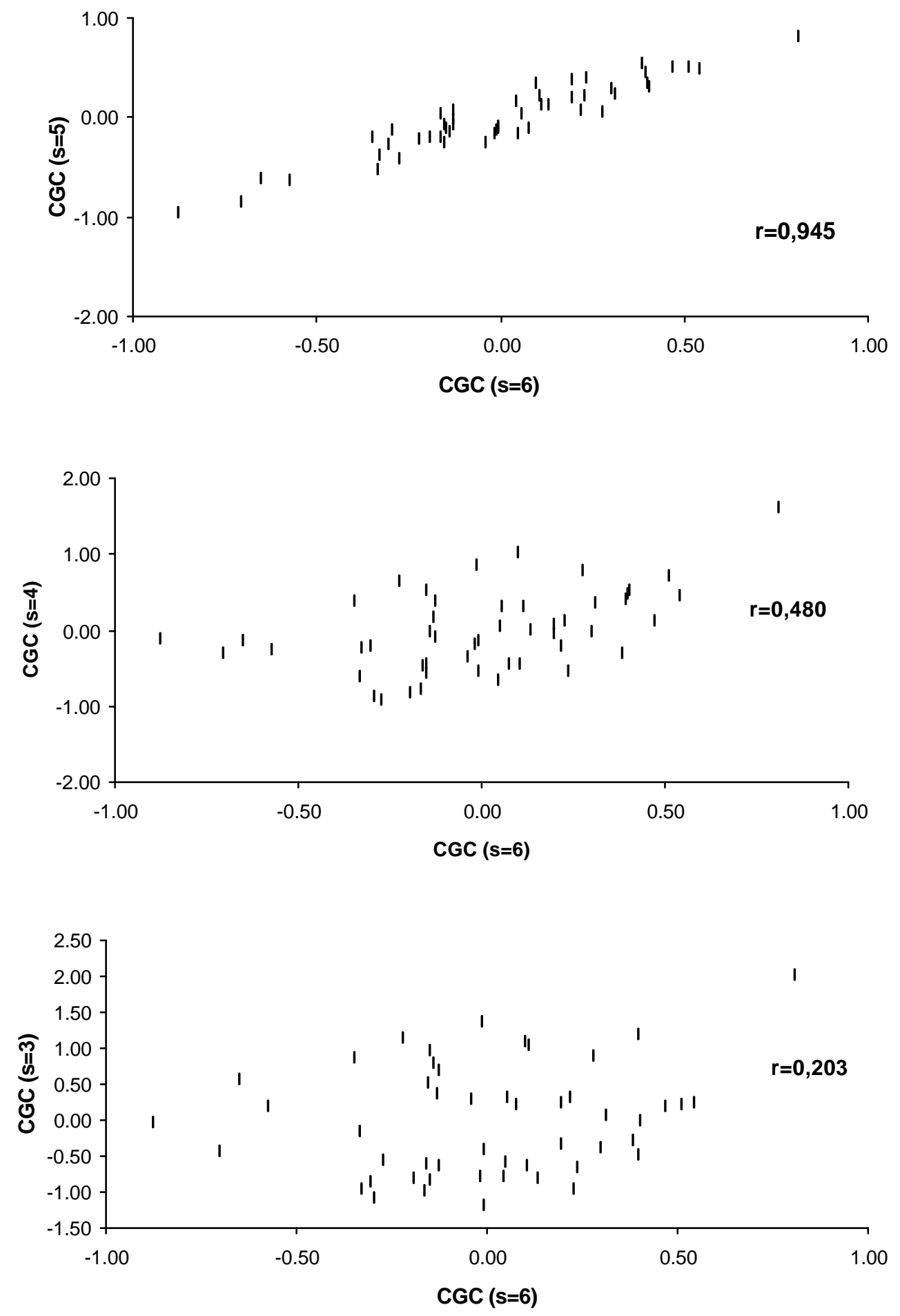

Figura 6 - Dispersão das estimativas obtidas para CGC do DPCI (A) da população GN04 , obtidas entre os valores de $s$ iguais à $6 / 5 ; 6 / 4$ e $6 / 3$ e suas correlaç ões para o caráter peso de espigas (t/ha). Jataí-GO, 2001/02. 

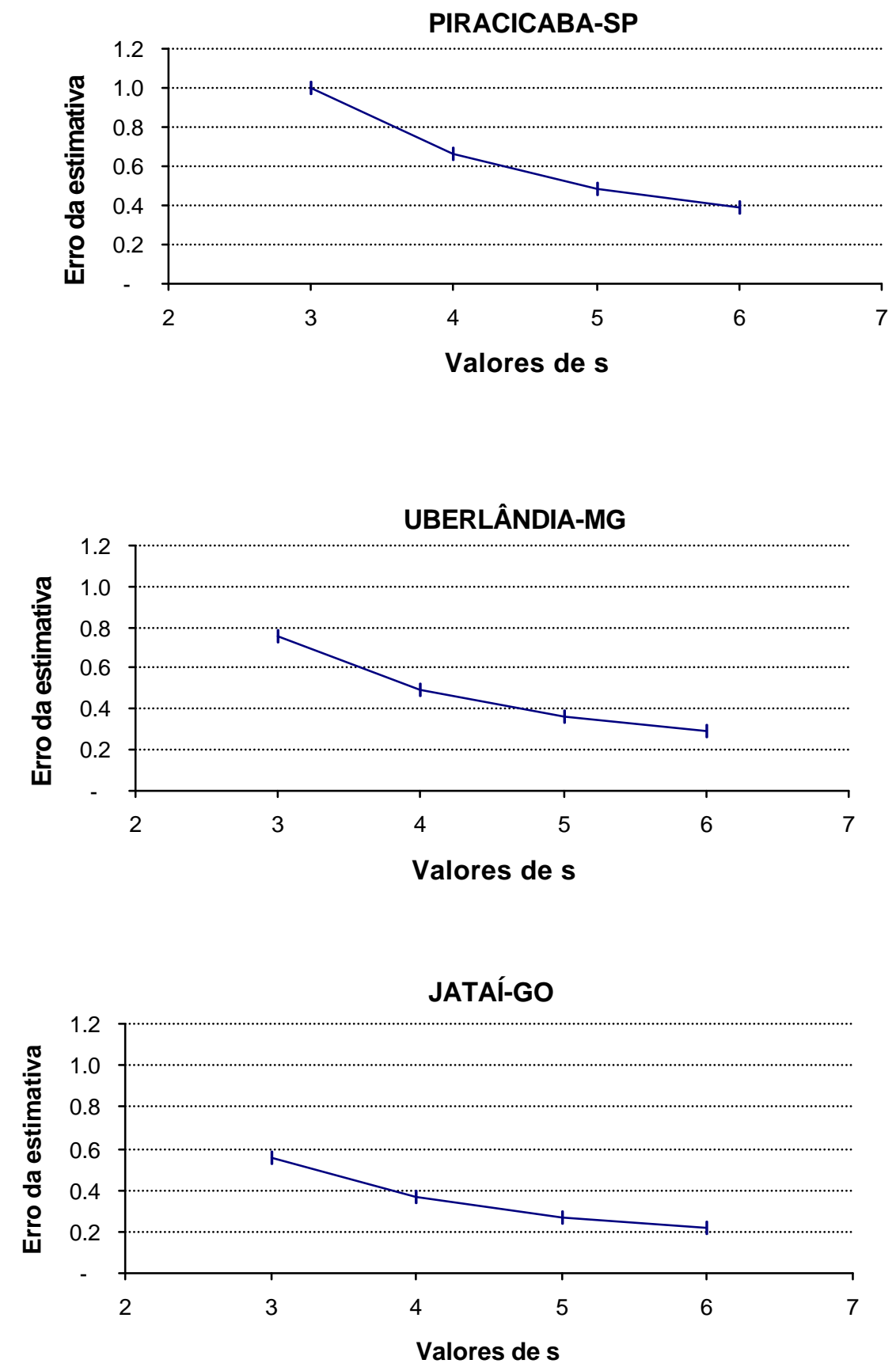

Figura 7 - Distribuição dos erros associados às estimativas de gi e gj para os diferentes tamanhos de s para o caráter peso de espigas (t/ha) do DPCI (A) em três locais. Piracicaba-SP2001/02; Uberlândia-MG 2001/02 e Jataí-GO, 2000. 

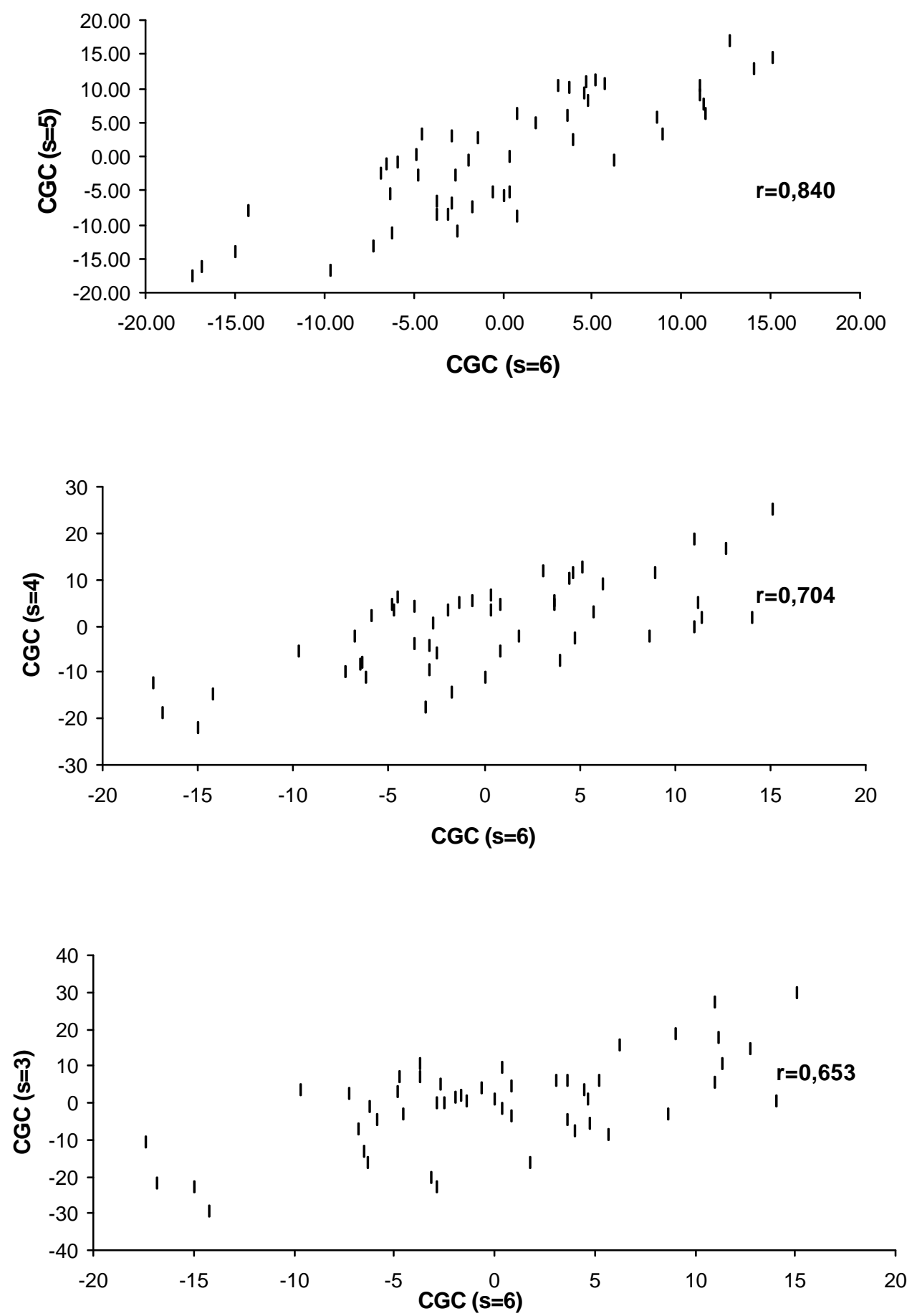

Figura 8 - Dispersão das estimativas obtidas para CGC do DPCI (A) da população GN03 , obtidas entre os valores de $\mathbf{s}$ iguais à $6 / 5 ; 6 / 4$ e $6 / 3$ e suas correlações para o caráter altura de planta (cm). Piracicaba-SP, 2001/02. 

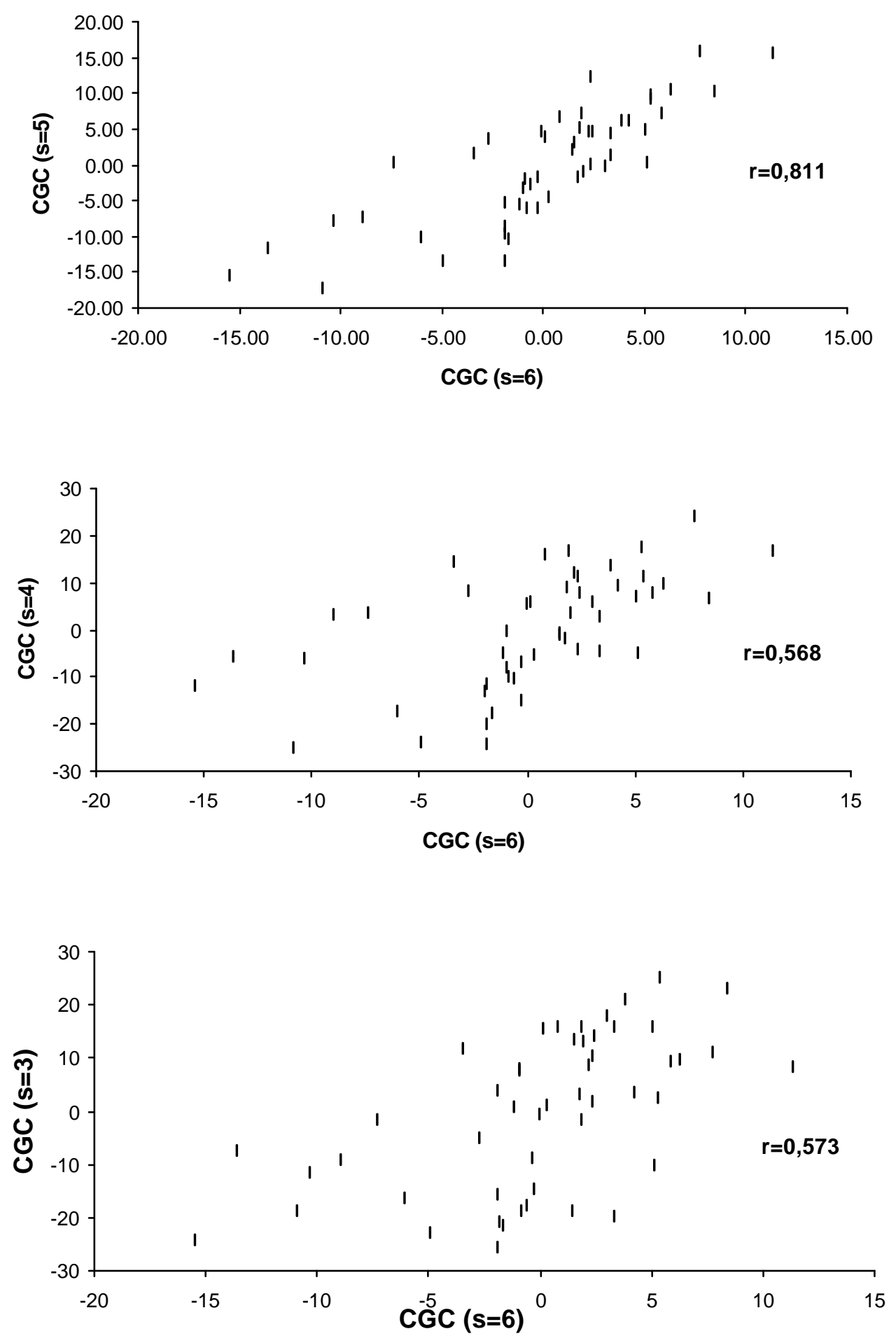

Figura 9 - Dispersão das estimativas obtidas para CGC do DPCl (A) da população GN03 , obtidas entre os valores de $s$ iguais à $6 / 5 ; 6 / 4$ e $6 / 3$ e suas correlações para o caráter altura de planta (cm). Uberlândia-MG, 2001/02. 

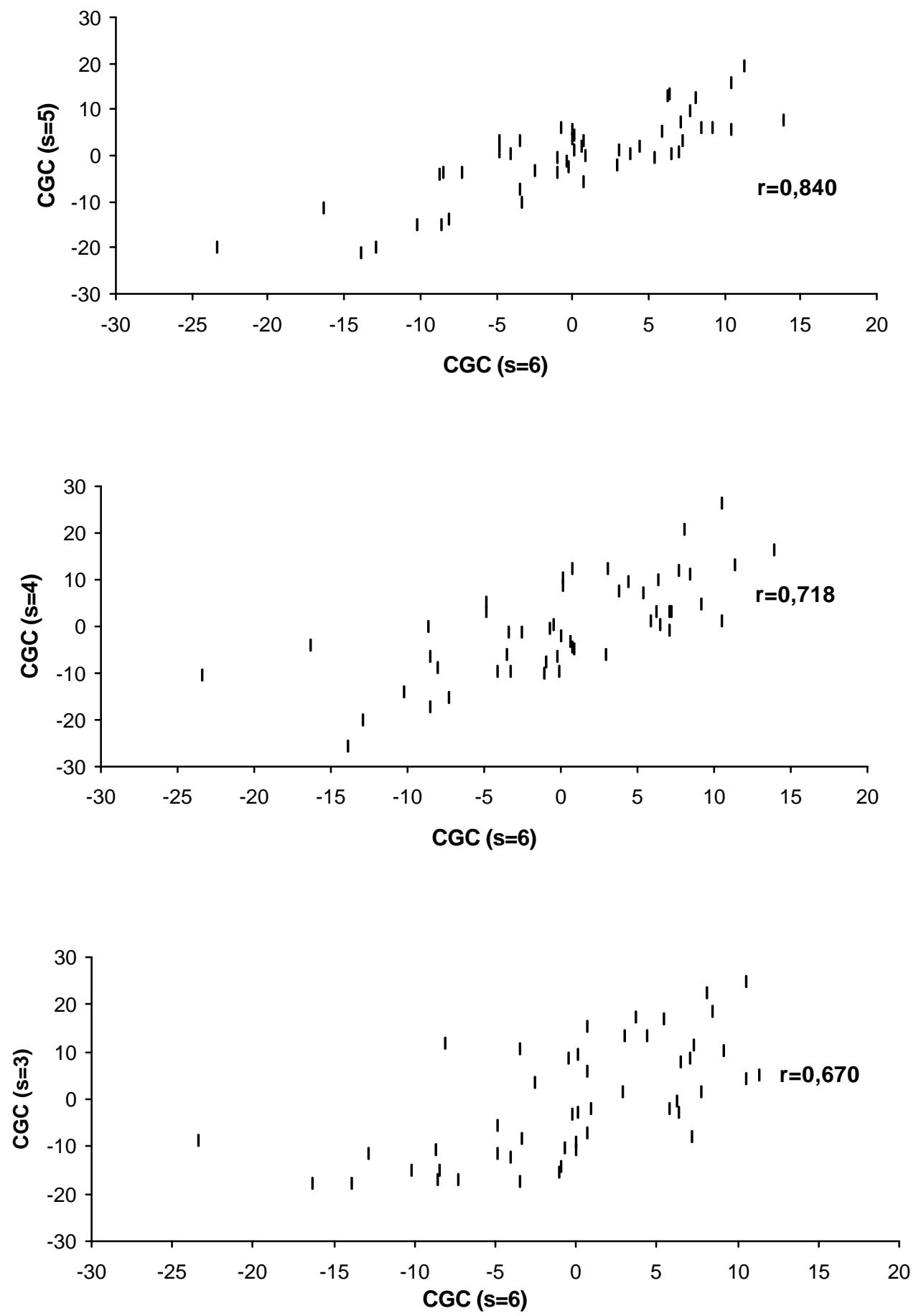

Figura 10 - Dispersão das estimativas obtidas para CGC do DPCI (A) da população GN-04, obtidas entre os valores de $\mathbf{s}$ iguais à $6 / 5 ; 6 / 4$ e 6/3 e suas correlações para o caráter altura de planta $(\mathrm{cm})$. Piracicaba-SP, 2001/02. 

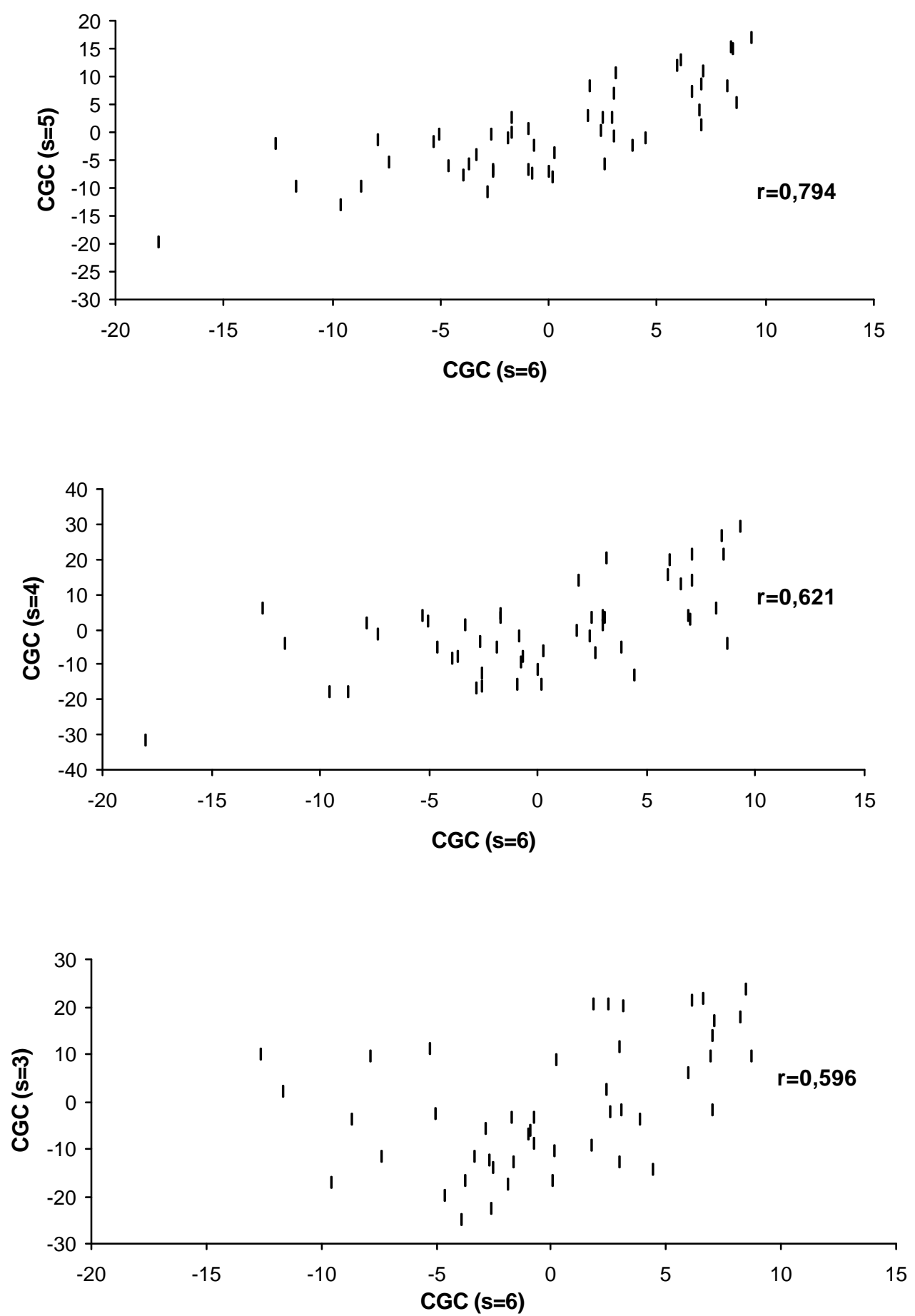

Figura 11 - Dispersão das estimativas obtidas para CGC do DPCI (A) da população GN-04, obtidas entre os valores de $s$ iguais à $6 / 5 ; 6 / 4$ e $6 / 3$ e suas correlações para o caráter altura de planta (cm). Uberlândia-MG, 2001/02. 

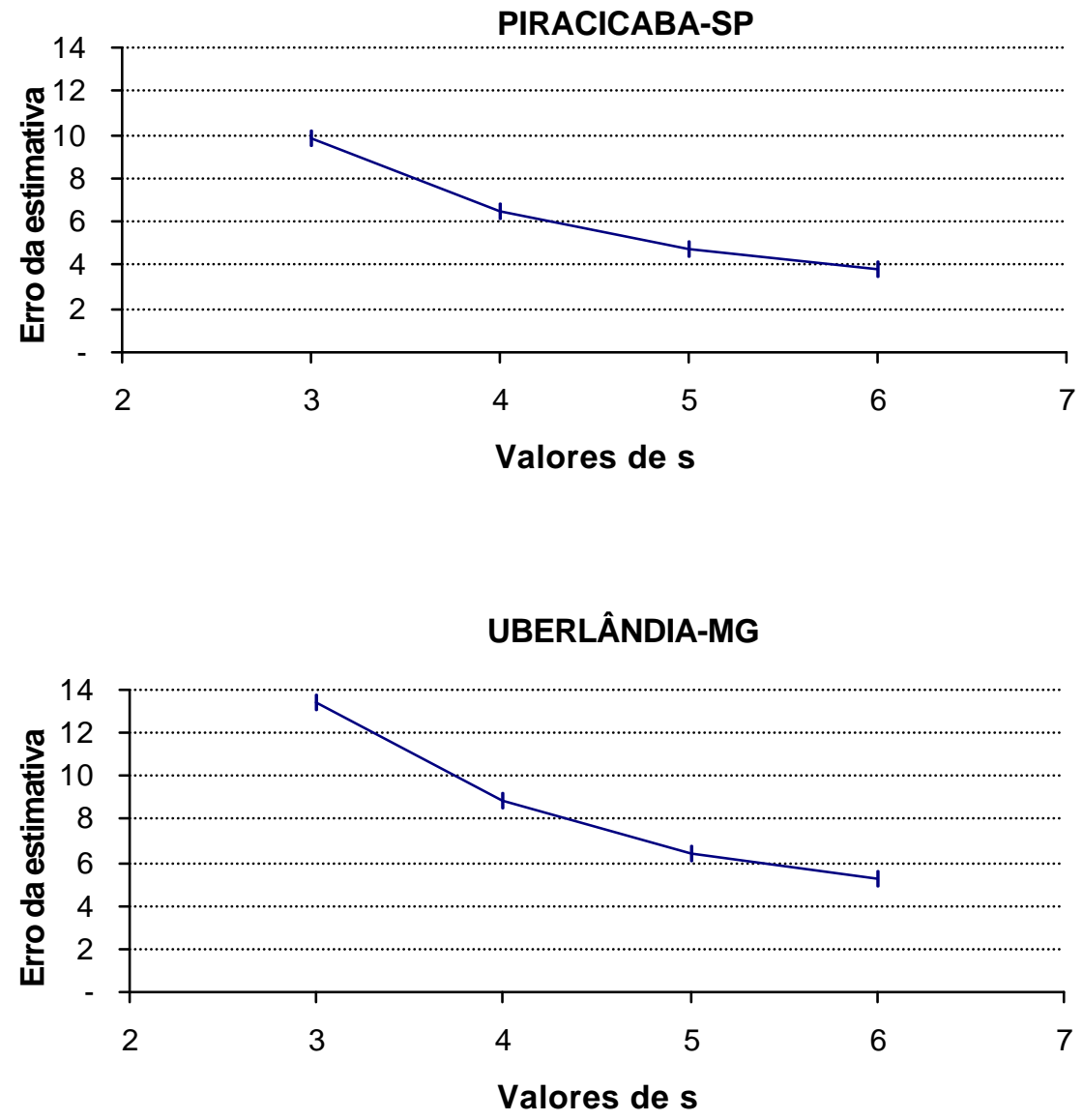

Figura 12 - Distribuição dos erros associados às estimativas de gi e gj para os diferentes tamanhos de s para o caráter altura de planta $(\mathrm{cm})$ do $\mathrm{DPCl}$ (A) em dois locais. Piracicaba-SP2001/02; Uberlândia-MG, 2001/02. 

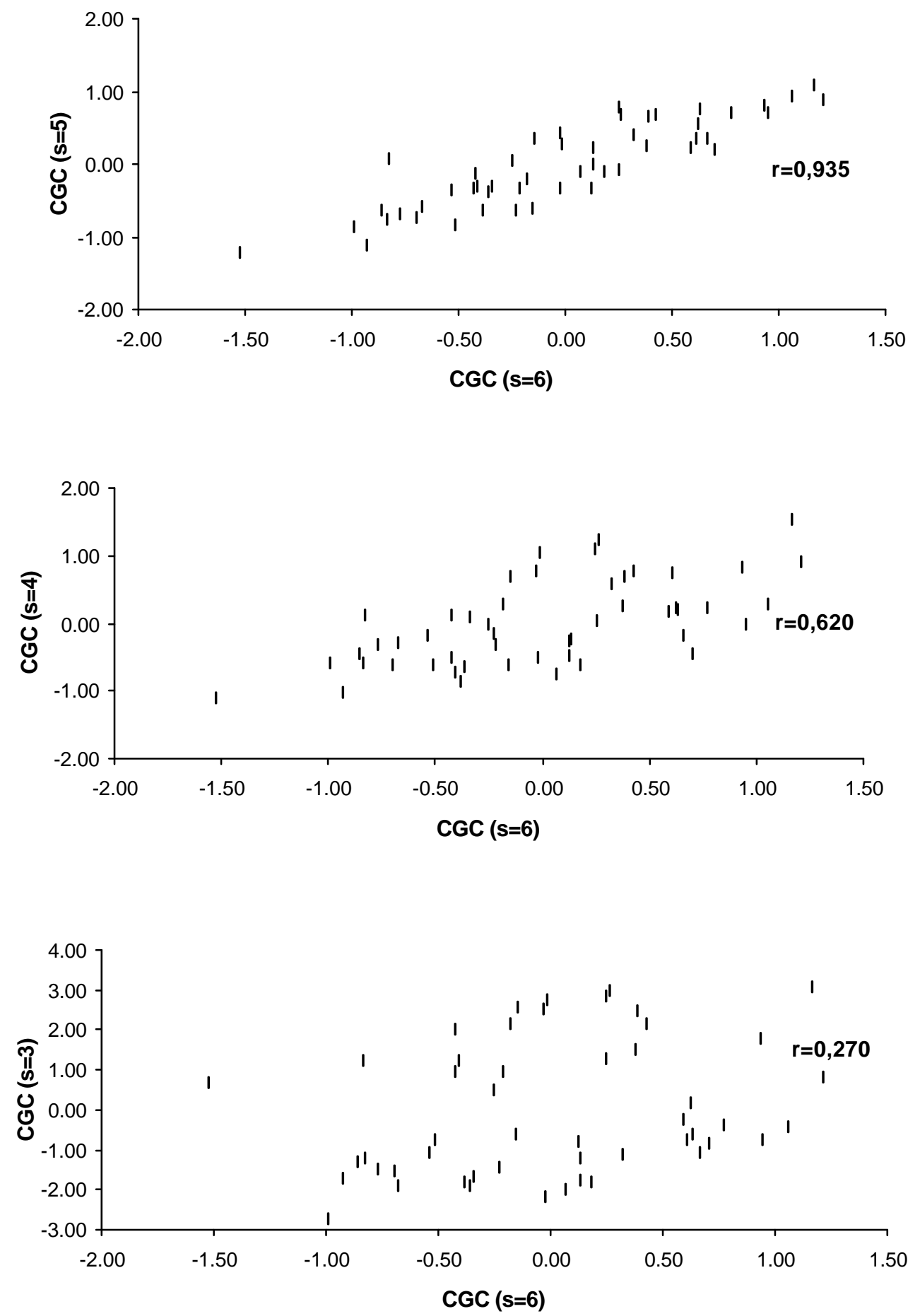

Figura 13 - Dispersão das estimativas obtidas para CGC do DPCI (B) da população GN-03, obtidas entre os valores de $\mathbf{s}$ iguais à 6/5; 6/4 e 6/3 e suas correlações para o caráter peso de espigas (t/ha). Piracicaba-SP, 2001/02. 

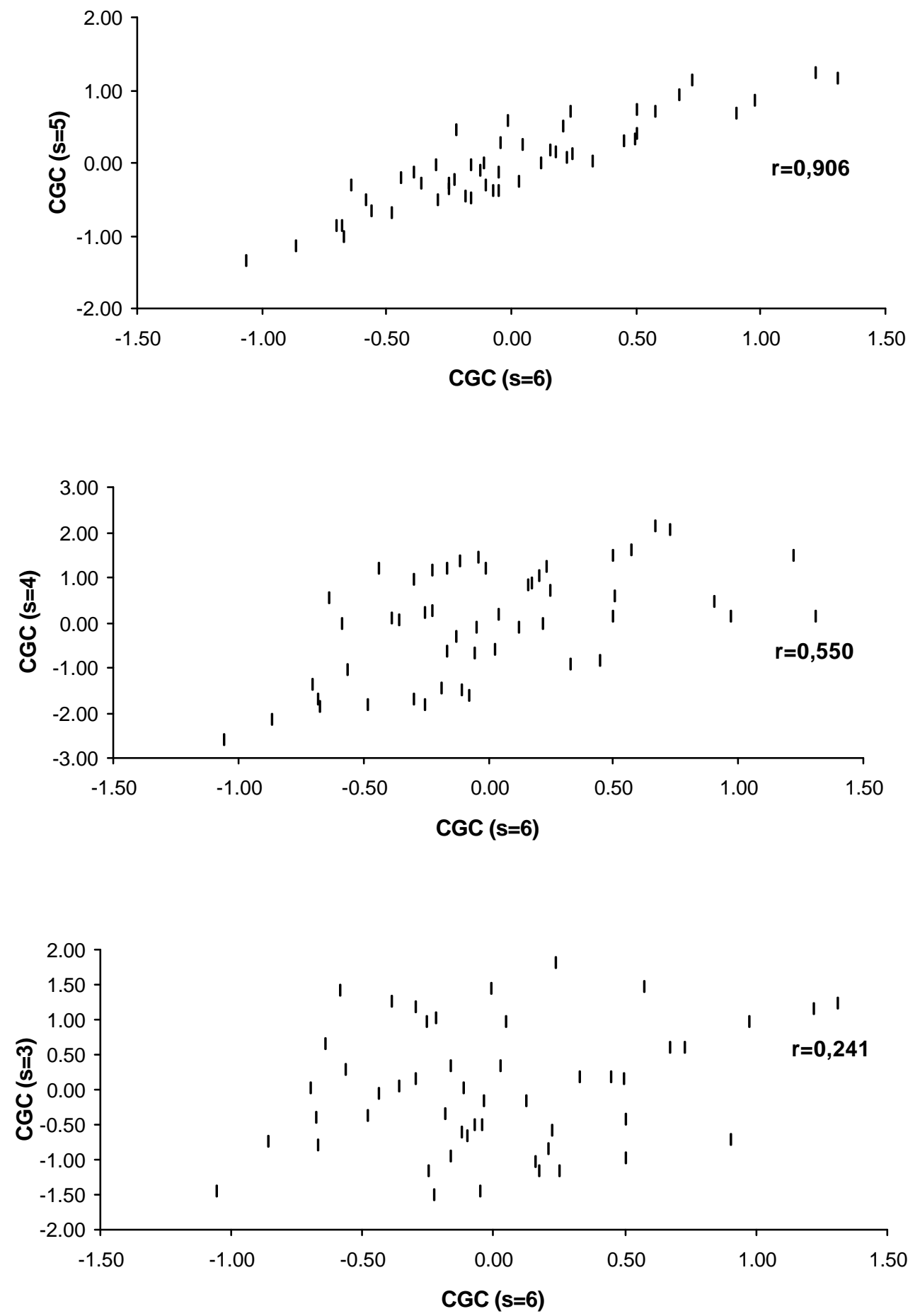

Figura 14 - Dispersão das estimativas obtidas para CGC do DPCI (B) da população GN-03, obtidas entre os valores de $s$ iguais à 6/5; 6/4 e 6/3 e suas correlações para o caráter peso de espigas (t/ha). Uberlândia-MG, 2001/02. 

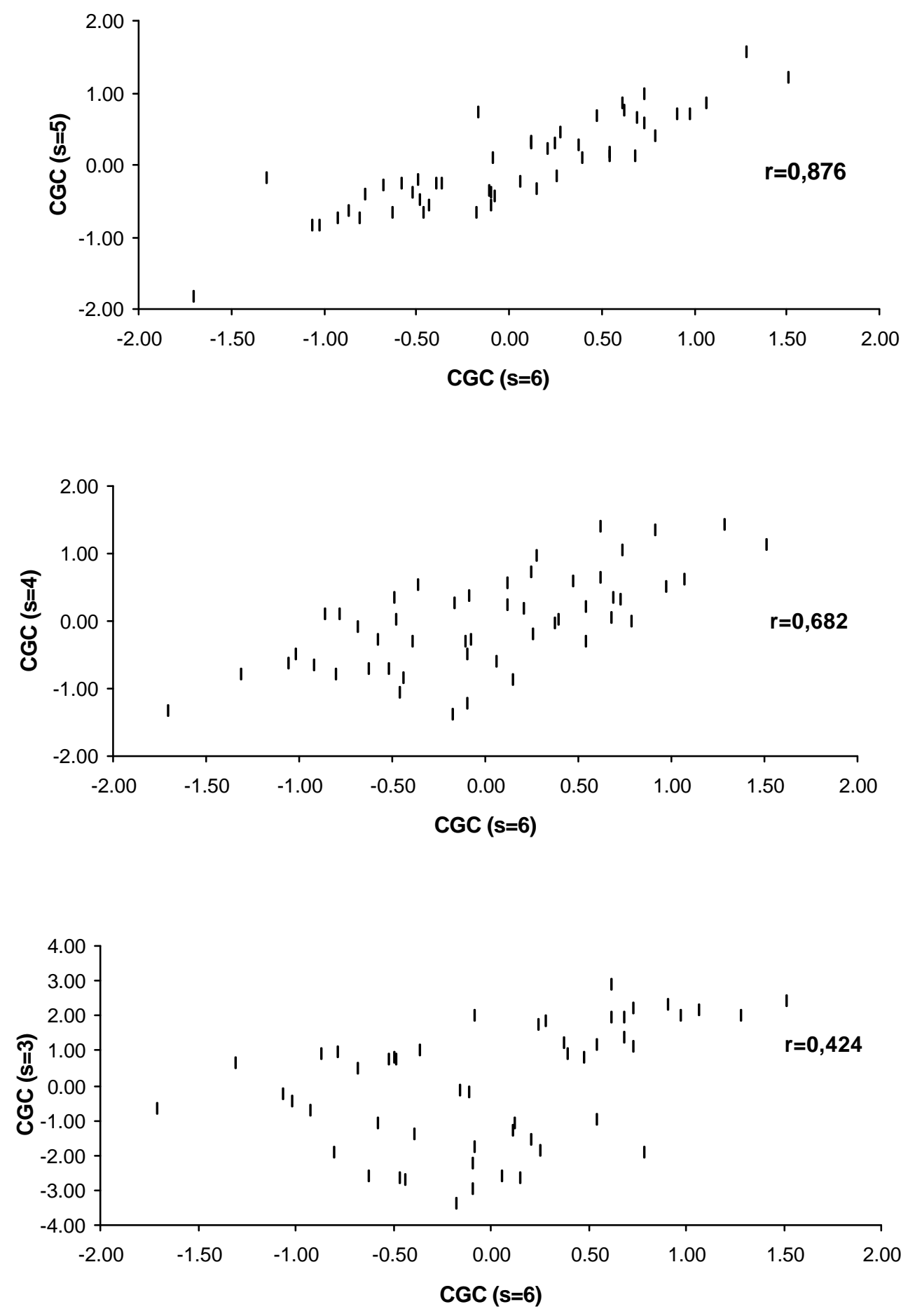

Figura 15 - Dispersão das estimativas obtidas para CGC do DPCI (B) da população GN-04, obtidas entre os valores de $\mathbf{s}$ iguais à 6/5; 6/4 e 6/3 e suas correlações para o caráter peso de espigas (t/ha). Piracicaba-SP, 2001/02. 

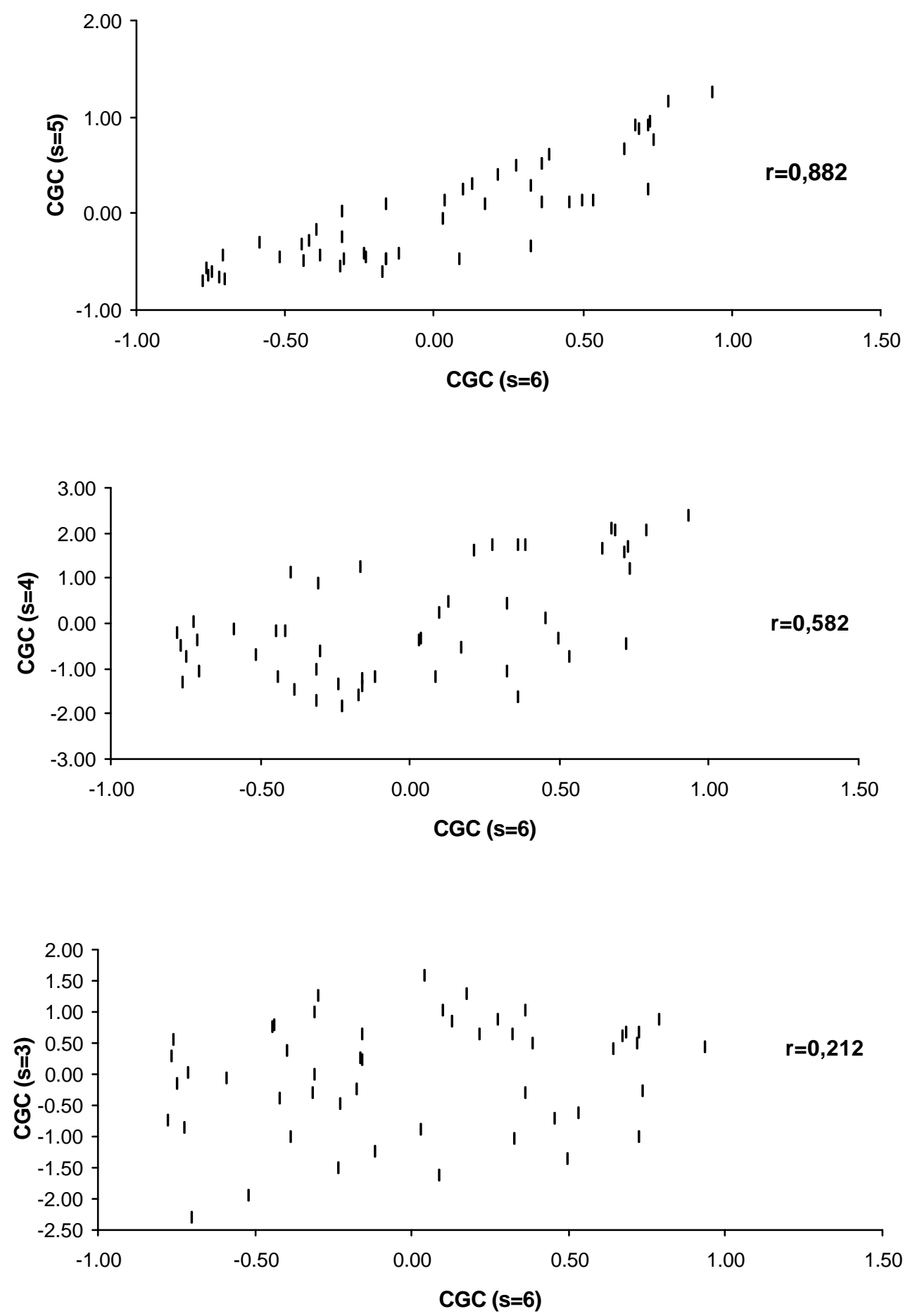

Figura 16 - Dispersão das estimativas obtidas para CGC do DPCI (B) da população GN-04, obtidas entre os valores de $s$ iguais à $6 / 5 ; 6 / 4$ e $6 / 3$ e suas correlações para o caráter peso de espigas (t/ha). Uberlândia-MG, 2001/02. 

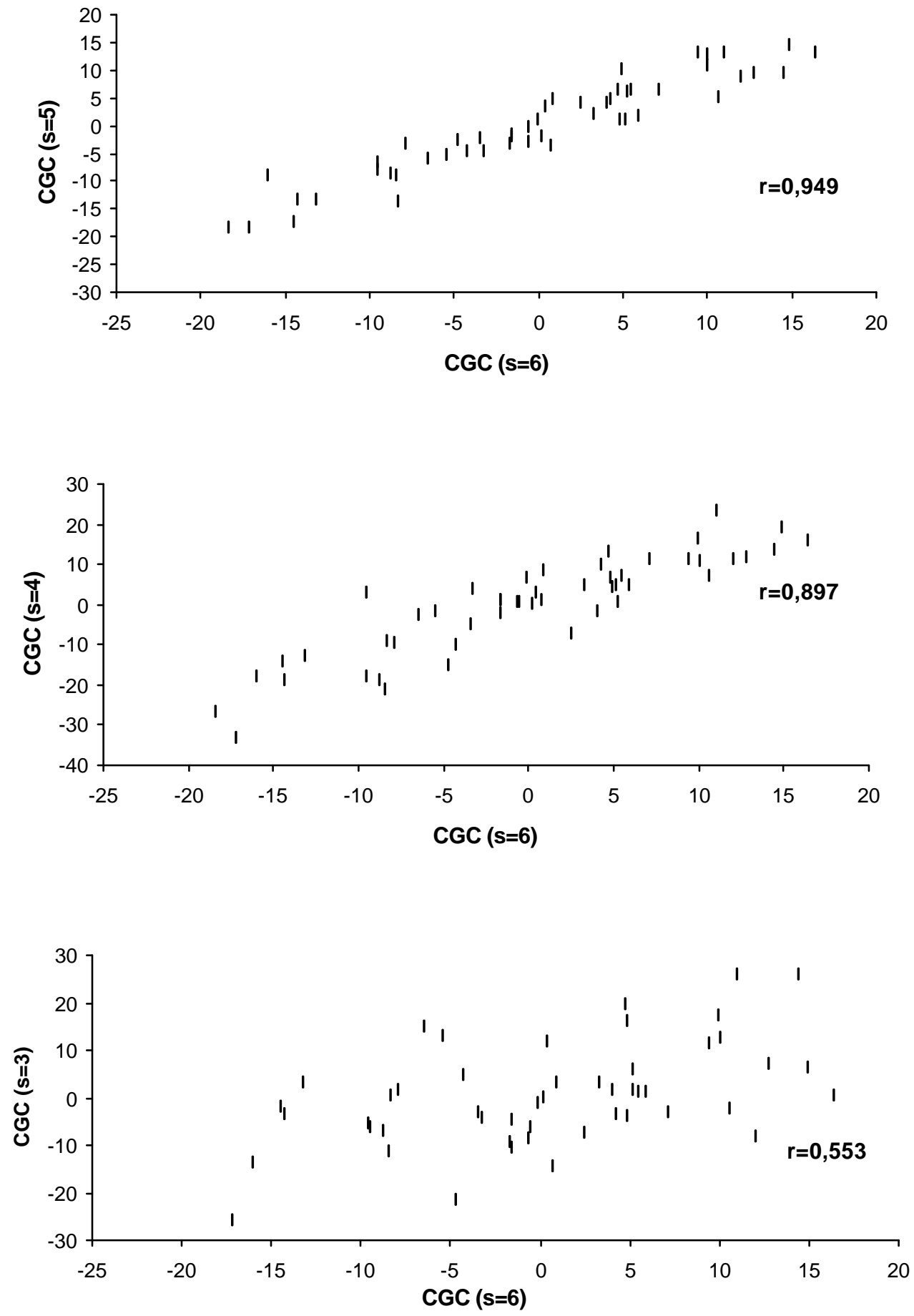

Figura 17 - Dispersão das estimativas obtidas para CGC do DPCI (B) da população GN-03, obtidas entre os valores de $\mathbf{s}$ iguais à $6 / 5 ; 6 / 4$ e $6 / 3$ e suas correlações para o caráter altura de planta (cm). Piracicaba-SP, 2001/02. 

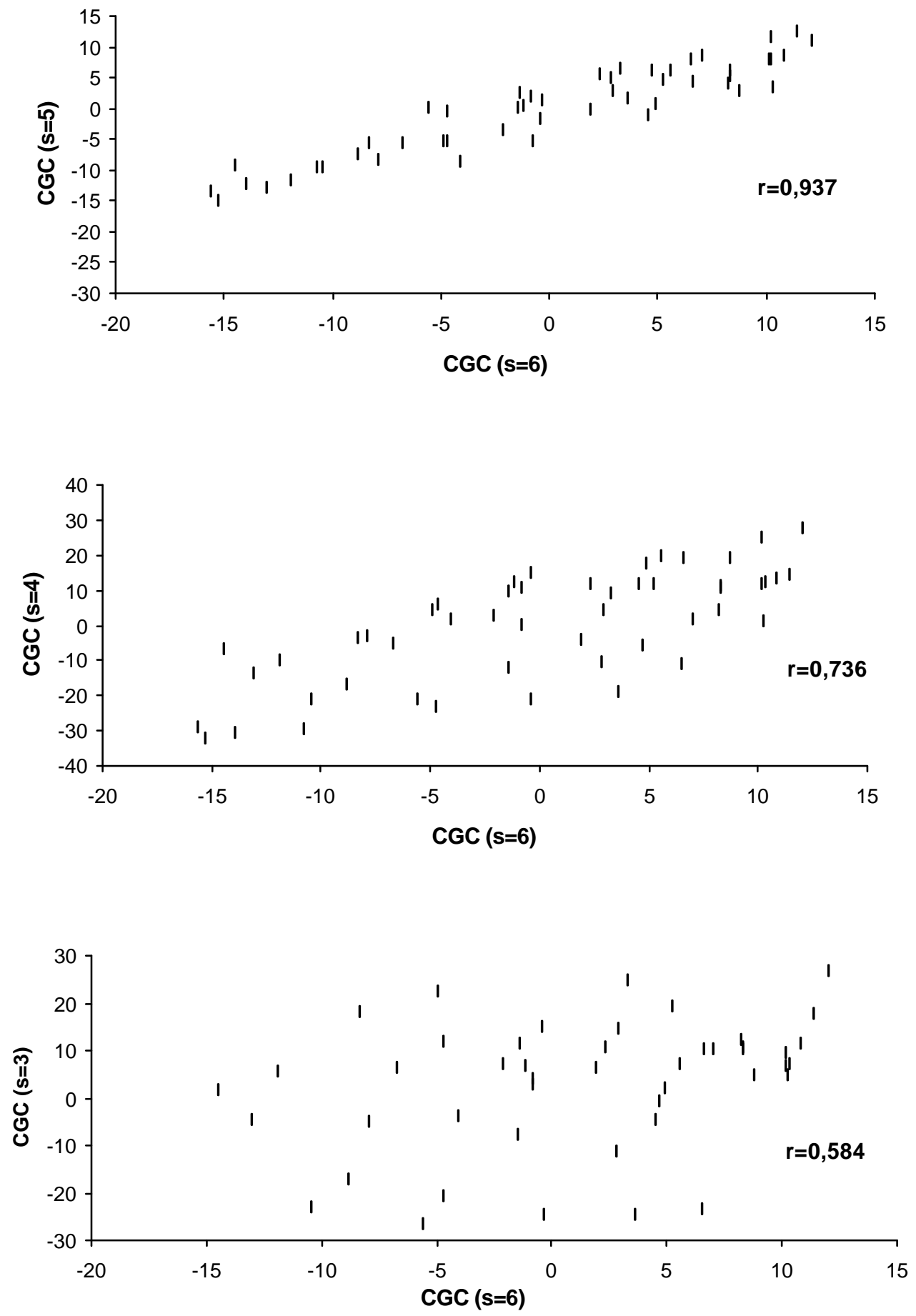

Figura 18 - Dispersão das estimativas obtidas para CGC do DPCI (B) da população GN-03, obtidas entre os valores de $s$ iguais à $6 / 5 ; 6 / 4$ e $6 / 3$ e suas correlações para o caráter altura de planta (cm). Uberlândia-MG, 2001/02. 

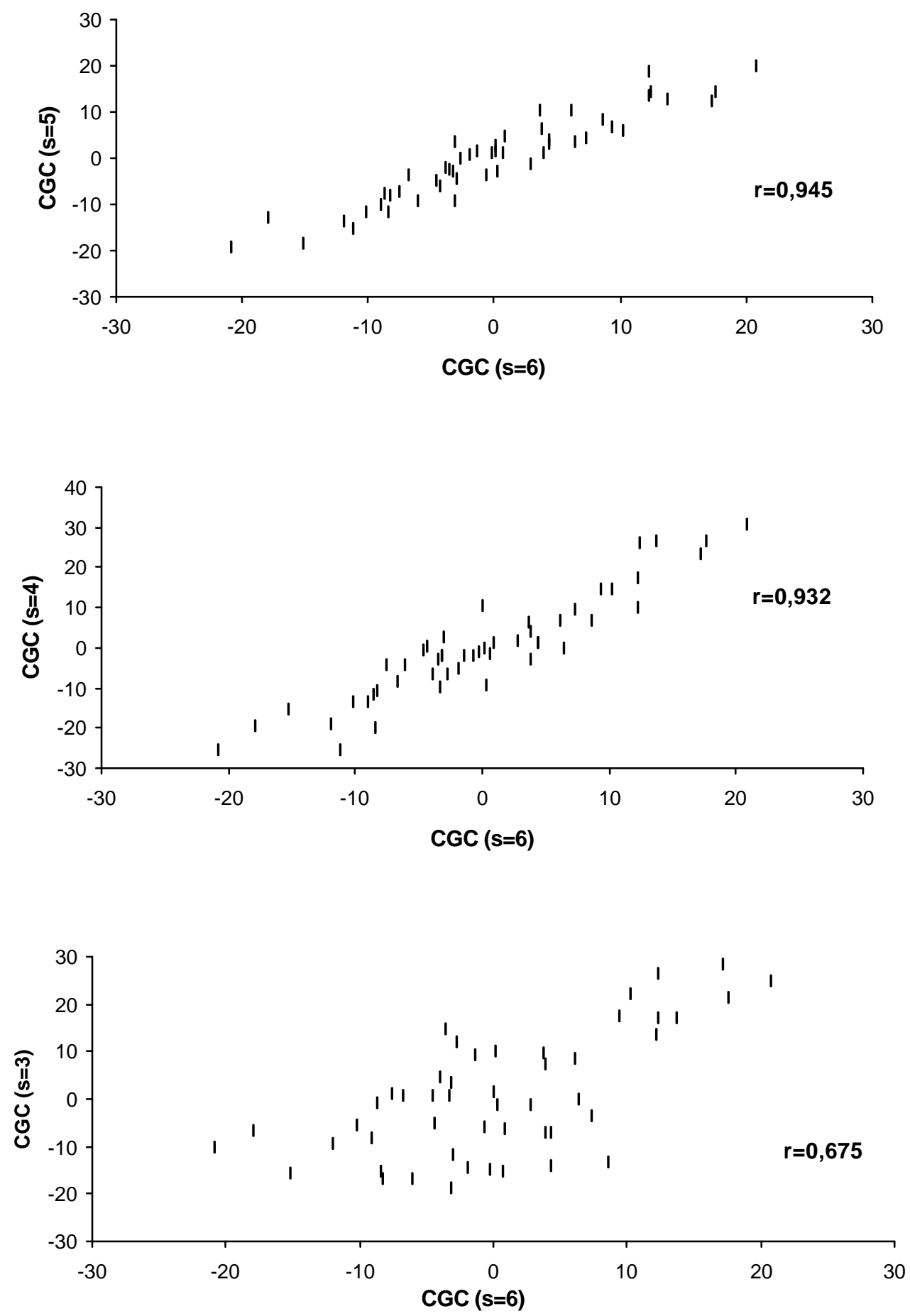

Figura 19 - Dispersão das estimativas obtidas para CGC do DPCI (B) da população GN-04, obtidas entre os valores de $s$ iguais à $6 / 5 ; 6 / 4$ e $6 / 3$ e suas correlações para o caráter altura de planta (cm). Piracicaba-SP, 2001/02. 

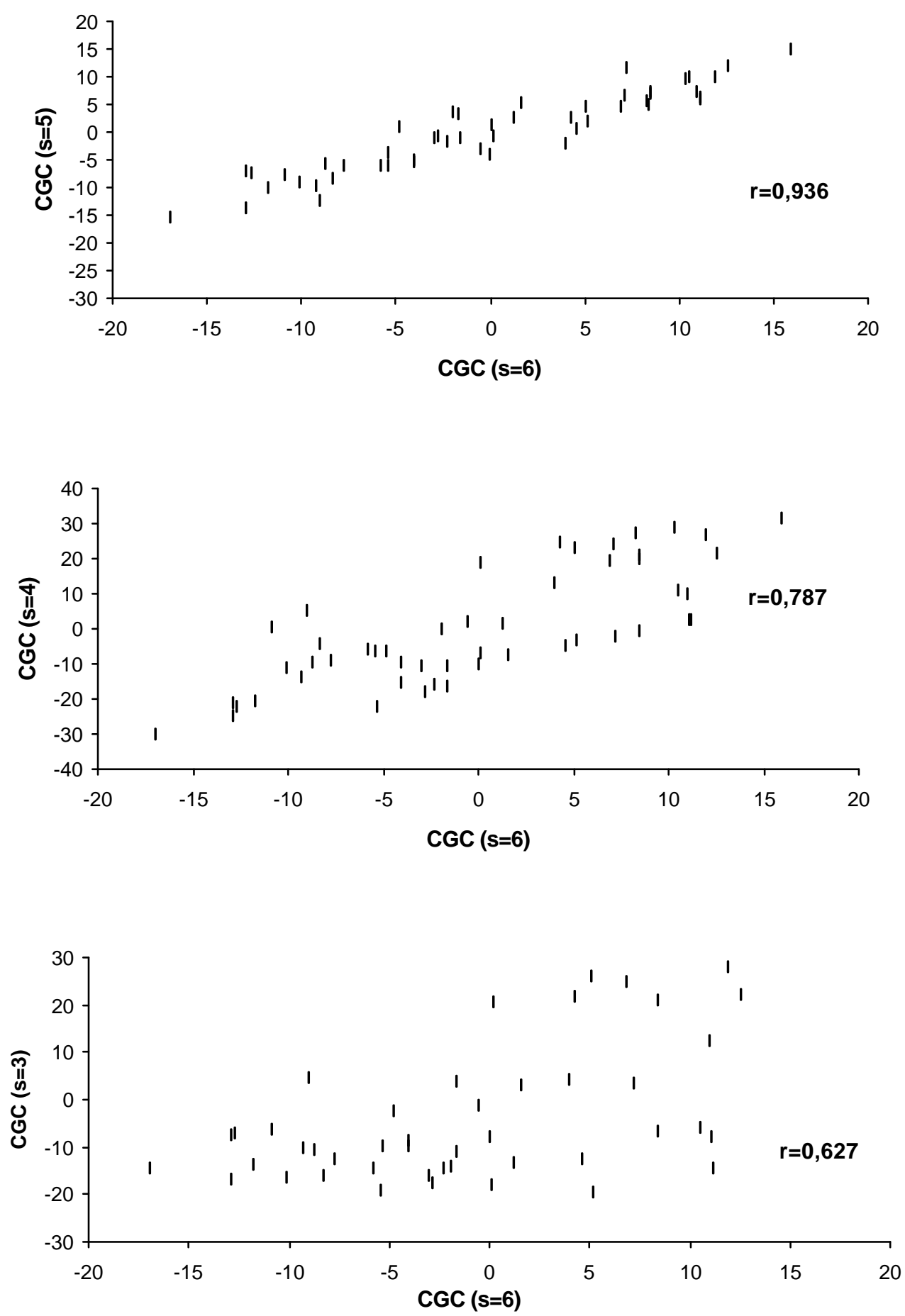

Figura 20 - Dispersão das estimativas obtidas para CGC do DPCI (B) da população GN-04, obtidas entre os valores de $\mathbf{s}$ iguais à 6/5;6/4 e 6/3 e suas correlações para o caráter altura de planta $(\mathrm{cm})$. Uberlândia-MG, 2001/02. 

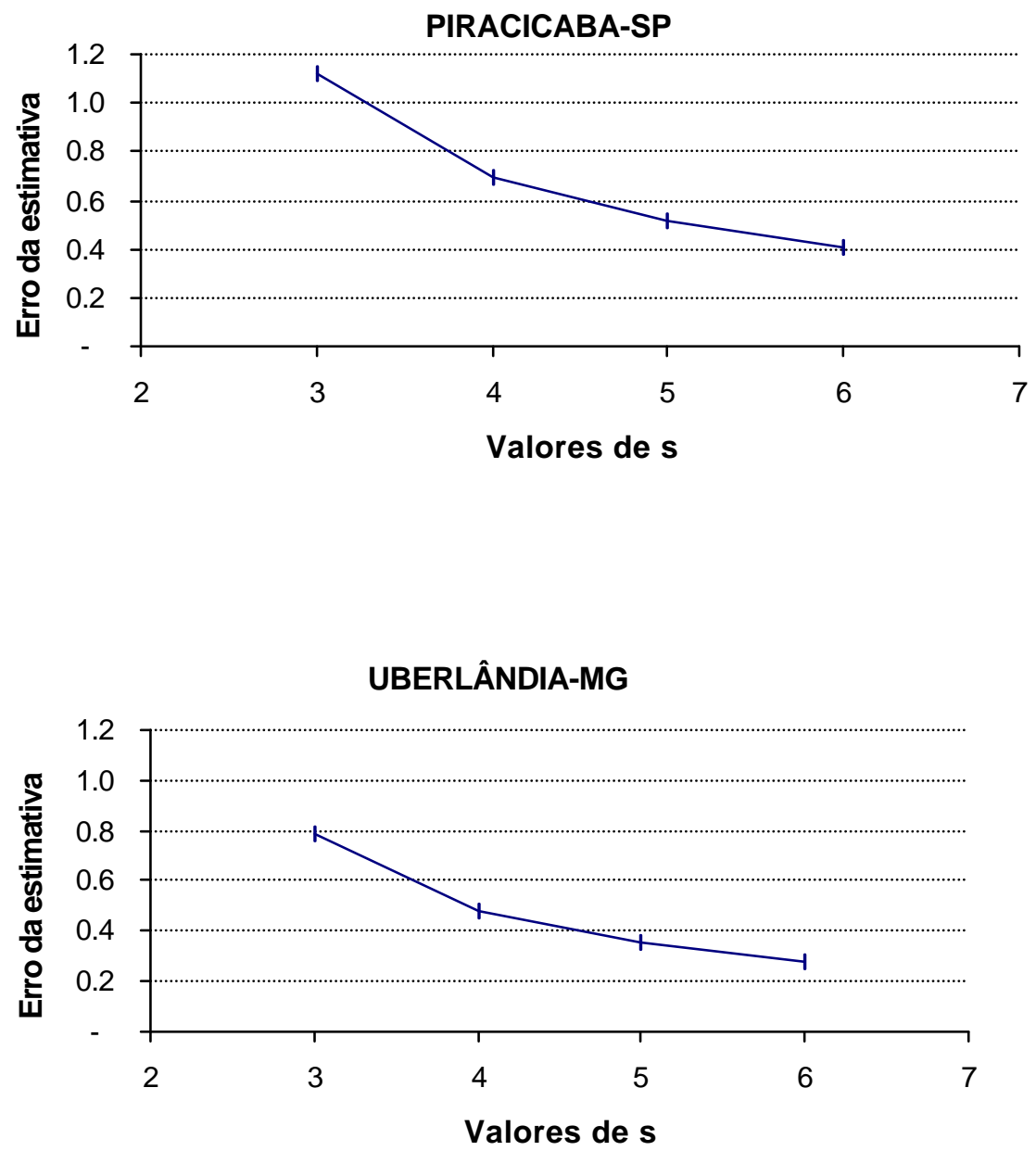

Figura 21 - Distribuição dos erros associados à estimativas de gi e gj para os diferentes tamanhos de $\mathbf{s}$ para o caráter peso de espigas (t/ha) do DPCl (B) em dois locais. Piracicaba-SP2001/02; Uberlândia-MG, 2001/02. 

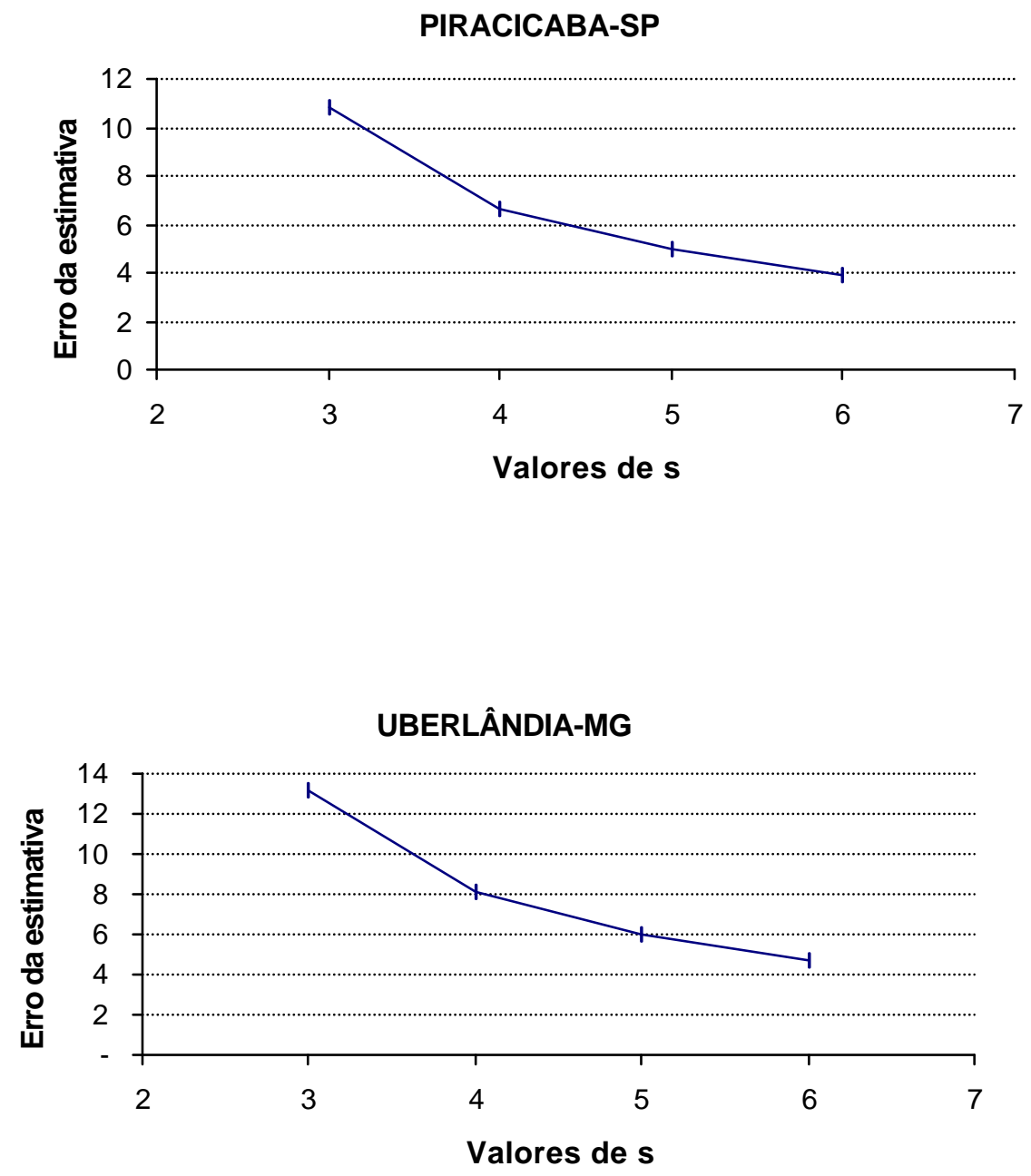

Figura 22 - Distribuição dos erros associados às estimativas de gi e gj para os diferentes tamanhos de $\mathbf{s}$ para o caráter altura de planta $(\mathrm{cm})$ do DPCI (B) em dois locais. Piracicaba-SP2001/02; Uberlândia-MG, 2001/02. 

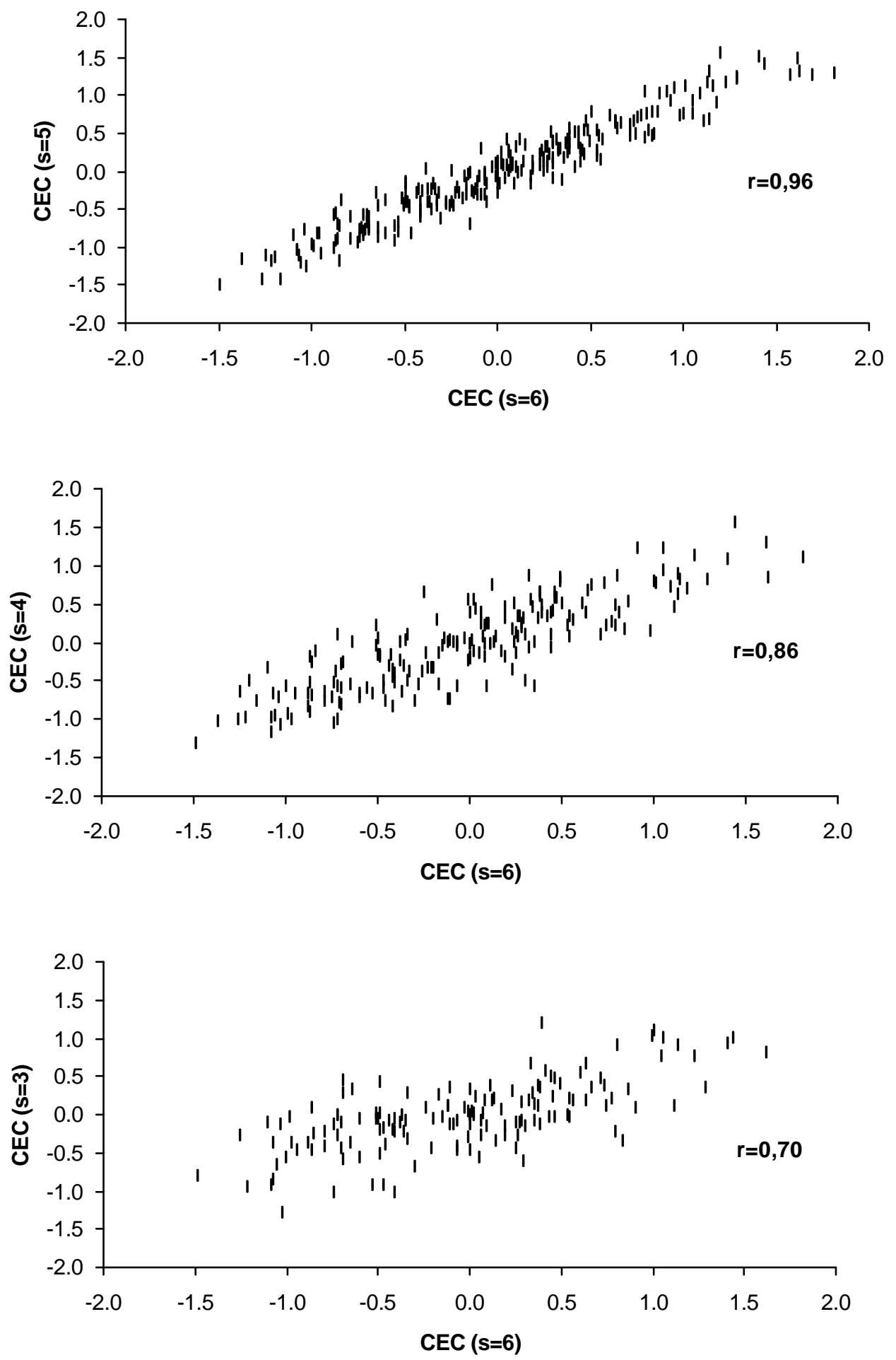

Figura 23 - Dispersão das estimativas obtidas para CEC do DPCI (A), obtidas entre os valores de $\mathbf{s}$ iguais à $6 / 5 ; 6 / 4$ e $6 / 3$ e suas correlações para o caráter peso de espigas (t/ha). Piracicaba-SP, 2001/02. 

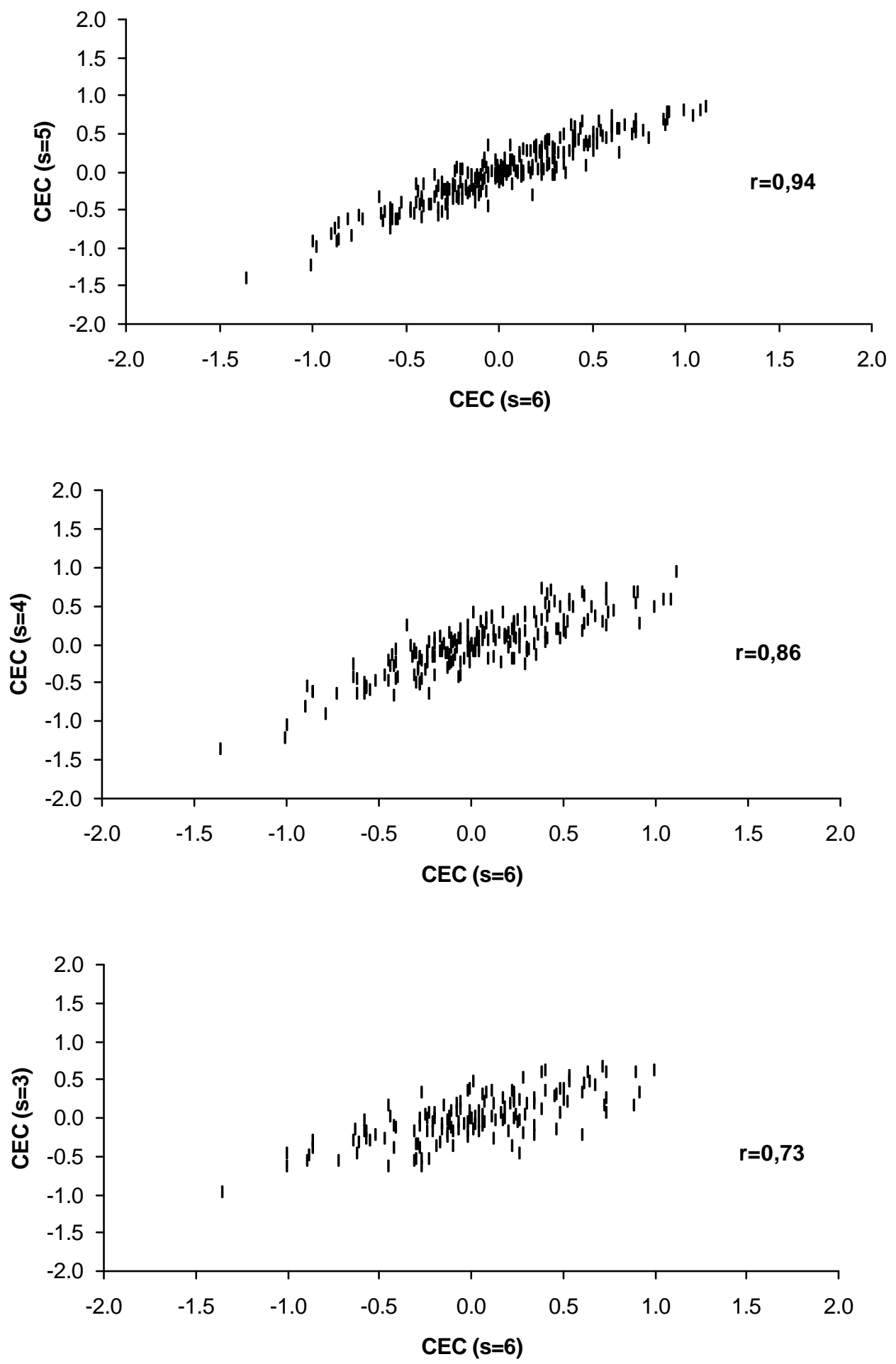

Figura 24 - Dispersão das estimativas obtidas para CEC do DPCl (A), obtidas entre os valores de $s$ iguais à $6 / 5 ; 6 / 4$ e 6/3 e suas correlações para o caráter peso de espigas (t/ha). Uberlândia-MG, 2001/02. 

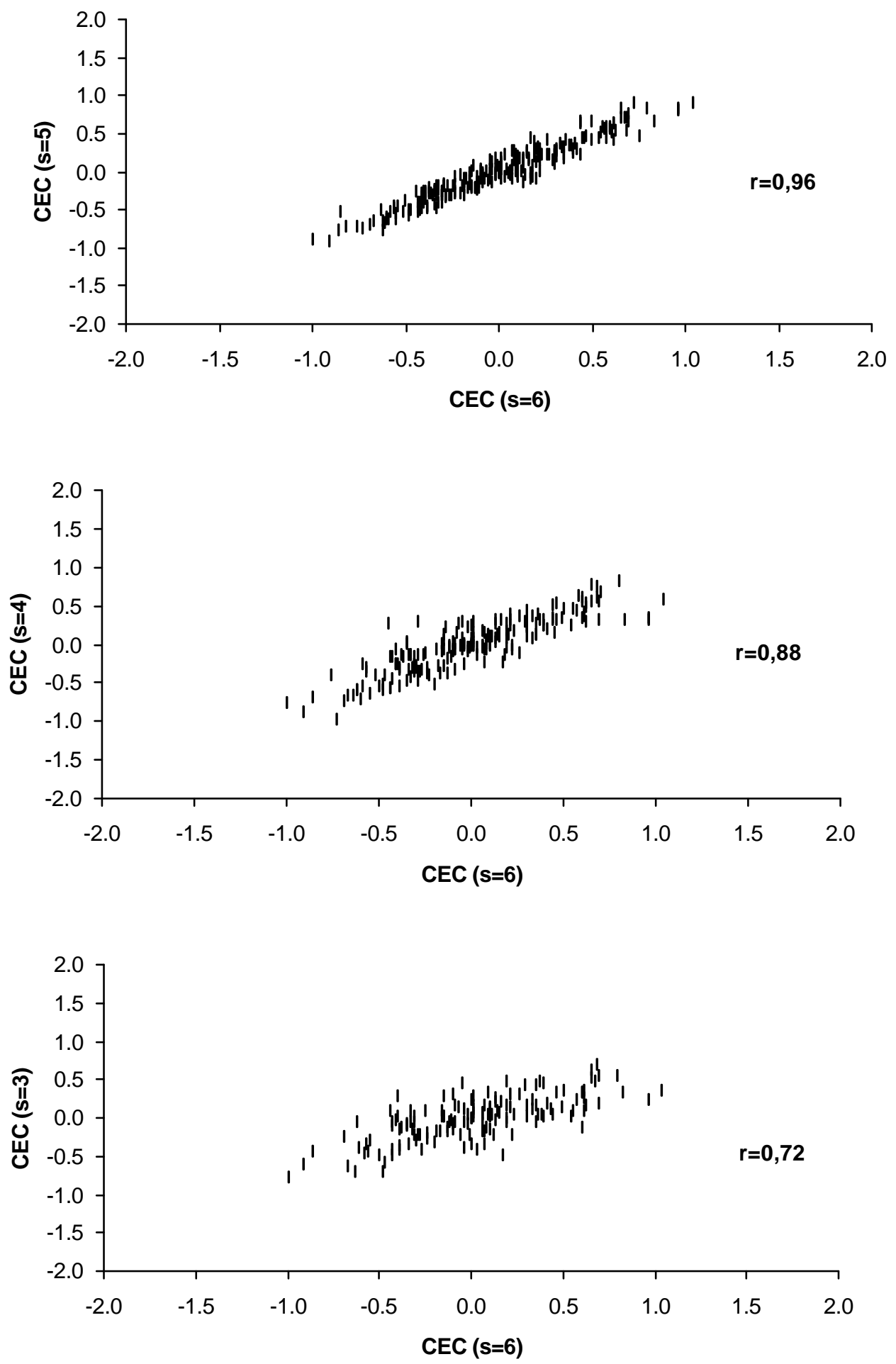

Figura 25 - Dispersão das estimativas obtidas para CEC do DPCI (A), obtidas entre os valores de $\mathbf{s}$ iguais à $6 / 5 ; 6 / 4$ e 6/3 e suas correlações para o caráter peso de espigas (t/ha). Jataí-GO, 2002. 

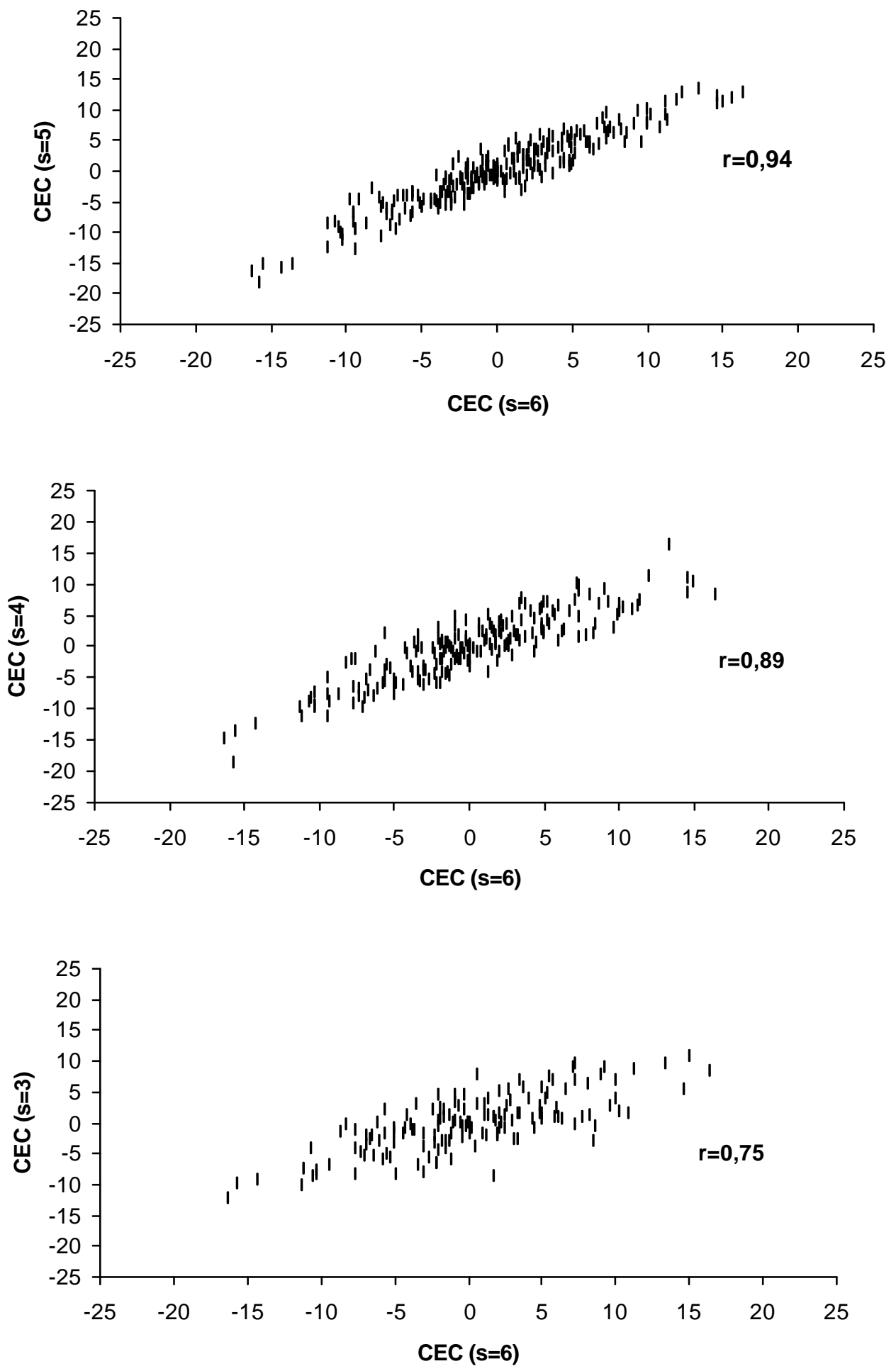

Figura 26 - Dispersão das estimativas obtidas para CEC do DPCI (A), obtidas entre os valores de $\mathbf{s}$ iguais à $6 / 5 ; 6 / 4$ e 6/3 e suas correlações para o caráter altura de planta (cm). Piracicaba-SP, 2001/02. 

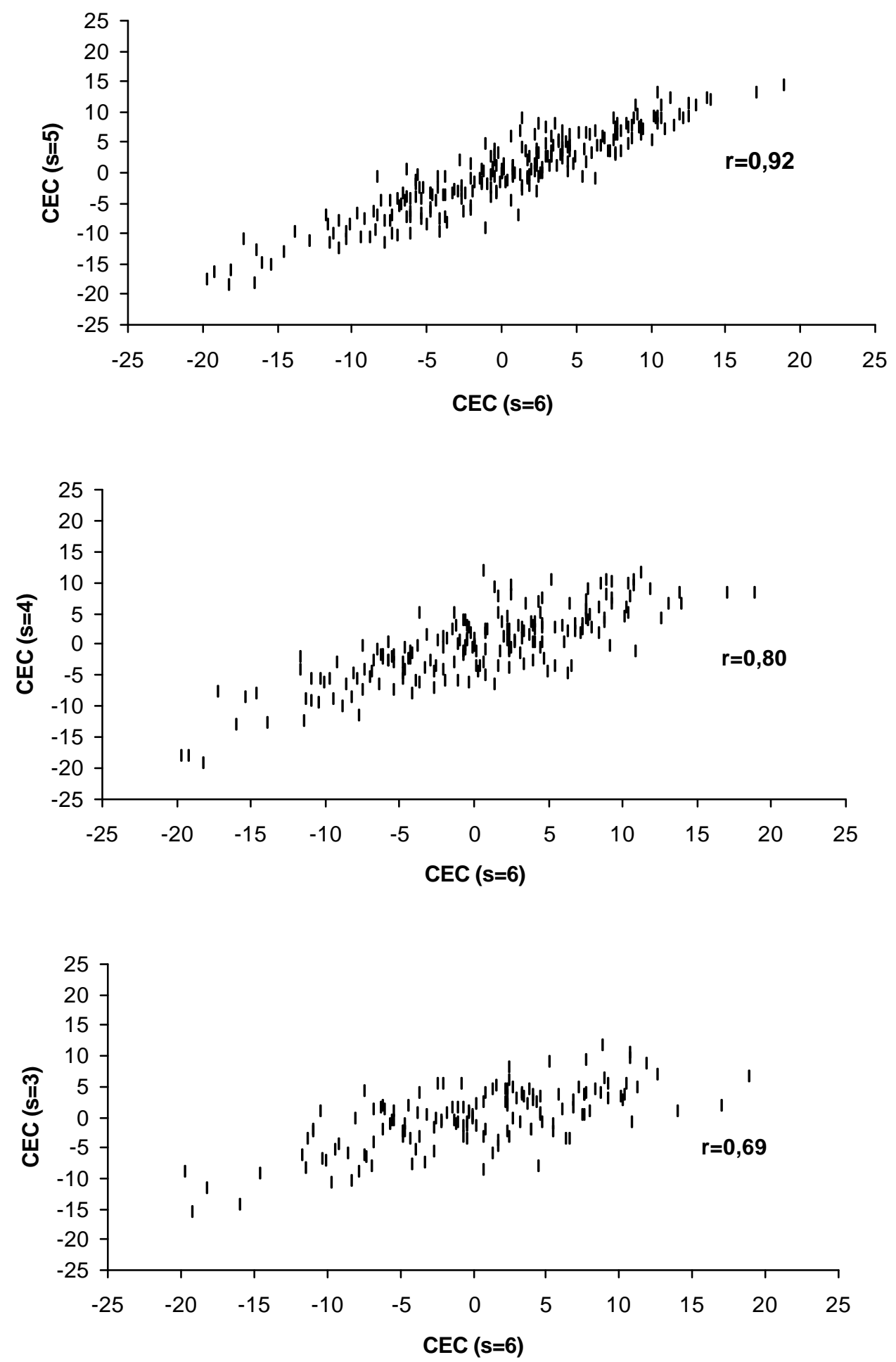

Figura 27 - Dispersão das estimativas obtidas para CEC do DPCI (A), obtidas entre os valores de $s$ iguais à $6 / 5 ; 6 / 4$ e $6 / 3$ e suas correlações para o caráter altura de planta (cm). Uberlândia-MG, 2001/02. 

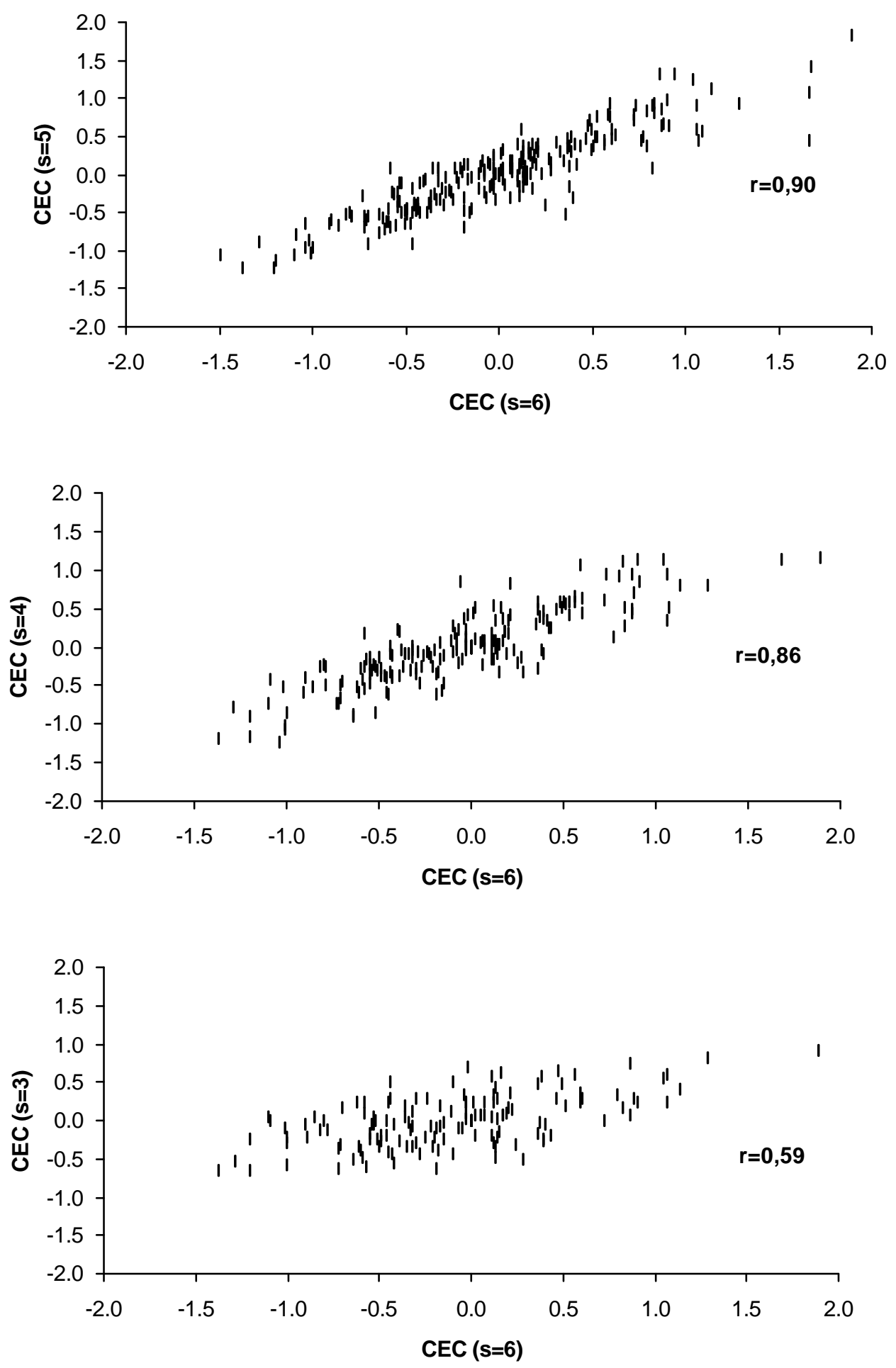

Figura 28 - Dispersão das estimativas obtidas para CEC do DPCI (B), obtidas entre os valores de $s$ iguais à $6 / 5 ; 6 / 4$ e 6/3 e suas correlações para o car áter peso de espigas (t/ha). Piracicaba-SP, 2001/02. 

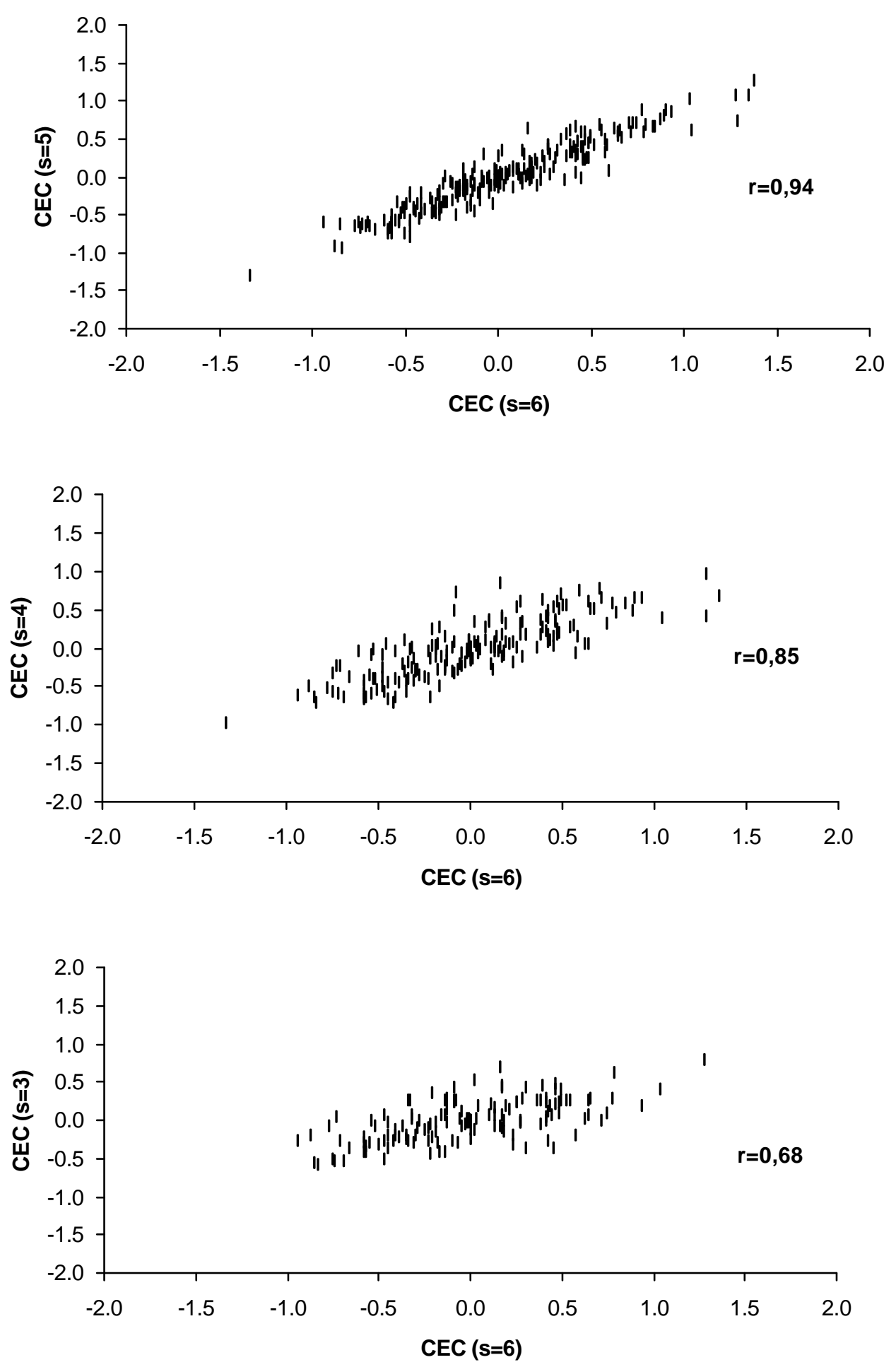

Figura 29 - Dispersão das estimativas obtidas para CEC do DPCI (B), obtidas entre os valores de $\mathbf{s}$ iguais à $6 / 5 ; 6 / 4$ e $6 / 3$ e suas correlações para o caráter peso de espigas (t/ha). Uberlândia-MG, 2001/02. 

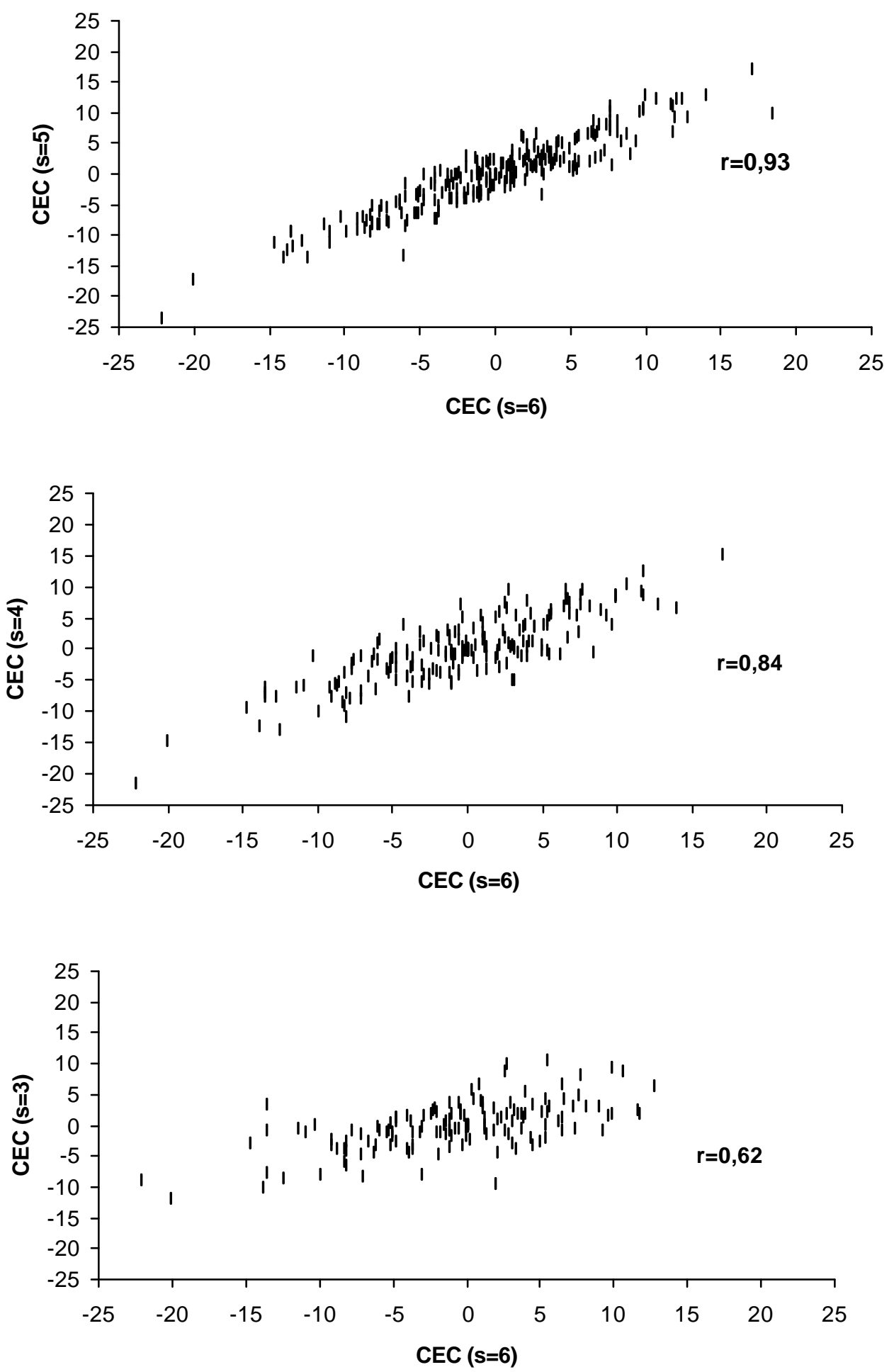

Figura 30 - Dispersão das estimativas obtidas para CEC do DPCI (B), obtidas entre os valores de $\mathbf{s}$ iguais à $6 / 5 ; 6 / 4$ e 6/3 e suas correlações para o caráter altura de planta $(\mathrm{cm})$. Piracicaba-SP, 2001/02. 

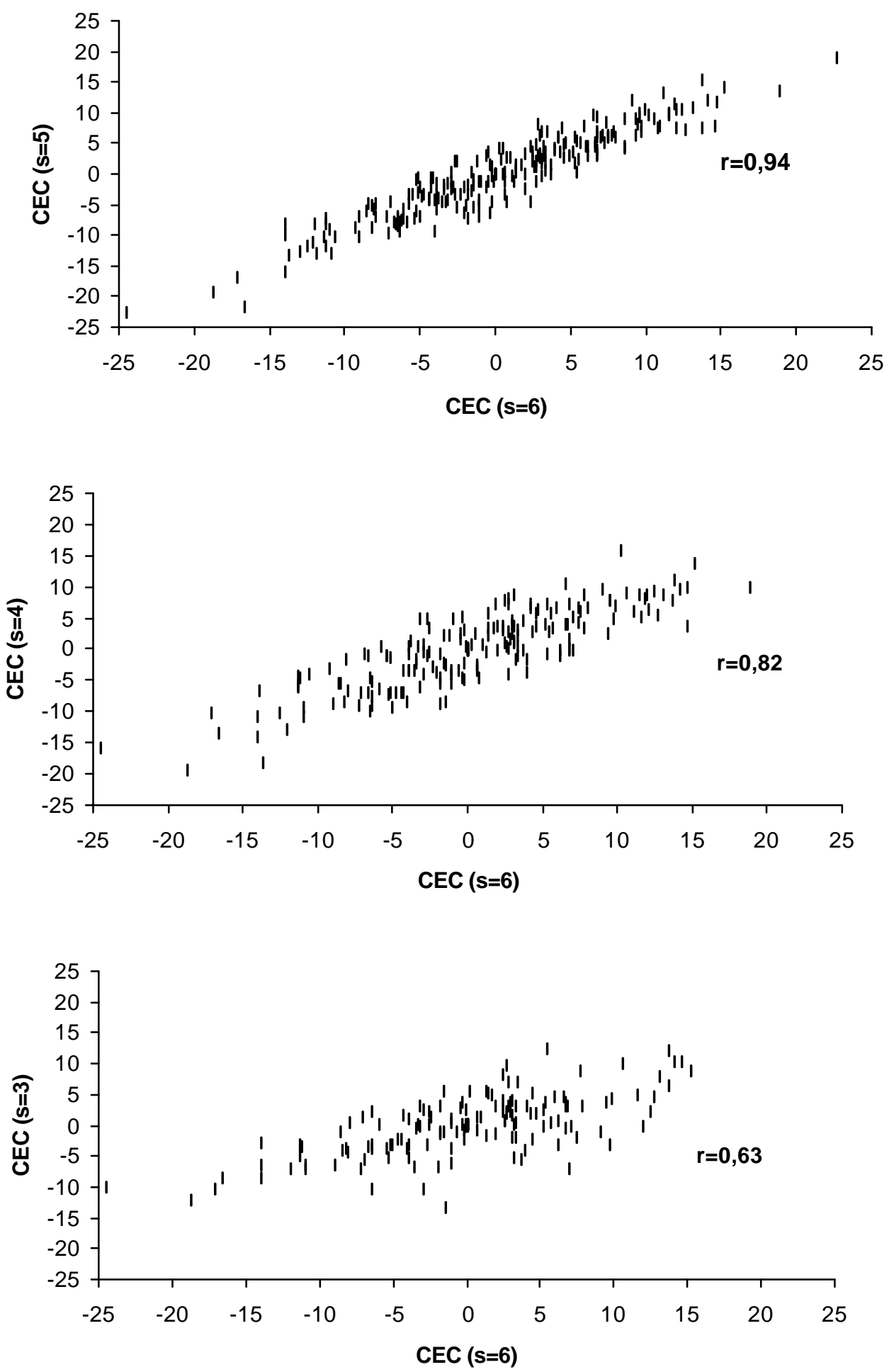

Figura 31 - Dispersão das estimativas obtidas para CEC do DPCI (B), obtidas entre os valores de s iguais à $6 / 5 ; 6 / 4$ e $6 / 3$ e suas correlações para o caráter altura de planta (cm). Uberlândia-MG, 2001/02. 


\section{REFERÊNCIAS BIBLIOGRÁFICAS}

ANDRADE, J.A.C. Dialélico parcial circulante interpopulacional em milho (Zea mays L.) com dois níveis de endogamia dos parentais. Piracicaba, 1995. 134p. Tese (Doutorado) - Escola Superior de Agricultura "Luiz de Queiroz", Universidade de São Paulo.

ANDRÉ, C.M.G. Avaliação da melhor predição linear não tendenciosa (BLUP) associada ao uso de marcadores moleculares na análise dialelica. Lavras, 1999. 101p. Dissertação (Mestrado) - Universidade Federal de Lavras.

ANNAND, I.J.; MURTY, B.R. Serial analysis of combining ability on diallel and fractional diallel cross in linseed. Theoretical and Applied Genetics, v.39, n.2, p.88-94, 1969.

ARAÚJO, P.M. Dialelo parcial circulante interpopulacional e cruzamentos "top-cross" na avaliação de linhagens parcialmente endogâmicas de milho (Zea mays L.). Piracicaba, 2000. 170p. Tese (Doutorado) - Escola Superior de Agricultura "Luiz de Queiroz", Universidade de São Paulo.

BARBIN, D. Componentes de variância: teoria e aplicações. Piracicaba: ESALQ, Depto. Matemática e Estatística, 1993. 120p.

BELLUCCI, A.A. Avaliação de populações derivadas de híbridos de milho (Zea mays L.) em cruzamentos nos esquemas dialélicos e top cross. Piracicaba, 1995. 134p. Dissertação (Mestrado) - Escola Superior de Agricultura "Luiz de Queiroz", Universidade de São Paulo. 
BERNARDO, R. Best linear unbiased prediction of maize single-cross performance. Crop Science, v.36, p.50-56, 1996a.

BERNARDO, R. Best linear unbiased prediction of maize single-cross performance give erroneous inbred relationships. Crop Science, v.36, p.862-866, 1996b.

BERNARDO, R. Genetics model for predicting maize single-cross performance and unbalanced yield trial data. Crop Science, v.35, p.141-147, 1995.

BERNARDO, R. Prediction of maize single-croos performance using RFLP's and informations from related hybrids. Crop Science, v.34, n.1, p.25-5, 1994.

BRAY, R.A. Quantitative evaluation of the circulant partial diallel cross. Heredity, v.27, p.189-202, 1971.

CRUZ, C.D.; REGAZZI, A.J. Modelos biométricos aplicados ao melhoramento genético. Viçosa: Universidade Federal de Viçosa, 1994. 390p.

DANTAS, A.C.V. Cruzamento dialelico parcial circulante para avaliação de linhagens de milho (Zea mays L.) e predição de híbridos. Piracicaba, 1988. 153p. Tese (Doutorado) - Escola Superior de Agricultura "Luiz de Queiroz", Universidade de São Paulo.

DANTAS, J.L.L. Cruzamentos dialélicos parciais para a avaliação de híbridos intermediários entre duas populações de milho (Zea mays L.). Piracicaba, 1992. 216p. Tese (Doutorado) - Escola Superior de Agricultura "Luiz de Queiroz", Universidade de São Paulo.

DAVIS, R.L. Report of plant breeder. Puerto Rico: Agricultural Experiments Annual Report, p.14-15, 1927.

DEMPFLE, L. Estimation of breeding values. In: HILL, W.G; MACKAY, T.F.C. (Ed.). Evolution and animal breeding. Wallingford: $C A B$ International, 1989. p.181-188. 
DHILLON, B.S; SINGH, J. Evaluation of circulant partial diallel crosses in maize. Theoretical and Applied Genetics, v.52, n.1, p.29-37, 1978.

DUARTE, J.B. Sobre o emprego e a análise do delineamento em blocos aumentados no melhoramento genético vegetal. Piracicaba, 2000. 293p. Tese (Doutorado) - Escola Superior de Agricultura "Luiz de Queiroz", Universidade de São Paulo.

EBERHART, S.A.; GARDNER, C.O. A general model for genetic effects. Biometrics, v.22, p.864-881, 1966.

GARDNER, C.O.; EBERHART, S.A. Analysis and interpretation of the variety cross diallel and related population. Biometrics, v.22, p.439-452, 1966.

GERALDI, I.O.; MIRANDA FILHO, J.B. Adapted models for the analysis of combining ability of verieties in partial diallel crosses. Revista Brasileira de Genética, v.11, p.419-430, 1988.

GONÇALVES, P.S. Esquema circulante de cruzamentos para avaliação de linhagens de milho (Zea mays L.) ao nível interpopulacional. Piracicaba, 1987. 140p. Tese (Doutorado) - Escola Superior de Agricultura "Luiz de Queiroz", Universidade de São Paulo

GORGULHO, A.P. Avaliação de variedades de milho (Zea mays L.) sob dois esquemas de cruzamentos: dialelico parcial e "top cross" intergrupos. Piracicaba, 1997. 117p. Tese (Doutorado) - Escola Superior de Agricultura "Luiz de Queiroz", Universidade de São Paulo.

GRIFFING, B. Concept of general and specific combining ability in relation to diallel crossing systems. Australian Journal of Biological Sciences, v.9, p.463-493, 1956.

HALLAUER, A.R. Relation of gene action and type of tester in maize breeding procedures. In: CORN AND SORGHUM RESEARCH CONFERENCE, 30.,1975. Proceedings. Washington: American Seed Trade, 1975. p.150-165. 
HALLAUER, A.R.; MIRANDA FILHO, J.B. de. Quantitative genetics in maize breeding. Ames: lowa State University Press, 1988. 468p. $2^{\text {nd }}$ ed.

HENDERSON, C.R. Aplication of linear model in animal breeding. Ontorio: University of Guelph, 1984. 462p.

HENDERSON, C.R. Best linear Unbiased estimation and prediction under a selection model. Biometrics, v.31, p.423-447, 1975a.

HENDERSON, C.R. Estimation of variance and covariance components. Biometrics, v.9, p.226-252, 1953.

HENDERSON, C.R. General flexibility of linear model for sire evaluation. Jounal Dairy Science, v.57, n.8, p.963-972, 1974.

HOEGEMEYER, T.C.; HALLAUER, A.R. Selection among and within full-sib families to develop single-crosses of maize. Crop Science, v.16, p.76-81, 1976.

HULL, F.H. Recurrent selection for specific combining ability in corn. Agronomy Journal, v.37, p.134-145, 1945.

JENKINS, M.T. Methods of estimating the performance of double crosses in corn. Journal of American Society of Agronomy, v.26, n.1, p.199-204, 1934.

JENKINS, M.T.; BRUNSON, A.M. Methods of testing inbred lines of corn in cross breed combinations. Journal of American Society Agronomy, v.24, p.523-530, 1932.

JINKS, J.L.; HAYMAN, B.I. The analysis of diallel crosses. Maize Genetics Cooperation News Letter, v.27, p.48-54, 1953.

JONES, D.F. The effects of inbreeding and crossbreeding upon development. Bulletin of the Connecticut Agricultural Experimental Station, v.207, p.5-100, 1918.

KEMPTHORNE, O.; CURNOW, R.N. The partial diallel cross. Biometrics, v.17, p.229-250, 1961. 
MARTINS, C.S.; MIRANDA FILHO, J.B. Evaluation of inbred lines from two maize (Zea mays. L.) brachytic populations in single crosses following the two-factor mating desing. Brazilian Journal of Genetics, v.20, p.265-273, 1997.

MIRANDA FILHO, J.B.; GERALDI, I.O. An adapted model for the analysis of partial diallel crosses. Revista Brasileira de Genética, v.7, p.667-688, 1984.

MIRANDA FILHO, J.B.; GORGULHO, E. P. Cruzamentos com testadores e dialelos. In: Recursos genéticos e melhoramentos-plantas. Rondonópolis: Fundação MT, 2001. p.649-672.

MIRANDA FILHO, J.B.; VENCOVSKY, R. The partial circulant diallel cross at the interpopulation level. Genetic and Molecular Biology, v.22, n.2, p.249255, 1999.

MURTY, B.R.; ARUNACHALAM, V.; ANAND, I.J. Diallel and partial diallel analysis of some yield factores in Linus usitatissimum. Heredity, v.22, p.35-41, 1967.

NASS, L.L.; MIRANDA FILHO, J.B . Synthesis of new composites of maize (Zea mays L.) for populations improvement in Brazil. In: REUNION LATINO AMERICANA DEL MAIZ, 18., Sete Lagoas, 1999. Memorias. Sete Lagoas: Embrapa, CNPMS; México: CYMMYT, 1999, p.309-317.

NASS, L.L.; MIRANDA FILHO, J.B.; COSTA, F.M.P. da. Parâmetros genéticos em quatro compostos de milho. In: CONGRESSO NACIONAL DE MILHO E SORGO, 23., Uberlândia, 2000. A inovação tecnológica e a competitividade no contexto dos mercados globalizados. Sete Lagoas: Embrapa Milho e Sorgo; Uberlândia: ABMS / Universidade Federal de Uberlândia, 2000. p.68. 
PANTER, D.M.; ALLEN, F.L. Using best linear unbiased predictions to enhance breeding for yield in soybean: II Selection of superior crosses from a limited number of yield trials. Crop Science, v.35, n.2, p.405-410, 1995.

REIS, A.J.S. Análise de componentes de heterose ao nível interpopulacional a partir de cruzamentos dialélicos parciais circulantes. Goiânia, 2000. 93p. Dissertação (Mestrado) - Universidade Federal de Goiás.

RESENDE, M.D.V. Melhoramento genético de essências florestais. In: SIMPÓSIO SOBRE ATUALIZAÇÃO EM GENÉTICA E MELHORAMENTO DE PLANTAS, Lavras, 1997. Anais. Lavras: UFLA, 1997. p.59-93.

ROBINSON, G.K. That BLUP is a good thing: a estimation of random effects. Statistical Science, v.6, n.1, p.15-51, 1991.

SANTOS, M.X.; PACHECO, C.A.P.; GUIMARÃES, P.E.O. et al. Diallel among twenty eight varieties of maize. Revista Brasileira de Genética, v.7, n.3, p.277-282, 1994.

SAS INSTITUTE. SAS language and procedure: usage. Version 6.1 ed. Software. Cary, 1995.

SCAPIM, C.A.; CARVALHO, C.G.P.; CRUZ, C.D. Uma proposta de classificação dos coeficientes de variação para a cultura do milho. Pesquisa Agropecuária Brasileira, v.30, n.5, p.683-686, 1995.

SHULL, G.H. A pure line method of corn breeding. Report "American Breeders Association", v.5, p.51-59, 1909.

SHULL, G.H. The composition of a field of maize. Report "American Breeders Association”, v.4, p.296-301, 1908.

SOUZA JUNIOR, C.L. de. Variabilidade genética em milho (Zea mays L.) e relações com a seleção recorrente intra e inter-populacional. Piracicaba, 1983. 151p. Tese (Doutorado) - Escola Superior de Agricultura "Luiz de Queiroz", Universidade de São Paulo. 
SOUZA JUNIOR, C.L. Melhoramento de espécies alógamas. In: Recursos genéticos e melhoramentos de plantas. Rondonópolis: Fundação MT, 2001. p.159-200.

SPRAGUE, G.F.; TATUM, L.A. General vs specific combining ability in single crosses of corn. Journal of American Society of Agronomy, v.34, p.923-932, 1942.

STANGLAND, G.R.; RUSSEL, W.A.; SMITH, O.S. Evaluation of the performance and combining ability of selectd lines derived from improvement maize population. Crop Science, v.23, p.647-651, 1983

VEIGA, R.D. Eficiência dos dialelos circulantes na escolha de genitores, avaliada com simulação de dados. Lavras, 1998. 95p. Tese (Doutorado) Universidade Federal de Lavras.

VENCOVSKY, R. Alguns aspectos teóricos e aplicados relativos a cruzamentos dialélicos de variedades. Piracicaba, 1970. 110p. Tese (Livre Docência) Escola Superior de Agricultura "Luiz de Queiroz", Universidade de São Paulo.

VENCOVSKY, R.; BARRIGA, P. Genética biometrica no fitomelhoramento. Ribeirão Preto: Sociedade Brasileira de Genética, 1992. 496p.

VERNEQUE, R. da $S$. Procedimento numéricos e estimação de componentes de covariância em análise multivariada pelo método da máxima verossimilhança restrita: modelos mistos aplicados ao melhoramento animal. Piracicaba, 1994. 157p. Tese (Doutorado) Escola Superior de Agricultura "Luiz de Queiroz", Universidade de São Paulo.

WHITE, T.L.; HODGE, G.R. Predidting breeding values with applications in forest tree improvement. London: Kluwer, 1989. 367p. 